Journal of Student Affairs in Africa

Volume 5 Issue 12017

Voices from around the globe

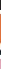

Guest editors

Kathleen Callahan

Chinedu Mba

\footnotetext{
AFRICAN
}

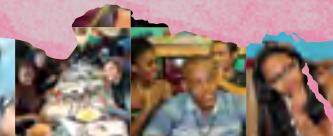

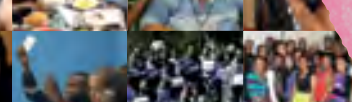

4.

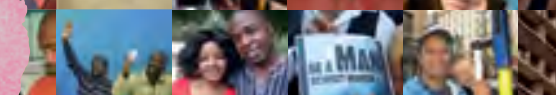

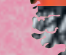

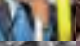

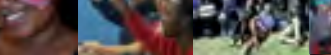
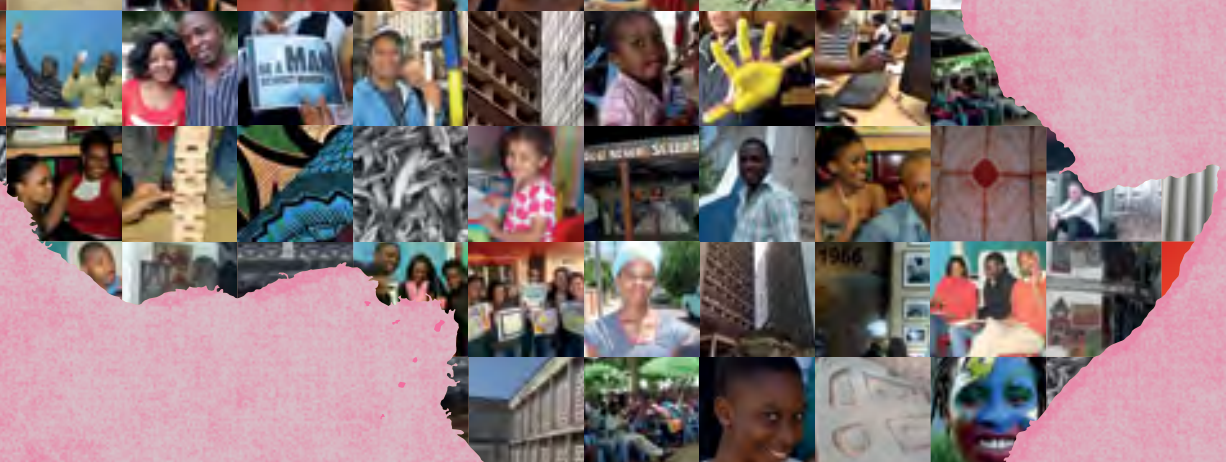


\section{Editorial team}

\section{Editor-in-chief}

Prof. Teboho Moja, New York University

\section{IASAS guest editors}

Dr Kathleen Callahan, Christopher Newport University

Chinedu Mba, Algonquin College

\section{Editorial executive}

Dr Birgit Schreiber, Stellenbosch University (Book Review Editor)

Dr Thierry M. Luescher, Human Sciences Research Council (Journal Manager)

Prof. Teboho Moja, New York University

Dr Martin Mandew, Durban University of Technology

Prof. Akilagpa Sawyerr, Ghana Academy of Arts and Sciences

Dr W.P. Wahl, University of the Free State

\section{International editorial advisory board}

Dr Lisa Bardill Moscaritolo, Pace University

Prof. Cecile Bodibe, Empowaworx

Dr John Butler-Adam, SA Journal of Science

Prof. Ronelle Carolissen, Stellenbosch University

Prof. Jon Dalton, Emeritus, Florida State University

Dr Tom Ellett, New York University

Prof. Magda Fourie-Malherbe, Stellenbosch University

Dr Ransford E.V. Gyampo, University of Ghana

Dr Manja Klemenčič, Harvard University

Prof. Patrício Langa, Universidade Eduardo Mondlane

Prof. Christina Lunceford, Bowling Green State University

Dr Llewelyn MacMaster, Stellenbosch University

Dr Ibrahim Ogachi Oanda, CODESRIA

Dr Adesoji Oni, University of Lagos

Prof. Dawn Person, California State University Fullerton

Prof. Juma Shabani, University of Burundi

Distinguished Prof. John Schuh, Emeritus, Iowa State University

Distinguished Prof.Vincent Tinto, Emeritus, Syracuse University

Prof. Nan Yeld, University of Cape Town

\section{Publishing and website}

Ms Mimi Seyffert-Wirth, Stellenbosch University

Mr Wikus van Zyl, African Sun Media 


\section{Contents}

\section{Editorial}

Voices from Around the Globe

Birgit Schreiber, Thierry M. Luescher E Teboho Moja $\mathbf{v}$

\section{Guest editorial}

Special Guest IASAS Edition: Issues and Challenges in Student Affairs and Services

Around the World

Kathleen Callahan \& Chinedu Mba vii

\section{Research articles}

Paving the Road to Success: Reflecting Critically on Year One of an Undergraduate Student Support Programme at a large South African university

Danie de Klerk, Linda Spark, Andrew Jones \& Tshepiso Maleswena 1

Experience of International Education of East Asian Students in English-speaking Countries: A Four-Dimensional Approach

Maria L. Martinez \& Kevin T. Colaner 15

Interpersonal Conflicts and Styles of Managing Conflicts among Students at Bahir Dar University, Ethiopia Arega Bazezew \& Mulugeta Neka 27

\section{Reflective practice}

Professionalisation of Student Affairs Educators in China: History, Challenges, and Solutions

Yongshan Li \&Yuanyuan Fang 41

Advocating for Standards in Student Affairs Departments in African Institutions:

University of Botswana experience

Barbra M. Pansiri \& Refilwe P. Sinkamba 51

Promoting Social Change amongst Students in Higher Education: A Reflection on the Listen, Live and Learn Senior Student Housing Initiative at Stellenbosch University Munita Dunn-Coetzee \& Magda Fourie-Malherbe $\mathbf{6 3}$

\section{On campus}

Global Summit on Student Affairs and Services

Lisa Bardill Moscaritolo \& Karen Davis 77

\section{Book/Journal reviews}

Dennis C. Roberts \& Susan R. Komives (Eds.) (2016). Enhancing Student Learning and Development in Cross-Border Higher Education. San Francisco: Jossey-Bass.

Reviewed by Munita Dunn-Coetzee $\mathbf{8 1}$

Asia-Pacific Journal for Student Affairs (AJSA)

Reviewed by Lisa Bardill Moscaritolo \& Kathleen Callahan 85

Osfield, K.J., Perozzi, B., Bardill Moscaritolo, L. \& Shea, R. (2016). Supporting Students Globally in Higher Education. Washington, D.C.: NASPA.

Reviewed by Jennifer A. Hamilton $\mathbf{8 9}$ 
Author biographies 93

Thank you to our reviewers 101

Call for submission of papers 102

Publications by African Sun Media 105

Submissions 106 
EDITORIAL

\section{Voices from Around the Globe}

Birgit Schreiber, ${ }^{\star}$ Thierry M. Luescher ${ }^{\star \star}$ \& Teboho Moja ${ }^{\star \star \star}$

$J S A A$ has been seeking to provide an opportunity for Student Affairs professionals and higher education scholars from around the globe to share their research and experiences of student services and student affairs programmes from their respective regional and institutional contexts. This has been given a specific platform with the guest-edited issue "Voices from Around the Globe" which is the result of a collaboration with the International Association of Student Affairs and Services (IASAS), and particularly with the guest editors, Kathleen Callahan and Chinedu Mba.

In this respect, we are pleased that the present issue highlights the intersection of global and local issues in Student Affairs, and of debates around local professionalisation and epistemic-discursive communities of practice in Student Affairs. Global and local issues are not so much about the spatial but the framework and lens of Student Affairs, which simultaneously aim to be locally relevant and embedded, and globally referenced to an overarching set of guidelines abstracted from the local and articulated at the global. Correspondingly it is instructive to invoke the notion of the Global Gemeinschaft (Robertson, 1995) as one community in the world, with many communities inherent within it; the notion that new identity is shaped by global-international and global-local influences on the epistemic-discursive community of Student Affairs (Castell, 1997). Furthermore, the JSAA-IASAS collaborative issue also brings into focus global trends and their local expression, including the reorganisation of knowledge in Student Affairs in relation to changing local realities. By foregrounding Botswana, China, South Africa and the USA, a comparative discourse is set up which is part of the global.

Callahan and Mba's guest editorial provides a succinct overview of the guest-edited articles in the issue. We are particularly glad that several of them address matters directly related to the professionalisation of Student Affairs in their respective contexts: on the history, challenges and solution to professionalisation in China, on standard setting and

* Dr Birgit Schreiber is Senior Director: Student Affairs, of Stellenbosch University, South Africa, and a member of the Editorial Executive of JSAA. Email: birgitschreiber@sun.ac.za

** Dr Thierry M Luescher is Research Director: Education and Skills Development, in the Human Sciences Research Council (HSRC), Cape Town, South Africa, and Journal Manager of JSAA. Email: jsaa_editor@ outlook.com

*** Prof. Teboho Moja is Clinical Professor for Higher Education Studies, Steinhardt School of Culture, Education and Human Development, New York University, USA. 
quality assurance in Botswana, and on the development of a sister journal to JSAA, the Asia-Pacific Journal of Student Affairs in the Philippines. In addition, we add to the guestedited collection the article by Arega Bazezew and Mulugeta Neka on incidents of, causes for, and the management of interpersonal conflicts among undergraduate students at Bahir Dar University in Ethiopia.

Finally, it is a great achievement to be credited to our authors, reviewers and editors that since January 2017, the Journal of Student Affairs in Africa is accredited in South Africa by the national Department of Higher Education and Training as a subsidy-earning scholarly journal on the SA-list of accredited journals. This means that authors affiliated to South African universities can submit their peer-reviewed articles, i.e. research articles and reflective practice articles, as recognised research outputs for subsidy purposes. Furthermore, $J S A A$ is now also fully indexed and full-text available from the Education Resources Information Centre (ERIC) in addition to our co-hosting with African Journals Online (AJOL) and the Directory of Open Access Journals (DOAJ).

\section{References}

Castells, M. (1997). The Power of Identity. The Information Age, 2. Malden and Oxford: Blackwell.

Robertson, R. (1995). Glocalization: Time-Space and Homogeneity-Heterogeneity. In: M. Featherstone, S. Lash \& R. Robertson (Eds.), Global Modernities. London: Sage Publications, 25-45. https://doi.org/10.4135/9781446250563.n2 
GUEST EDITORIAL

\title{
Special Guest IASAS Edition: Issues and Challenges in Student Affairs and Services Around the World
}

\author{
Kathleen Callahan ${ }^{\star} \&$ Chinedu $\mathrm{Mba}^{\star \star}$
}

The mission of the International Association of Student Affairs and Services (IASAS) is to serve "as a global advocate for students in higher education, student affairs and services practitioners, and the profession itself" (IASAS, 2017). It seems appropriate that the special edition of $J S A A$ focuses on issues and challenges in student affairs and services around the world. IASAS was formed from the awareness of and need for a global network for student affairs and services. It was in the mid-90s that the leadership in professional associations and institutions, along with key individuals, began to recognise a need for growth. It was the leadership within IASAS, specifically Roger Ludeman and his colleagues, who pushed for dialogue, connection, and networking around the world. Since its establishment and the recognition of the internationalisation of higher education, we have seen an increase in literature, meetings, presentations, and a general interest in global issues within the field of student affairs and services.

Global professional organisations such as IASAS are providing a space for professionals to engage with one another, to share common issues and concerns, and to dialogue with colleagues around the world. Events such as the Global Summits that have taken place over the past few years and other national, regional, and international professional conferences are allowing the sharing of knowledge, ideas, and best practices. Moreover, with journals such as $J S A A$, the field of student affairs and services is starting to hear more voices of professionals, and learn of both common and new issues and challenges within the field around the world.

Due to this growing shift in perspective, this issue highlights a few of those challenges as well as providing reviews of resources available to better our own understandings of student affairs and services around the world, and how we support our students. Authors in this issue as well as scholars are discussing the topic of professionalisation, training of student affairs staff, and the continual emphasis on students. We received submissions from South Africa, Botswana, China, and the USA with a total of five articles and three reviews of seminal works.

* Dr Kathleen Callahan is Lecturer for Leadership Studies at Christopher Newport University. Email: kathleen.callahan@cnu.edu

** Chinedu Mba is English as a Second Language/English for Academic Purposes Professor at Algonquin College, Ontario, Canada. She also serves as student advisor and as member of the College's Academic Advising Steering Committee. 
These articles not only bring thought-provoking and original viewpoints to discourse on the practice of student affairs, they promote and stimulate new dialogue around these topics, especially in developing contexts. In their paper 'Professionalisation of Student Affairs Educators in China: History, Challenges, and Solutions', Yongshan Li and Yuanyuan Fang address issues of the apparent lack of a consensus on the required professional training/background of student advisors in universities and its effect on the profession; the roles of government and institutions, and applicability of North American theories and practices in China and other countries with different socio-political realities. The second article 'Advocating for Standards in Student Affairs Departments in African Institutions: University of Botswana Experience', by Barbra Pansiri and Refilwe P. Sinkamba of the University of Botswana, underscores the benefits of having standards and functioning professional associations. The authors argue that 'quality assurance' should not be left to academic programmes but should be required of other units in institutions. According to them, the absence of professional associations responsible for accreditation and regulation of practice has been identified as a key challenge in Botswana, thus requiring student affairs practitioners in tertiary institutions to constantly have to defend their role and importance in the student success cycle.

From the USA, Maria Martinez and Kevin Colaner submitted a paper which has broader applications for institutions with different psychosocial and socio-political realities. Their article which explores themes around the experiences of East Asian international students in English-speaking countries suggests that the increasing diversity of student population in tertiary institutions has made meeting students' needs more complex and complicated. They identify factors (psycho-social, institutional, socio-economic and linguistic) that affect students'. The case of East Asian students as a case in point reaffirms the importance of role clarification, standards, and professionalism in serving international students well. Another submission with equally global applicability is that submitted by Munita Dunn-Coetzee and Magda Fourie-Malherbe. Titled 'Promoting social change amongst students in higher education: A reflection on the Listen, Live, and Learn senior student housing initiative at Stellenbosch University', this submission shares an innovative initiative at the Stellenbosch University, which demonstrates one of the institution's more tangible efforts at addressing the struggle around access, success, and transformation. The Listen, Live and Learn (LLL) initiative is one way of becoming more relevant and participating more actively in graduating empowered citizens ready to contribute to building South Africa. The final article comes from University of the Witwatersrand. Written by Danie de Klerk, Linda Spark, Andrew Jones and Tshepiso Maleswena, the paper 'Paving the road to success: Reflecting critically on year one of an undergraduate student support programme at a large South African university' is a reflective piece on the creation, execution, and results of a holistic student success intervention programme. Like the others, the authors have very interesting and relevant content that add value to the discourse.

The first review comes from an important contribution to the literature from editors Roberts and Komives entitled Enhancing Student Learning and Development in Cross-border Higher Education. The second review is the second edition of Supporting Students Globally in 
Higher Education from editors Osfield, Perozzi, Bardill Moscaritolo, and Shea. This follows the first edition published 10 years ago in one of the first books published on the topic of internationalisation of student affairs and services. Next, a review of the first volume of the Asia-Pacific Journal for Student Affairs: The Official Journal of the Philippine Association of Administrators of Student Affairs (PAASA). And finally, this issue includes a reflection on the third Global Summit of Student Affairs and Services that took place in South Africa in 2016.

We truly want to thank $J S A A$ for allowing this guest edition and providing a wonderful publication that allows scholars and practitioners from around the world to contribute in meaningful work. And the authors for submitting thoughtful research and reflections that can contribute to a gap in the literature in many topical areas within student affairs and higher education.

\section{References}

IASAS (International Association of Student Affairs and Services). (2017). About IASAS. Retrieved from http://iasas.global/aboutiasas/ 


\title{
RESEARCH ARTICLE
}

\section{Paving the Road to Success: Reflecting Critically on Year One of an Undergraduate Student Support Programme at a large South African university}

\author{
Danie de Klerk, ${ }^{\star}$ Linda Spark, ${ }^{\star \star}$ Andrew Jones ${ }^{\star \star \star} \&$ Tshepiso Maleswena ${ }^{\star \star \star \star}$
}

\begin{abstract}
Student success, faculty and university throughput, and the need for adequate and appropriate student support remain prevalent issues in the South African and global higher education sectors. Subsequently, the Faculty of Commerce, Law, and Management at a large South African university applied for Teaching and Development Grant funding in order to address these areas of concern. The grant was awarded and initially intended to help students at risk by implementing appropriate interventions to prevent them from dropping out of university or being excluded. However, being labelled as "at risk" was not well received by students and so the grant holders designed a new programme, adopting a decidedly more holistic approach. As such, the Road to Success Programme was born. The first three months saw those involved conceptualise, plan, and develop strategies, material, and interventions that were implemented in January 2015. The vision was to scaffold and support first-year students, particularly those in danger of being academically excluded, through an integrated network of tutorials, workshops, online support, and a series of resources called Toolkits for Success, in an attempt to help students achieve their academic goals. Despite a number of challenges, ranging from funding shortfalls and food security to students' emotional wellbeing and resilience, 2015 proved invaluable in terms of refining strategies, gaining insight, and programme growth. Preliminary data shows an increased pass rate for students who engaged with the RSP, with higher pass rates linked to greater RSP attendance. Consequently, this article serves as a critical reflection of the RSP at the end of its inaugural year and will share data, highlight lessons learned and challenges faced, and discuss how the programme has been taken to scale in 2016.
\end{abstract}

\section{Keywords}

access with success, higher education, holistic support, pass rate, socio-economic challenges, South Africa, student success, student support, success programme, throughput

* Danie de Klerk is a Lecturer and Coordinator: Road to Success Programme, Faculty of Commerce, Law, and Management, University of the Witwatersrand, South Africa.

* Linda Spark is a Senior Tutor and Grant Holder: Road to Success Programme, Faculty of Commerce, Law, and Management, University of the Witwatersrand.

*** Andrew Jones is a Grant Holder: Road to Success Programme, Faculty of Commerce, Law, and Management, University of the Witwatersrand.

**** Tshepiso Maleswena is an Associate Lecturer and Coordinator: Road to Success Programme, Faculty of Commerce, Law, and Management, University of the Witwatersrand. 


\section{Introduction}

The need for additional, often co-curricular, student support at university, faculty, ${ }^{1}$ school, department, and/or course level, is prevalent throughout the South African and global higher education sectors (Andrews \& Osman, 2015; Moser, Berlie, Salinitri, McCuistion \& Slaughter, 2015; Naude \& Bezuidenhout, 2015; Tovar, 2015). Nevertheless, factors contributing to the initial design and implementation of student-support interventions may vary significantly. Correspondingly, South Africa's Department of Higher Education and Training (DHET), Council on Higher Education (CHE), and the South African Institute for Distance Education (Saide) concern themselves with these matters by facilitating development grants (e.g. the DHET's Teaching Development Grant (TDG), soon to be the University Capacity Development Grant, which aims to establish at-risk support interventions (among other things) at South African tertiary institutions and engage in projects to address student support and success (e.g. Saide's partnership with the Kresge Foundation's Siyaphumelela Programme, which focuses on data analytics as a means of improving student success and retention). These are but some of the initiatives in place to address the many and varied challenges faced by the country's post-secondary institutions.

\section{Contextualisation}

\section{Background}

Massification of the South African higher education sector (Hornsby \& Osman, 2014; Lucket \& Sutherland, 2000) mirrors global trends over the last two decades (Bai, 2006; Giannakis \& Bullivant, 2016; Kivinen, Hedman \& Kaipainen, 2007; Lee, 2016; Pretorius and Xue, 2003; Ru-Jer, 2012; Trow, 2000; Trow, 2006; Yeom, 2016). Add to this increased attrition rates locally and abroad (Andrews \& Osman, 2015; Goncalves \& Trunk, 2014; Hughes, 2013; Martínez, Borjas, Herrera \& Valencia, 2015; Mestan, 2016), the access with success dichotomy (Ngo \& Kwon, 2015; Prakhov, 2016), socio-economic challenges faced by students in South Africa and many other countries (Dockery, Seymour \& Koshy, 2016), and a variety of mental health concerns prevalent on university campuses worldwide (Hugo, Boshoff, Traut, Zungu-Dirwayi \& Stein, 2003; Lund, Kleintjes, Kakuma, Flisher \& MHaPP Research Programme Consortium, 2010; Williams, Herman, Stein, Heeringa, Jackson, Moomal \& Kessler, 2008), and the scene is set for poor pass rates and serious threats to student success.

\section{The Access with Success Dichotomy}

The National Plan for Higher Education in South Africa (DoE, 2001) identifies as one of its key objectives the promotion of "equity of access and fair chances of success to all who are seeking to realise their potential through higher education, while eradicating all forms of unfair discrimination and advancing redress for past inequalities" (p. 6). The strategic

1 In the South African context the word "faculty" does not refer to academic or lecturing members of staff, but a cluster or group of schools/units/departments concerned with a particular discipline or subject area. 
objectives within this working paper remain clear: increase access to higher education for poor and disabled students in order to redress past inequalities and ensure that university staff and student profiles eventually reflect the demographics of South Africa. Yet fifteen years after its publication, inequities remain rife, with disparities in student participation and throughput rates evident across population groups (Higher Education South Africa (HESA), 2011). Moreover, admission to university is based on national exams that can discriminate against those who attended poorer and/or rural schools, thus favouring students from higher income groups or who may have attended better secondary schools, and elucidating why under-prepared students mostly come from under-resourced schools (Mdepa \& Tshiwula, 2012). The demand for access to higher education also continues to increase at rates far greater than existing resources and infrastructure can accommodate (Shaik, Karodia, David \& Soni, 2014) and many countries cannot provide access to all those who qualify for higher education (Gyimah-Brempong \& Ondiege, 2011; Leibowitz \& Bozalek, 2014). Additionally, there appears to be a direct correlation between access and funding, and between poverty and retention in African universities (Mdepa \& Tshiwula, 2012). It is unlikely that simply focusing on access to higher education will address equity of opportunity; rather South African universities should be supportive environments where academics and students alike are willing to think innovatively. This can be achieved by adopting appropriately transformed learning and teaching strategies and techniques, ensuring staff and students have access to adequate induction programmes and holistic support, and through effective academic mentoring (Ratangee, 2006). Only by ensuring epistemological access to knowledge can knowledge be democratised, and in turn address disparities in throughput and graduation rates, as well as issues with the transformation of higher education institutions (Du Plooy \& Zilindile, 2014; Ratangee, 2006). Yet this is not the only challenge faced by South Africa's tertiary sector.

\section{Socio-economic Challenges in South Africa}

In 2015, the country experienced a tipping point when thousands of students across multiple campuses revolted against nationwide university fee increases. The \#FeesMustFall campaign brought South African students' socio-economic plight to the public's attention, placing the spotlight on one of the major factors affecting access to and retention in tertiary education (Breier, 2010; Gyimah-Brempong \& Ondiege, 2011). Research shows that a lack of information about the financial implications of tertiary education can cause students to avoid university, or it can allow them to enter without fully understanding the financial impact (Breier, 2010). South Africa has one of the highest levels of inequality in the world (Breier, 2010; Leibowitz \& Bozalek, 2014), with most African families being particularly poor (Leibowitz \& Bozalek, 2014). One challenge is to provide resources to finance everyone who qualifies for admission to university. The principle of equity suggests that nobody should be denied an education on the basis of socio-economic status (GyimahBrempong \& Ondiege, 2011), yet government funding is based on a shared-cost model, implying that the cost of education should be carried by both student and government (Gyimah-Brempong \& Ondiege, 2011). 
A large portion of students accessing higher education come from middle- or highincome groups, though the availability of grants, bursaries, scholarships, and student loans (e.g. the National Student Financial Aid Scheme (NSFAS), similar to the US Federal Pell Grant system) make it possible for poorer students to access tertiary education (GyimahBrempong \& Ondiege, 2011; Leibowitz \& Bozalek, 2014; Mdepa \& Tshiwula, 2012). Although NSFAS covers expenses other than tuition, it also tries to fund as many students as possible, which means students seldom obtain full funding. Subsequently, recipients are compelled to commute long distances, stay in accommodation not conducive to studying, and/or lack food and other necessities (Breier, 2010; Mdepa \& Tshiwula, 2012). Moreover, not all applicants receive NSFAS funding, while many prospective students remain unaware of alternative funding opportunities (Mdepa \& Tshiwula, 2012). This lack of financial resources is one of the major challenges faced by students (Mdepa \& Tshiwula, 2012) who often drop out because of financial obstacles. So, even after gaining access, a high number of poorer students will fail to complete their degrees (Mdepa \& Tshiwula, 2012), while those who do stay are usually expected to support family members and as a result may go hungry or sleep in lecture theatres or libraries (Breier, 2010).

On a larger scale, government funding has not kept up with enrolment growth and subsidies have been consistently declining in recent years (Gyimah-Brempong \& Ondiege, 2011), yet funding for higher education in South Africa remains lower than in countries at similar levels of development (Leibowitz \& Bozalek, 2014). To offset the declining subsidies most universities regularly increase tuition fees, which negatively impacts poorer students and exacerbates social and economic inequalities (WangengeOuma, 2010). In South Africa, only about 31\% of students contribute to the financing of tertiary education (Cloete, 2016), up from $24 \%$ in the last decade, while government subsidies have decreased from $49 \%$ to $40 \%$ in the same period (Cloete, 2016). Subsequently, the current approach to financing tertiary education in South Africa is insufficient and not sustainable (Gyimah-Brempong \& Ondiege, 2011; Leibowitz \& Bozalek, 2014), and intensifies other threats to student success.

\section{Mental Health Concerns on South African Campuses}

A number of publications by international scholars focus on the plight of students on campuses, yet there seems to be a lack of published knowledge about mental health interventions and challenges at South African tertiary institutions. Moreover, the conceptual framework on which empirical data from South African university cases should be based lacks the requisite theoretical underpinnings (Petersen \& Lund, 2011; Colleges Struggling with Growing Demand for Mental Health Services, n.d.). As such, the design of methodologies for South Africa will have to be based on and adapted from research conducted at international colleges and universities, with an emphasis on effective education, awareness, and interventions. Cluver and Orkin's (2009) research is central to assessing elements contributing to mental health disorders in young people at South African universities. Bullying at school, children being orphaned by AIDS, and poverty are some of 
the prominent contributing factors (Cluver \& Orkin, 2009) and it has been documented that " $[\mathrm{m}]$ ental disorders account for a large proportion of the disease burden in young people in all societies" (Patel, Flisher, Hetrick \& McGorry, 2007, p. 1303). Additionally, the World Health Organization's AIMS report (WHO, 2007) provides a broad yet integral insight into the mental health systems that exist in this country. Where Cluver and Orkin (2009) focuses on specific demographics, the WHO-AIMS report (2007) provides a more nuanced account of South Africa's mental health challenges, taking into account factors like the financing of mental health services, legislation, and policy frameworks that have been put into place. Subsequently, when considering the challenges faced by higher education in South Africa, it is not surprising that stakeholders have developed programmes and support structures to address student success (Engelbrecht, Harding \& Potgieter, 2014; Potgieter, Harding, Kritzinger, Somo \& Engelbrecht, 2015; McGhie \& du Preez, 2015), in line with international practice (Bensimon, 2007; Hatch, 2016; Perez \& Ceja, 2010; Perna, Rowan-Kenyon, Thomas, Bell, Anderson \& Li, 2008; Stanton-Salazar, 2011; StantonSalazar,Vasquez \& Mehan, 2000; Wathington, Pretlow \& Barnett, 2016).

\section{The Road to Success Programme}

\section{Background}

In 2014, TDG funding was either directly awarded for projects in the Faculty of Commerce, Law, and Management (CLM) at the author's university or as part of projects for the entire university. The Faculty received money for a total of four projects and whilst each project constitutes a separate entity, they have been combined into an overall programme with a common aim: to improve first-year throughput, enhance student success, and provide effective support for undergraduate students. Subsequently, At-Risk Coordinators were employed to coordinate programme efforts, identify students at risk, develop and implement interventions, and engage with students in one-on-one and/or group settings. These positions are academic in nature and although they involve little or no formal teaching, data analytics, the scholarship of teaching and learning, and student success form part of the duties.

In the latter part of 2014 an intervention workshop was conducted for students classified as At Risk. The workshop was poorly attended, with the two major reasons students provided for not attending being a lack of integration into the normal academic programme (the workshop was conducted during the September study break) and students' perceived denial about the stigma associated with being classified as At Risk. As such, the name Road to Success Programme (RSP) arose from the need for a positive, successorientated student support initiative that runs parallel to the academic curriculum and one that students would want to participate in. So, although poor student performance, particularly at first-year level, was the driving force behind this project, the RSP aims to provide co-curricular, non-academic interventions that run concurrently with the standard academic support provided by courses. At the beginning of 2015 it was rolled out to all 
first-year students in addition to small cohorts of readmitted ${ }^{2}$ and At-Risk students, in an attempt to help them achieve their academic goals.

\section{Overall Target and Benefit}

The core objective of this programme is to improve the course pass rates of first-year students by $10 \%$ and to provide At-Risk students with the requisite mentor/tutor support. The anticipated outcome of RSP interventions is to improve students' preparedness for formative and summative assessments, which would ideally result in improved student performance and throughput. Moreover, the additional interventions for At-Risk students should enable them to progress, particularly in instances where support addresses non-academic factors. Consequently, the programme comprises an integrated network of group tutorials, one-on-one consultations, online support, and toolkits that serve to support CLM undergraduates in an attempt to help them achieve their short-, medium-, and longterm academic goals. Additionally, it focuses on assisting students from the Faculty's three undergraduate schools in dealing with emotional, psychological, and socio-economic challenges, to ultimately ensure they realise their potential, graduate with integrity, and take responsibility for their own success.

\section{The First Year}

In the first quarter of 2015, thirty (30) Success Tutors (senior undergraduate students) were appointed, following a shortlisting and interview process. They were trained through CLM's Tutor Training Programme and the university's Counselling and Careers Development Unit, and would facilitate non-academic student support across the aforementioned RSP focus areas. With the success of the programme hinged on student buy-in, a marketing campaign was launched (involving the design of pamphlets, banners, shirts, social media sites, and posters) to inform undergraduates of the RSP's support and benefits. Additionally, an academic literacy programme was developed and implemented, while Toolkits for Success formed the foundation of all non-academic group tutorials, covering things like time management, study skills for university purposes, note taking, planning, reflective practice, and more. In quarter two the RSP started working on initiatives pertaining to clothing and food provisions for needy students, with a corporate partnership starting off what would become the RSP Food- and Clothing Banks.

The commencement of semester two saw the RSP conduct one-on-one interviews with all first-year students who had failed two or more examinations at mid-year, as well as the entire cohort of readmitted students (a condition of their readmission). These interviews allowed for greater insight into students' circumstances and requirements. Because of the programme's holistic nature, both cohorts were channelled into focus groups (with a

2 At the authors' university there is a system that requires students to meet a particular set of minimum requirements at the end of an academic year to remain a registered student. Students who do not meet these requirements are excluded from the faculty in which they are studying. An appeal process could see a student readmitted the following year, providing they adhere to certain conditions of readmission. 
maximum of 10 students per group), which met once a week, capitalised on the diversity of the students (they were from different degree programmes and years of study), and used reflective practice to scaffold students through semester two. Quarter four was characterised by sessions on study planning, examination preparation, and peer support as a means of making sure students were on track for the end-of-year examinations. End-of-year evaluations were administered and students were asked to evaluate the RSP and their focus groups, but it should be noted that the \#FeesMustFall protests had a crippling effect on the evaluation process.

\section{Challenges and Mitigation Strategies}

A plan to use the university's Learning Management System (LMS) to conduct forums was stymied by slow response times and server problems. Scheduling and venue booking for the more than 1,000 students who signed up for the RSP also proved challenging, as the RSP does not form part of the mainstream curriculum and is not accommodated on the academic timetable. This was resolved by using the LMS to allow students more flexibility in booking their sessions (a functionality not affected by the aforementioned server problems). At one point storage space for clothing and food became a problem, but this was overcome by acquiring additional office space. The RSP still finds that some students do not read their emails regularly, fail to carry out instructions, and often do not take the mandate of the programme seriously until it is too late. The biggest challenge faced in the final quarter of 2015 was the \#FeesMustFall student protests, which saw the university close for nearly two weeks. Many RSP students had their study planning and momentum disrupted by the temporary suspension of the university academic programme, which in turn led to increased anxiety and stress. The RSP tried to manage these concerns as best they could.

\section{Analysis}

\section{Descriptive statistics}

Approximately 1050 first-year and readmitted students were signed up for the RSP in January 2015, which marked the beginning of semester one and a new academic year. By the end of the semester 772 students had engaged (i.e. attended one or more interventions) with the programme, which constituted a $74 \%$ overall engagement. In semester two about 500 readmitted and At-Risk first-year students were signed up for the RSP, with 342 having engaged with the RSP by the end of the semester (i.e. 68\%). Although this means fewer students engaged in semester two than in semester one, the team ascribes it to two factors: (1) fewer students were signed up in the second semester, and (2) the \#FeesMustFall protests that occurred during the fourth quarter.

Table 1 below contrasts the overall faculty pass rate with the average pass rates of RSP students who engaged with a specific percentage of sessions (i.e. $70 \%$ to $79 \%, 80 \%$ to $89 \%$, and $90 \%$ to $100 \%)$. Semester one (2015) results seem quite sporadic, which can be attributed to the fact that it was the programme's first semester, while semester two (2015) results start 
alluding to a link between student engagement with the RSP and academic success. This provided the core team with evidence that RSP interventions appeared to be benefiting students and influenced the adjustments realised in semester one of the following year. The table shows a clear upward trend in the pass rates of students who engaged with the RSP in semester one of 2016 and reflects that greater RSP attendance is linked to average pass rates above the overall faculty average.

Table 1: Engagement rate and student pass rates

\begin{tabular}{|c|c|c|c|}
\hline Semester and Year & $\begin{array}{c}\text { RSP Engagement } \\
\text { Level }\end{array}$ & $\begin{array}{c}\text { Average RSP } \\
\text { Student Pass Rate }\end{array}$ & $\begin{array}{l}\text { Average Overall } \\
\text { Faculty Pass Rate }\end{array}$ \\
\hline \multirow{3}{*}{ Semester 1 (2015) } & $70 \%$ to $79 \%$ & $100 \%$ & \multirow{3}{*}{$70 \%$} \\
\hline & $80 \%$ to $89 \%$ & $56 \%$ & \\
\hline & $90 \%$ to $100 \%$ & $66 \%$ & \\
\hline \multirow{3}{*}{ Semester 2 (2015) } & $70 \%$ to $79 \%$ & $82 \%$ & \multirow{3}{*}{$85 \%$} \\
\hline & $80 \%$ to $89 \%$ & $66 \%$ & \\
\hline & $90 \%$ to $100 \%$ & $100 \%$ & \\
\hline \multirow{3}{*}{ Semester 1 (2016) } & $70 \%$ to $79 \%$ & $62 \%$ & \multirow{3}{*}{$69 \%$} \\
\hline & $80 \%$ to $89 \%$ & $70 \%$ & \\
\hline & $90 \%$ to $100 \%$ & $77 \%$ & \\
\hline
\end{tabular}

\section{Recommendations and Lessons Learned}

In the authors' experience, students (and staff) often harbour negative perceptions about support initiatives, so increased awareness of a programme, its benefits, and its successes must be emphasised. Students suggest these programmes require additional work and commitment, so mechanisms to include support activities within their existing timetables are vital; our toolkit on time management has been crucial in this endeavour. The statistics show that student buy-in and attendance serve as both input and output to the success of these programmes, so a strategy for marketing the benefits and highlighting the successes is required to encourage engagement. Academics are often the first to identify non-academic issues with students, so their awareness, support, and recommendation of these programmes are vital. Moreover, grant-funded programmes usually receive financial support for a fixed period of time. As a result, it is necessary to seek and request funding to sustain such programmes. Approaching businesses, investigating alternative revenue streams from within the university, running additional paid-for courses, and answering proposals where funding is offered, are a few of the possibilities.

While many will argue that it is not the role of academics (or indeed a university) to provide food, accommodation, books and/or clothing to students who are not paying for them, in an environment where students are severely impacted by socio-economic factors, it is important to assist where possible. This may include involving external entities looking for pro-bono engagements, or simply asking the university community for donations. 
In most universities there will also be specific departments that deal with some of these matters, so it is necessary to make students (and staff) aware of all available help. It should be noted that the operational activities of these programmes require a substantial time commitment from those involved. As such, it is important to focus on collecting data on these initiatives and conducting studies to determine which interventions are useful and/or successful, provide evidence to stakeholders, and publish research in the area of student support.

\section{Towards the Future}

The Road to Success Programme has made some salient strides in its year of inception (2015). This progress, coupled with increased student engagement, allows the team to infer that the future will be more effective in terms of student involvement. The year 2016 has seen the emphasis shift from a first-year student focus, to rolling the programme out to all CLM undergraduates. From a supplementary-support perspective, the RSP's corporate partnerships have helped create male and female clothing banks and donated food to the RSP foodbank. An intensive awareness drive was launched to reach out to students, while a sponsored weekly hot-beverage station aimed to encourage students to pay-it-forward by donating food and toiletries to help fellow students in need. Other future initiatives include: a faculty-specific Academic Literacy Programme (ALP); formalising the RSP as a compulsory, co-curricular initiative for all incoming first-year students; an annual CLM pre-university school prior to the commencement of the new academic year, offered to all new first years; work-readiness initiatives through partnerships with internal and external stakeholders; Success Tutor training and development initiatives; and an interdisciplinary Enquiry-Based Learning course for all CLM undergraduates. The RSP continues to evolve through the scholarship of student support and success, data analytics, and student engagement, alluding to a promising future.

\section{Conclusion}

With the massification of the tertiary sector, concerning success rates, and socio-economic challenges unlikely to dissipate anytime soon, the need for proactive and pre-emptive solutions to address these issues become imperative. In this paper the authors outlined their holistic student support and success initiative in the form of the Road to Success Programme. The aim was to allow others insight into their unique approach to enhancing student success, which serves to supplement and complement the academic programme. The authors hope the lessons they have learned and subsequently shared in this article will provide others working in the space with practical advice to help conceptualise, develop, implement, and enhance their own initiatives. The RSP remains dedicated to evolving and refining their student success and support programme, and in the long run address (at least some of) the challenges faced by higher education both locally and globally. 


\section{References}

Andrews, D. \& Osman, R. (2015). Redress for academic success: Possible 'lessons' for university support programmes from a high school literacy and learning intervention. South African Journal of Higher Education, 29(1), 354-372.

Bai, L. (2006). Graduate unemployment: Dilemmas and challenges in China's move to mass higher education. The China Quarterly, 185, 128-144. https://doi.org/10.1017/S0305741006000087

Bensimon, E.M. (2007). The underestimated significance of practitioner knowledge in the scholarship on student success. The Review of Higher Education, 30(4), 441-469. https://doi.org/10.1353/ rhe. 2007.0032

Breier, M. (2010). From 'financial considerations' to 'poverty': Towards a reconceptualization of the role of finances in higher education student drop out. Higher Education, 60(6), 657-670. https:// doi.org/10.1007/s10734-010-9343-5

Cloete, N. (2016). For sustainable funding and fees, the undergraduate system in South Africa must be restructured. South African Journal of Science, 111(3/4), 5-9. https://doi.org/10.17159/sajs.2016/ a0146

Cluver, L. \& Orkin, M. (2009). Cumulative risk and AIDS-orphanhood: Interactions of stigma, bullying and poverty on child mental health in South Africa. Social Science \& Medicine, 69(8), 1186-1193. https://doi.org/10.1016/j.socscimed.2009.07.033

Colleges Struggling With Growing Demand For Mental Health Services. (n.d.). Retrieved 16 September 2016 from http://www.sadag.org

Dockery, A.M., Seymour, R. \& Koshy, P. (2016). Promoting low socio-economic participation in higher education: A comparison of area-based and individual measures. Studies in Higher Education, 41(9), 1692-1714. https://doi.org/10.1080/03075079.2015.1020777

DoE (Department of Education) (2001). National plan for higher education in South Africa. Pretoria.

Du Plooy, L. \& Zilindile, M. (2014). Problematising the concept epistemological access with regard to foundation phase education towards quality schooling. South African Journal of Childhood Education, 4(1), 187-201.

Engelbrecht, J., Harding, A. \& Potgieter, M. (2014). Evaluating the success of a science academic development programme at a research-intensive university. African Journal of Research in Mathematics, Science and Technology Education, 18(3), 287-298. https://doi.org/10.1080/10288457. 2014.962726

Giannakis, M. \& Bullivant, N. (2016). The massification of higher education in the UK: Aspects of service quality. Journal of Further and Higher Education, 40(5), 630-648. https://doi.org/10.1080/0 309877X.2014.1000280

Goncalves, S.A. \& Trunk, D. (2014). Obstacles to success for the nontraditional student in higher education. Psi Chi Journal of Psychological Research, 19(4), 164-172. https://doi.org/10.24839/21648204.JN19.4.164

Gyimah-Brempong, K. \& Ondiege, P. (2011). Reforming higher education: Access, equity, and financing in Botswana, Ethiopia, Kenya, South Africa, and Tunisia. In: The Africa Competitiveness Report 2011 (pp. 39-66). Geneva: World Economic Forum, the World Bank and the African Development Bank.

Hatch, D.K. (2016). A brief history and a framework for understanding commonalities and differences of community college student success programs. New Directions for Community Colleges, 175, 19-31. https://doi.org/10.1002/cc.20209

HESA (Higher Education South Africa) (2011). Insight, (3), 1-27. 
Hornsby, D. \& Osman, R. (2014). Massification in higher education: Large classes and student learning. Higher Education, 67(6), 711-719. https://doi.org/10.1007/s10734-014-9733-1

Hughes, H.A. (2013). Factors influencing attrition rates in midwifery students. Nursing Standard, 27(26), 42-48. https://doi.org/10.7748/ns2013.02.27.26.42.e7130

Hugo, C.J., Boshoff, D.E., Traut, A., Zungu-Dirwayi, N. \& Stein, D.J. (2003). Community attitudes toward and knowledge of mental illness in South Africa. Social Psychiatry \& Psychiatric Epidemiology, 38(12), 715-719. https://doi.org/10.1007/s00127-003-0695-3

Kivinen, O., Hedman, J. \& Kaipainen, P. (2007). From elite university to mass higher education: Educational expansion, equality of opportunity and returns to university education. Acta Sociologica, 50(3), 231-247. https://doi.org/10.1177/0001699307080929

Lee, S. (2016). Massification without equalisation: The politics of higher education, graduate employment and social mobility in Hong Kong. Journal of Education and Work, 29(1), 13-31. https://doi.org/10.1080/13639080.2015.1049024

Leibowitz, B. \& Bozalek, B. (2014). Access to higher education in South Africa: A social realist account. Widening Participation and Lifelong Learning, 16(1), 91-109. https://doi.org/10.5456/ WPLL.16.1.91

Lucket, K. \& Sutherland, L. (2000). Assessment practices that improve teaching and learning. In: S. Makoni (Ed.), Improving teaching and learning in higher education (pp. 98-129). Johannesburg: Witwatersrand University Press.

Lund, C., Kleintjes, S., Kakuma, R., Flisher, A.J. \& MHaPP Research Programme Consortium. (2010). Public sector mental health systems in South Africa: Inter-provincial comparisons and policy implications. Social Psychiatry and Psychiatric Epidemiology, 45(3), 393-404. https://doi. org $/ 10.1007 / \mathrm{s} 00127-009-0078-5$

Martínez, A., Borjas, M., Herrera, M. \& Valencia, J. (2015). Relationship between measures of academic quality and undergraduate student attrition: The case of higher education institutions in the Colombian Caribbean region. Higher Education Research and Development, 34(6), 1192-1206. https://doi.org/10.1080/07294360.2015.1024622

McGhie, V. \& du Preez, M. (2015). Addressing the learning needs of at-risk students at the University of the Western Cape. South African Journal of Higher Education, 29(1), 164-180.

Mdepa, W. \& Tshiwula, L. (2012). Student diversity in South African higher education. Widening Participation and Lifelong Learning, 13 (Special Issue), 19-33. https://doi.org/10.5456/ WPLL.13.S.19

Mestan, K. (2016). Why students drop out of the Bachelor of Arts. Higher Education Research and Development, 35(5), 983-996. https://doi.org/10.1080/07294360.2016.1139548

Moser, L., Berlie, H., Salinitri, F., McCuistion, M. \& Slaughter, R. (2015). Enhancing academic success by creating a community of learners. American Journal of Pharmacentical Education, 79(5), 70. https://doi.org/10.5688/ajpe79570

Naude, L. \& Bezuidenhout, H. (2015). Moving on the continuum between teaching and learning: Communities of practice in a student support programme. Teaching in Higher Education, 20(2), 221-230. https://doi.org/10.1080/13562517.2014.978752

Ngo, F. \& Kwon, W. (2015). Using multiple measures to make math placement decisions: Implications for access and success in community colleges. Research in Higher Education, 56(5), 442-470. https://doi.org/10.1007/s11162-014-9352-9

Patel, V., Flisher, A.J., Hetrick, S. \& McGorry, P. (2007). Mental health of young people: A global public health challenge. The Lancet, 369(9569), 1302-1313. https://doi.org/10.1016/S01406736(07)60368-7 
Perez, P.A. \& Ceja, M. (2010). Building a Latina/o student transfer culture: Best practices and outcomes in transfer to universities. Journal of Hispanic Higher Education, 9(1), 6-21. https://doi. org/10.1177/1538192709350073

Perna, L.W., Rowan-Kenyon, H.T., Thomas, S.L., Bell, A., Anderson, R. \& Li, C. (2008). The role of college counselling in shaping college opportunity: Variations across high schools. The Review of Higher Education, 31(2), 131-159. https://doi.org/10.1353/rhe.2007.0073

Petersen, I. \& Lund, C. (2011). Mental health service delivery in South Africa from 2000 to 2010: One step forward, one step back. SAMJ: South African Medical Journal, 101(10), 751-757.

Prakhov, I. (2016). The barriers of access to selective universities in Russia. Higher Education Quarterly, 70(2), 170-199. https://doi.org/10.1111/hequ.12087

Pretorius, S.G. \& Xue Y.Q. (2003). The transition from elite to mass higher education: A Chinese perspective. Prospects, 33(1), 89-101. https://doi.org/10.1023/A:1022616532317

Potgieter, M., Harding, A., Kritzinger, Q., Somo, C. \& Engelbrecht, J. (2015). Reflections of science students on their experiences of an academic development programme in South Africa. South African Journal of Higher Education, 29(1), 108-131.

Ru-Jer, W. (2012). Social class barriers of the massification of higher education in Taiwan. Chinese Education and Society, 45(6), 70-81. https://doi.org/10.2753/CED1061-1932450506

Ratangee, N. (2006). Academic literacy, the PTEEP and the prediction of academic success. Unpublished master's thesis. University of Witwatersrand, Johannesburg, South Africa.

Shaik, A., Karodia, A., David, J. \& Soni, D. (2014). Private providers can widen access to higher education: A fertile idea whose time has come. Breaking Barriers, 29 January.

Stanton-Salazar, R.D. (2011). A social capital framework for the study of institutional agents and their role in the empowerment of low-status students and youth. Youth \& Society, 43(3), 1066-1109. https://doi.org/10.1177/0044118X10382877

Stanton-Salazar, R.D., Vasquez, O.A. \& Mehan, H. (2000). Engineering academic success through institutional support. In: S.T. Gregory (Ed.), The academic achievement of minority students: Perspectives, practices, and prescriptions (pp. 213-247). New York, N.Y.: University Press of America.

Tovar, E. (2015). The role of faculty, counselors, and support programs on Latino / a community college's students' success and intent to persist. Community College Review, 43(1), 46-71. https:// doi.org/10.1177/0091552114553788

Trow, M. (2000). From mass higher education to universal access: The American advantage. Minerva, 37(4), 303-328. https://doi.org/10.1023/A:1004708520977

Trow, M. (2006). Reflections on the transition from elite to mass to universal access. In: J.J.F. Forest \& P.G. Altbach (Eds.), International Handbook of Higher Education (pp. 243-280). Dordrecht: Springer. https://doi.org/10.1007/978-1-4020-4012-2_13

Wangenge-Ouma, G. (2010). Funding and the attainment of transformation goals in South Africa's higher education. Oxford Review of Education, 36(4), 481-497. https://doi.org/10.1080/0305498 5.2010 .491181

Wathington, H., Pretlow, J. \& Barnett, E. (2016). A good start? The impact of Texas' developmental summer bridge program on student success. Journal of Higher Education, 87(2), 150-177. https:// doi.org/10.1353/jhe.2016.0010

Williams, D.R., Herman, A., Stein, D.J., Heeringa, S.G., Jackson, P.B., Moomal, H. \& Kessler, R.C. (2008). Twelve-month mental disorders in South Africa: prevalence, service use and demographic correlates in the population-based South African Stress and Health Study. Psychological Medicine, 38(2), 211-220. https://doi.org/10.1017/S0033291707001420 
WHO (World Health Organization) (2007). WHO-Aims report on mental health systems in South Africa. Chicago.

Yeom, M. (2016). Critical reflection on the massification of higher education in Korea: consequences for graduate employment and policy issues. Journal of Education and Work, 29(1), 48-63. https:// doi.org/10.1080/13639080.2015.1049026 
RESEARCH ARTICLE

\title{
Experience of International Education of East Asian Students in English-speaking Countries: A Four-Dimensional Approach
}

\author{
Maria L. Martinez ${ }^{\star} \&$ Kevin T. Colaner ${ }^{\star \star}$
}

\begin{abstract}
Global participation in international education in the last two decades has increased exponentially. International students face difficulties in adjusting to the culture of their host country due to their unique needs (Bertram, Poulakis, Elsasser \& Kumar, 2014). This article presents themes comprising the international education phenomenon involving the experiences of East Asian international students in English-speaking countries. The literature reviewed for this article pertains to many aspects of international education, covering the factors that influence the decision to embark on the international education journey to the adjustment experienced by students to the host culture. The authors suggest that the international education experience is comprised of four dimensions: structural, linguistic, internal, and external. We also posit that Confucianism, which many East Asian students follow, influences not only the psycho-social dimension of the international education experience but also their instructional preferences within the structural dimension. We further contend that students' actual and perceived proficiency (or the lack thereof) in the host country's language greatly shapes all aspects of the student's international education experience, which then determines the degree of acculturative stress involved and plays a key role in each of the three dimensions.

Because of the anticipated continued growth in the number of international students from East Asia attending higher education institutions in English-speaking countries such as the United States, Australia, Canada, and parts of Africa, it is important to examine how each of the dimensions proposed impact each other. Approaching the study of the international education experience one dimension at a time, as many scholars have done, does not completely address all of the unique needs of international students. We suggest that research in this area be conducted holistically by exploring the ecology surrounding the international student. Taking this ecological approach will help clearly define the role that home and host countries and host higher education institutions must take in serving the international students well.
\end{abstract}

\section{Keywords}

acculturation, campus climate, Confucianism, engagement, international education, language, psychosocial, student development

* Dr Maria L. Martinez is the Associate Vice President of Enrollment Management at San Francisco State University. San Francisco CA, USA.

** Dr Kevin T. Colaner serves as the Associate Vice President for Student Services at California State Polytechnic University, Pomona. Pomona CA, USA. 


\section{Introduction}

The body of knowledge on international education is broad and multi-faceted. While varied in theoretical approach and focus, an over-arching theme that binds these works is the recognition that, because of their unique needs, international students face difficulties in adjusting to the culture of their host country. In addition to this theme, a deficit model appears to undergird the exploration of the experiences of international students. East Asian students attending universities in English-speaking countries are particularly painted in a deficient way, often subject to acculturative stress due to difficulties in adjusting to the host country's culture and language. In understanding this sub-group of international students attending universities in English-speaking countries, it is important to note their Confucian traditions and that instilled in their behaviour is the value of harmonious integration of opposites. Characterised by the popular 'yin and yang' concept, Confucianism, as it relates to learning, includes: placing a very high value on education for the purpose of gaining knowledge (more so than practicality and work experience); seeing learning as a moral duty; knowing that learning involves reflection and application; studying hard as a family responsibility; respecting teachers and knowing that they care about their students; and seeing teachers as models of morality and knowledge (McMahon, 2011). This mindset shapes how international students with Confucian traditions experience international education.

Relative to their Confucian tradition, this paper presents the themes, as gleaned from the literature, comprising the international education phenomenon involving the experiences of East Asian international students in English-speaking countries such as the United States, United Kingdom, parts of Africa, and Canada. We posit that these themes reflect the dimensions of the international education experience. Shown in Table A, these dimensions are the Internal or Psycho-social, the Institutional or Structural, the External or Socio-economic, and the Linguistic dimensions.

Following the discussion about these dimensions are recommendations offered to improve the international student experience, particularly for the aforementioned East Asian international students in English-speaking countries. These recommendations are borne out of our extensive experiences as student affairs professionals in various universities in the United States that host large numbers of East Asian international students. 
Table A

\begin{tabular}{|l|l|l|}
\hline \multicolumn{1}{|c|}{$\begin{array}{c}\text { Internal } \\
\text { (Psycho-social) }\end{array}$} & \multicolumn{1}{|c|}{$\begin{array}{c}\text { Structural } \\
\text { (Institutional) }\end{array}$} & $\begin{array}{c}\text { External } \\
\text { (Socio-economic) }\end{array}$ \\
\hline $\begin{array}{l}\text { Personal values and culture } \\
\text { influence experience }\end{array}$ & $\begin{array}{l}\text { Institutional support } \\
\text { enhances learning and } \\
\text { development }\end{array}$ & $\begin{array}{l}\text { Socio-economic forces } \\
\text { influence student mobility } \\
\text { (push-pull) }\end{array}$ \\
\hline $\begin{array}{l}\text { Positive personal attributes } \\
\text { moderate acculturative stress }\end{array}$ & $\begin{array}{l}\text { Social interaction shapes } \\
\text { experience }\end{array}$ & $\begin{array}{l}\text { Tension between native values } \\
\text { and host values }\end{array}$ \\
\hline $\begin{array}{l}\text { Confucian philosophy's emphasis on harmony can lead to } \\
\text { adaptability in instructional preferences }\end{array}$ & \multicolumn{2}{|c|}{ Linguistic } \\
\hline \multicolumn{2}{|c|}{ Language proficiency moderates acculturative stress } \\
\hline \multicolumn{2}{|c|}{}
\end{tabular}

\section{Internal: Psycho-Social Quadrant}

The study of international education cannot be done without discussing culture. Hofstede's theory of cultural dimensions is used (Gahan \& Abeysekera, 2009; Tan \& Liu, 2014) to provide context to the native traits of international students that influence their ability or inclination to adapt to foreign ways of behaving and thinking. A number of studies (Bertram, Poulakis, Elsasser \& Kumar, 2013; Broesch \& Hadley, 2012; Falcone, Espi, Ashai, Butler \& Franco, 2013; Pritchard, 2011) use the sociological perspective of Acculturation Theory (Berry, 2008) to explain the different orientations to acculturation that students may adopt during their sojourn. Understanding this concept is important given that East Asian international students, who struggle to adjust to the individualistic orientation of Western pedagogy and student development programmes (McMahon, 2011), compose the largest sub-group of international students in the United States. According to McMahon (2011), Chinese students attending universities in the United Kingdom experience culture shock with regard to the student-instructor relationship. In their host country, this relationship is normally more structured and is bound by curricular or professional needs and interests whereas at home, there is more extra-curricular mentorship that extends to personal matters. The process that sojourners go through to deal with these differences is known as acculturation.

Research on international education reveals the fundamental role of acculturation in the experience of international students. "In broad terms, acculturation refers to an immigrant's process of cultural, psychological, and social adaptation to the culture" (Martinez, 2016, p. 44) of the host country. Acculturative stress arises from problems with psychological, cultural, and social adaptation (Yakunina, Weigold, Weigold, Hercegovac \& Elsayed, 2013). Studies using the construct of multicultural personality, assertiveness, and academic self-efficacy (Lee \& Ciftci, 2014; Roesch, Wee \& Vaughn, 2006) explain why some students adjust to their foreign environment better than others. Using the psychological 
perspective, these studies identified the factors influencing the way a sojourner experiences international education. Two of these factors are explained here.

One, possessing the personal characteristics of universal-diverse orientation, personal growth initiative, and hardiness with the student's adjustment enables an international student to have a less stressful and less challenging adjustment to the new environment (Yakunina et al., 2013). These personal characteristics reduce the degree of acculturative stress encountered by these students. Two, personal values influence the way international students experience the unfamiliar world around them. As part of one's culture, personal values "are students' individual value characteristics that shape their evaluation of the factors related to the internal and external learning environments, thus influencing student experience and satisfaction" (Arambewela \& Hall, 2013, p. 976). Arambewela and Hall's (2013) study of the relationship between students' on- and off-campus environments and their satisfaction of the international education experience, shows that respect for self and from others, self-fulfillment, belongingness, security, accomplishment (which make up selfefficacy) and the sense of fun and excitement (which make up the hedonism construct) have a mediating influence on student satisfaction. In particular, there is a positive relationship between students' self-efficacy and satisfaction with their learning environment within the university. "Students with greater self-efficacy attributes are motivated to maximize the benefits of the services and facilities within the university environment" (Arambewela \& Hall, 2013, p. 982). While a positive relationship between self-efficacy and satisfaction exists, Arambewela and Hall (2013) also suggest a negative relationship between hedonism and student satisfaction. Given the primary goal of East Asian international students to study and achieve academic success, "if international students have too much fun and enjoyment in community life, their academic achievements are likely to be less satisfactory" (Arambewela \& Hall, 2013, p. 982). Awareness of how the hedonistic construct impacts student satisfaction has implications for the policies and procedures surrounding the provision of student services to ensure student success.

Other studies suggest that the engagement of East Asian international students in leisure is not altogether detrimental to their success abroad. Their participation in on- or off-campus campus leisure activities facilitates their acculturation and adjustment to college (Gomez, Urzua \& Glass, 2014). Attendance at social events or engaging in sports with other students is a way for them to establish a strong social network. Their interactions with host nationals or other international students provide them a sense of belonging and security that motivates them to venture outside their comfort zones and engage in unfamiliar activities (Glass, 2012). The significance of engaging in these activities is especially highlighted by pre-arrival notions shaped by Western movies. College life in the West is depicted in movies as primarily about having fun (Bourke, 2013). Given this delicate relationship between their academic success and acculturation, higher education administrators and staff responsible for providing guidance to international students must be aware of the importance of striking a healthy balance between encouraging students to enjoy the cross-cultural experiences their host country offers and the need to focus on their studies. Awareness of the interplay between these psycho-social factors within the internal 
dimension of the international education experience can help student affairs professionals in developing programmes that will enhance the acculturation of international students. The next section discusses the factors located in the institutional quadrant of international education.

\section{Institutional: Structural Quadrant}

Institutional support in the form of curricular and co-curricular activities that facilitate student learning and development is crucial to the academic and personal success of students. As suggested by Chuang (2012), being innovative in providing instruction to East Asian international students aligns with the capacity of this group to adapt to various approaches to instruction. This openness and flexibility in learning styles is attributed to the Confucian values of harmonious integration, virtuous behaviour, and respect for authority which Chuang (2011) found to intensify, rather than diminish, as Asians acculturate to the Western society. In addition, there are positive findings in other areas. Zhao, Kuh, and Carini's (2005) study indicates that international students engage with their faculty, accept academic challenge, and use computer technology (which is an important skill in the 21st century) more than their domestic counterparts. As it relates to East Asian students that have a Confucian orientation, McMahon's (2011) research shows they are more accustomed to having a close mentee-mentor relationship with faculty members because, from their Confucian point of view, teachers serve as mentors to students. These expectations impact the level of satisfaction international students experience in their academic environment. Purveyors of international education should be interested in increasing the satisfaction of this sub-group with their experience on-campus.

Universities in the United States conduct programmes geared toward enhancing the freshman experience. New student orientations and first-year experience classes have become common practices geared toward facilitating the transition of students from high school to college life (Terenzini \& Reason, 2005). First-year classes designed for international students can potentially provide similar transitional assistance. As seen in Kovtun's (2011) study, those who participate in first-year classes (1) gain understanding of social diversity in the United States, (2) improve their skills in writing, oral presentations, and research, and (3) enhance their psychosocial development (i.e., balance, persistence, optimism, strong will, resilience, diligence, self-confidence, and positive attitude). These are examples of how institutional structures can benefit international students.

Extending learning beyond classrooms, student affairs professionals, evident in the work of American organisations such as the NASPA: Student Affairs Administrators in Higher Education and the Global Community for Academic Advising (NACADA), focus on providing programmes and advice services that foster lifetime growth and development in students. The co-curricular activities they offer, i.e., on-campus socials, athletic events, student organisations, service learning, and leadership programmes, provide the social context that international students need to engage with the domestic as well as other international students to explore and challenge their belief systems and cultural practices. Participation in such programmes impacts the development of a global 
perspective of international students and others who engage with them (Chickering \& Braskamp, 2009). Multicultural curricular and co-curricular activities enhance the student participant's sense of belonging which has been suggested to have a buffering effect against negative experiences of discrimination and to constitute a contributing factor to positive academic outcomes (Glass \& Westmont, 2014). These positive outcomes rest, however, on the international students partaking in activities developed for them. As Yan and Berliner (2011) reported, international students tend to not interact with Americans and typically confine their social interactions within circles composed of their co-nationals. This behaviour further isolates this group from the mainstream which potentially impacts their psychological health in a negative way.

Exacerbating the problem arising from isolation from the mainstream is the reluctance to use services available on-campus. In spite of the known acculturative stress they face, the number of international students seeking assistance from university counseling centers is low, suggesting that their first choice of support for their mental health needs are their friends, family members, clergy, and physicians (Yakushko, Davidson \& Sanford-Martens, 2008). This issue has been raised in the international education arena. In Internationalization in US Higher Education: The Student Perspective, Mazon (2010) calls for the bridging of the gap between traditional student affairs professionals and international student affairs professionals "so that all students have an enhanced opportunity to take advantage of international programming that is less isolated, and more integrated into students' broader campus experiences. In this way, international students will be more fully integrated into the campus" (p. 208). Thus far, findings of the studies we have cited underscore the importance of actively engaging the academic community in the conversation about the unique need of international students. In the next section, we discuss how external factors impact their motivations and dispositions abroad.

\section{External: Socio-Economic Quadrant}

Research on what drives student mobility points to 'push' factors within the student's home country. Factors that lead student decisions to participate in international education include economic, social, and political forces (Biao \& Shen, 2009; Yan \& Berliner, 2011). For example, for families and students from mainland China, the decision to embark on international education is attributed to the disparities in access to higher education, goods, and career opportunities at home. Inadequate supply of higher education institutions in their country, immigration prospects, and better employment 'push' students to go abroad. Parents of these students willingly take on the financial burden imposed by this crossnational educational venture in order to attain the goals of economic progress they have set for their children (Bodycott, 2009). Embarking on international education, despite the stress that goes with it, is a way to improve their opportunity to improve their situation.

Although considerably motivated by these push factors, the acculturative stress felt by international students does not become any less because of the lack of social support abroad (Bertram, Poulakis, Elsasser \& Kumar, 2014). Acting upon the Confucian philosophy's 
emphasis on education and the value of filial piety that closely binds the students to their families back home, they feel immense pressure to succeed as international students. With Chinese students, "parents place great emphasis on the academic achievement of their children ... and receiving higher degrees from the United States brings honor to the family ... [and is] a guarantee of social and economic ascent either in China or in the US" (Yan \& Berliner, 2011, p. 179). The expectation that the investment in one's international education will generate income and lead to economic progress for the family places enormous stress on the international student. While stress to perform well in school is natural, this stress is compounded significantly for international students who also face intercultural challenges. From their study, Mitchell, Greenwood, and Guglielmi (2007) posited that "the actual academic performance of international students was not significantly different from that of the U.S. students. However, the anxiety about academics may be due to the unique demands of studying in a foreign country" (p. 127). Their stress cannot be ignored and must be planned for by the universities they attend. Similarly, as discussed next, the importance of services geared toward the development of their English language proficiency must be addressed.

\section{Linguistic Quadrant}

Underlying the three dimensions that have been discussed is linguistic proficiency. MillerCochran (2012) describes a number of innovative approaches to teaching English to second-language learners. The role of language is central to the experience of East Asian international students in English-speaking countries. In order to gain admission into universities in English-speaking countries, as non-native English speakers, international students must demonstrate proficiency in the English language through the Test of English as a Foreign Language (TOEFL) and International English Language Testing System (IELTS) that predict their academic performance.

Satisfactory scores in these tests do not however automatically translate to language proficiency once in the host country. As second-language learners, these students have to spend more time studying compared to their domestic counterparts primarily to overcome language difficulties (Daller \& Phelan, 2013). International students placed in English remedial classes are less likely to persist in their freshman year than those who are non-remedial students (Mamiseishvili, 2012). The language challenge is exacerbated by differences in academic training. For example, based on Coates and Dickinson's (2012) study, international education scholars learned that East Asian postgraduate students come without prior experience in report writing and constructing "English essays of more than 1000 words" (p. 299). This difference in academic training poses immense challenges which, when not overcome, may result in other non-academic issues. Inability to overcome the language barrier does not only lead to poor academic performance (FassHolmes \& Vaughn, 2014) but also leads to diminished self-reliance (Hung \& Hyun, 2010), and increased perception of discrimination (Karuppan \& Barari, 2011). More serious psychiatric issues have been linked to academic difficulties and poor language skills among 
East Asian students (Mitchell, Greenwood \& Guglielmi, 2007). The following describes the depression experienced by international students who struggle with the English language:

School was really ... it was really terrifying. I was barely speaking (English) when I came ... trying to keep up with the notes and other things in class. I didn't have the opportunity to learn English in [my] school. I was feeling really bad about that. I was kind of ... I balanced my depression at the time because I think everyone gets depressed the first time they come here [USA] ... depressed because, umm, it happens ... people get depressed.

(McLachlan \& Justice, 2009, p. 30)

Acculturative stress arising from lack of proficiency in English impacts the East Asian students' ability to have a full international education experience. The perception of having limited communication skills hampers positive socialisation. Non-citizen students in English-language countries (Sawir, Marginson, Forbes-Mewett, Nyland \& Ramia, 2012) who are unable to communicate in English feel they lack human security. Without the feeling of security, international students will avoid participation in activities involving non-Western individuals and confine their socialisation within groups of co-nationals. The studies discussed here demonstrate the need to approach these complex and interconnected challenges with an equally compelling and interconnected array of solutions. We recommend an ecological approach that addresses these four dimensions.

\section{Recommendations for Practice: An Ecological Approach}

Numerous studies have been conducted to investigate the relationship between international student satisfaction and various factors that include campus climate (Glass, 2011), ability to gain proficiency in the English language (Fass-Holmes \& Vaugh, 2014), and engagement with host nationals (Glass \& Westmont, 2014). Studies also indicate the benefits of institutional support to international students. Given these factors that impact the international student's experience, the outcome of the international student's academic pursuits largely depends on what higher education institutions do to facilitate their success. Referred to as the internationalisation of higher education, this trend is not achieved simply by increasing the number of international students enrolled in the universities. Rather, it requires a more comprehensive approach that involves increasing the cultural intelligence and sensitivities of faculty, students and professional staff. We offer the following recommendations on how internationalisation of higher education can be achieved in universities.

First and foremost, we must acknowledge and account for cultural influences impacting traditional student development theory application. Recognising the tension between native values and beliefs and those of the host country, it is essential that we concede that the values and cultural beliefs of the international students will influence their experience, and therefore we should adjust our programmes and services to honor this reality, thereby diminishing this tension. This adjustment requires an openness to learn from our international students and a willingness to embrace ideas and beliefs that may be 
foreign to our way of being. We must also help our international students to identify and reflect upon their personal values and goals for their international experience and connect traditional co-curricular and social activities to international students' values of community and belonging, rather than notions of fun and social excitement. Self-awareness and cultural awareness among student affairs professionals are crucial to their ability to empathise with the challenges faced by international students from non-English countries.

Next, we need to improve institutional structures to create a more welcoming and inclusive environment for our international students. This can be achieved by creating spaces and opportunities to shape social interactions that promote and enhance learning and development. Expanding existing First Year Experience programmes for international students by emphasising their strengths in using technology and their desire for greater academic challenge can be achieved by incorporating a focus on the history of higher education in the United States and the role that international students have played in that history. Institutions must find ways to encourage social integration of international and domestic students on campus. Peer support and mentoring programmes can fulfill the dual role of reducing the acculturative stress of international students while building the cultural competency and perhaps language skills of both the domestic host students and their international counterparts.

Incorporating a Confucian philosophy which emphasises balance and harmony in our practice can assist students in finding a balance between the push and pull factors, thereby helping to alleviate stress and improve the collegiate experience for our students. Knowing the incredible amount of stress our international students carry as a result of the personal and financial investment they and their families have made in their education, we are obligated to offer counseling and support services in a manner which our international students will find welcoming and accessible. This may require special outreach efforts, ensuring our staff is diverse, aware and trained in cultural issues, and even investing in bilingual counselors or language translation services as it may be especially difficult to make meaning of and communicate feelings when your vocabulary is limited.

Finally, the impact of lack of English proficiency leads to other more serious problems of safety, self-esteem, and limited socialisation. In order to foster the success and development of our international students we must address the language issue in all aspects of our programmes and services. Acknowledging the multi-linguistic abilities of our students, we can learn a few key phrases in order to welcome them and show a sign of respect. Creating "language partners" can help international students practise their English speaking skills in a non-threatening environment and enhance their socialisation to our campus. We should also acknowledge the need for and a place where international students can engage in their native tongue free of judgement and stress. We must acknowledge that language is key to the success of these students and set high expectations for advancement in this area while simultaneously granting them both the patience and support for them to improve their language acquisition. 


\section{Conclusion}

The international student experience can be viewed through four interrelated dimensions: internal (psycho-social), structural (institutional), external (socio-economic), and linguistic. Scholars of international education use theories pertaining to acculturation and student development to understand how international students experience these dimensions. The underlying philosophy of Confucianism of seeking balance and harmony serves as a unifying factor across these dimensions.

As the participation of East Asian students in international education continues, the need to understand this particular international student experience and their corresponding needs becomes greater and more urgent. The multi-dimensional nature of this challenge calls for a holistic approach to student services. This article provides strategies for student affairs professionals to improve campus climate and enhance linguistic proficiency through programmatic efforts that attend to the acculturative stress experienced by East Asian students. As a relatively new trend in higher education, universities need time to develop the strategies and means to deliver culturally responsive student services. While few, there is evidence that universities in the Western hemisphere are recognising this unmet need and have started to invest resources in this arena.

\section{References}

Arambewela, R. \& Hall, J. (2013). The interactional effects of the internal and external university environment, and the influence of personal values, on satisfaction among international postgraduate students. Studies in Higher Education, 38(7), 972-988. https://doi.org/10.1080/0307 5079.2011.615916

Bertram, D.M., Poulakis, M., Elsasser, B.S. \& Kumar, E. (2014). Social support and acculturation in Chinese international students. Journal of Multicultural Counseling and Development, 42, 107-124. https://doi.org/10.1002/j.2161-1912.2014.00048.x

Bodycott, P. (2009). Choosing a higher education study abroad destination: What mainland Chinese parents and students rate as important. Journal of Research in International Education, 8(3), 349-373. https://doi.org/10.1177/1475240909345818

Bodycott, P. \& Lai, A. (2012). The influence and implications of Chinese culture in the decision to undertake cross-border higher education. Journal of Studies in International Education, 16(3), 254-270. https://doi.org/10.1177/1028315311418517

Bourke, B. (2013). Coming to America: The influence of college-themed movies on perceptions of international students. College Student Journal, 462-469.

Broesch, J. \& Hadley, C. (2012). Putting culture back into acculturation: Identifying and overcoming gaps in the definition and measurement of acculturation. The Social Science Journal, 49, 375-385. https://doi.org/10.1016/j.soscij.2012.02.004

Chickering, A. \& Braskamp, L.A. (2009). Developing a global perspective for personal and social responsibility. Peer Review, AACEU, 27-30.

Chuang, S. (2011). The relationship between cultural values and learning preference: the impact of acculturation experiences upon East Asians. International Journal of Training and Development, 16, 1-22. https://doi.org/10.1111/j.1468-2419.2011.00391.x

Chuang, S. (2012). Different instructional preferences between Western and Far East Asian adult learners: a case study of graduate students in the USA. Instructional Science, 40, 477-492. https:// doi.org/10.1007/s11251-011-9186-1 
Coates, N. \& Dickinson, J. (2012). Meeting international postgraduate student needs: a programmebased model for learning and teaching support. Innovations in Education and Teaching International, 49(3), 295-308. https://doi.org/10.1080/14703297.2012.703018

Daller, M.H. \& Phelan, D. (2013). Predicting international student study success. Applied Linguistics Review, 4(1), 173-193. https://doi.org/10.1515/applirev-2013-0008

Falcone, T., Espi, F., Ashai, A., Butler, R.S. \& Franco, K. (2014). Holding on and letting go: acculturation versus biculturalism among international medical graduates in residency training. International Journal of Culture and Mental Health, 7(2), 229-235. https://doi.org/10.1080/1754286 3.2013.783089

Fass-Holmes, B. \& Vaughn, A. (2014). Are international undergraduates struggling academically? Journal of International Students, 4(1), 60-73.

Gahan, P. \& Abeysekera, L. (2009). What shapes an individual's work values? An integrated model of the relationship between work values, national culture and self-construal. The International Journal of Human Resource Management, 20(1), 126-147. https://doi.org/10.1080/09585190802528524

Glass, C.R. (2011). Educational experiences associated with international students' learning, development, and positive perceptions of campus climate. Journal of Studies in International Education, 16(3), 228-251. https://doi.org/10.1177/1028315311426783

Glass, C.R. \& Westmont, C.M. (2014). Comparative effects of belongingness on the academic success and cross-cultural interactions of domestic and international students. International Journal of Intercultural Relations, 38, 106-119. https://doi.org/10.1016/j.ijintrel.2013.04.004

Gomez, E., Urzua, A. \& Glass, C.R. (2014). International student adjustment to college: Social networks, acculturation, and leisure. Journal of Park and Recreation Administration, 32(1), 7-25.

Hung, H. \& Hyun, E. (2010). East Asian international graduate students' epistemological experiences in an American university. International Journal of Intercultural Relations, 34, 340-353. https://doi. org/10.1016/j.ijintrel.2009.12.001

Karuppan, C.M. \& Barari, M. (2011). Perceived discrimination and international students' learning: an empirical investigation. Journal of Higher Education Policy and Management, 33(1), 67-83. https:// doi.org/10.1080/1360080X.2011.537013

Kovtun, O. (2011). International student adaptation to a U.S. college: A mixed methods exploration of the impact of a specialized first-year course at a large Midwestern institution. Journal of Student Affairs Research and Practice, 48(3), 349-366. https://doi.org/10.2202/1949-6605.6336

Lee, J. \& Ciftci, A. (2014). Asian international students' socio-cultural adaptation: Influence of multicultural personality, assertiveness, academics self-efficacy, and social support. International Journal of Intercultural Relations, 38, 97-105. https://doi.org/10.1016/j.ijintrel.2013.08.009

Mamiseishvili, K. (2012). International student persistence in U.S. postsecondary institutions. Higher Education, 64, 1-17. https://doi.org/10.1007/s10734-011-9477-0

Martinez, M.L. (2016). Bridgers in the Third space: An In-country Investigation of the Leadership Practices of US-Educated Chinese Nationals. (Doctoral dissertation.) Retrieved from College of Educational Studies Dissertations.

Mazon, B.K. (2010). Taking the global leap: student affairs professionals and internationalization. Research in Comparative and International Education, 5(2), 205-209. https://doi.org/10.2304/ rcie.2010.5.2.205

McLachlan, D.A. \& Justice, J. (2009). A grounded theory of international student well-being. The Journal of Theory Construction \& Testing, 13(1), 27-32.

McMahon, P. (2011). Chinese voices: Chinese learners and their experiences of living and studying in the United Kingdom. Journal of Higher Education Policy and Management, 33(4), 401-414. https:// doi.org/10.1080/1360080X.2011.585739 
Miller-Cochran, S. (2012). Beyond "ESL writing": Teaching cross-cultural composition at a community college. TETYC, September, 20-30.

Mitchell, S.L., Greenwood, A.K. \& Guglielmi, M.C. (2007). Utilization of counseling services: Comparing international and U.S. college students. Journal of College Counseling, 10, 117-129. https://doi.org/10.1002/j.2161-1882.2007.tb00012.x

Pritchard, R. (2011). Re-entry trauma: Asian re-integration after study in the west. Journal of Studies in International Education, 15(1), 93-111. https://doi.org/10.1177/1028315310365541

Roesch, S.C., Wee, C. \& Vaughn, A.A. (2006). Relations between the big five personality traits and dispositional coping in Korean Americans: Acculturation as a moderating factor. International Journal of Psychology, 41(2), 85-96. https://doi.org/10.1080/00207590544000112

Sawir, E., Marginson, S., Forbes-Mewett, H., Nyland, C. \& Ramia, G. (2012). International student security and English language proficiency. Journal of Studies in International Education, 16(5), 434-454. https://doi.org/10.1177/1028315311435418

Tan, P.L. (2011). Towards a culturally sensitive and deeper understanding of "rote learning" and memorisation of adult learners. Journal of Studies in International Education, 15(2), 124-145. https:// doi.org/10.1177/1028315309357940

Tan, S. \& Liu, S. (2014). Ethnic visibility and preferred acculturation orientations of international students. International Journal of Intercultural Relations, 39, 183-187. https://doi.org/10.1016/j. ijintrel.2013.08.011

Terenzini, P.T. \& Reason, R.D. (2005, November). Parsing the first year of college: A conceptual framework for studying college impacts. Paper presented at the meeting of the Association for the Study of Higher Education, Philadelphia, P.A.

Yakunina, E.S., Weigold, I.K., Weigold, A., Hercegovac, S. \& Elsayed, N. (2013). International students' personal and multicultural strengths: Reducing acculturative stress and promoting adjustment. Journal of Counseling \& Development, 91, 216-223. https://doi.org/10.1002/j.15566676.2013.00088.x

Yakushko, O., Davidson, M.M. \& Sanford-Martens, T.C. (2008). Seeking help in a foreign land: International students' use patterns for a U.S. university counseling center. Journal of College Counseling, 11, 6-18. https://doi.org/10.1002/j.2161-1882.2008.tb00020.x

Yan, K. \& Berliner, D.C. (2011). Chinese international students in the United States: demographic trends, motivations, acculturation features and adjustment challenges. Asia Pacific Educational Review, 12, 173-184. https://doi.org/10.1007/s12564-010-9117-x

Zhao, C., Kuh, G.D. \& Carini, R.M. (2005). A comparison of international student and American student engagement in effective educational practices. The Journal of Higher Education, 76(2), 209-231. https://doi.org/10.1353/jhe.2005.0018 
RESEARCH ARTICLE

\title{
Interpersonal Conflicts and Styles of Managing Conflicts among Students at Bahir Dar University, Ethiopia
}

Arega Bazezew ${ }^{\star} \&$ Mulugeta Neka $^{\star \star}$

\begin{abstract}
Interpersonal conflict happens everywhere and at any time and is inherent in all societies. However, the methods of managing such conflict are quite different from one organisation to the other. The general objective of the study was to assess interpersonal conflicts and styles of managing conflicts among students at Bahir Dar University. Mixed-methods research composed of quantitative and qualitative approaches was implemented for the study. One-way Multivariate Analysis of Variance was employed to identify the interaction effect between dependent and independent variables. The study showed that the major sources of conflicts were ethnic differences, religious diversity, sexual abuse, theft and insulting. It was also noted that compromising, avoiding and collaborating were frequently used conflict management styles between students. It is recommended that university leaders and students be expected to understand the real causes of conflicts for healthier management styles.
\end{abstract}

\section{Keywords}

conflict, conflict management, student experience, diversity, ethnicity, gender, undergraduate studies, Ethiopia

\section{Introduction}

The term 'conflict' has been used in different ways, referring to different forms of conflict (racial, ethnic, religious, political and gender), types of conflict (within an individual, between individuals, within a group and between groups) and places where conflict occurs (at home, in organisations, and on battlefields) (Hartwick \& Barki, 2002, p.4). Scholars agree that the term 'conflict' is synonymous with individual/group disagreements, disputes, quarrels, physical fights and confrontations (Salleh \& Adulpakdee, 2012, p.15; Olu \& Abosede, 2003; Shahmohammadi, 2014). Although conflict hinders the attainment of one's goals, the consequences, however, might be beneficial if it brings help in the form of new insight for the groups. In relation to this, Dincyürek, Yeliz and Beidoglu (2009) and Waithaka (2015) argued that conflict has positive aspects: it helps individuals in knowing themselves, enhancing their awareness of others' characteristics, increases energy and motivation for

* Prof. Arega Bazezew is a livelihood and food security specialist and $\mathrm{PhD}$ coordinator in the Department of Geography and Environmental Studies, Bahir Dar University, Ethiopia. Email: aregaberlie@gmail.com

** Prof. Mulugeta Neka is Assistant Professor of Geography and Environmental Studies at Bahir Dar University in Ethiopia. 
problem solving, making life more interesting, and helps to solve small problems that could grow into big issues. However, Campbell, Carbally and Nustrand (1983), on the other hand, stated that conflicts are a normal segment of daily life; yet, it is considered as negative when it causes disagreements, stress, social chaos, destruction and violence between groups.

Interpersonal conflict, which involves value and/or personality differences arising from disagreements between individuals, is the core of this study. According to Gebretensay (2002, p. 56), interpersonal conflict might take various forms and manifest at various levels. It includes any overt and verbalised arguments or differences of opinion over any issue that could lead to a fight between students and between students and university leaders (Peter, 1996; Windle \& Warren, 1999). Salleh and Adulpakdee (2012, p.16) added that interpersonal conflict may arise when wants, needs and beliefs between two or more parties/groups fail to coincide. In general, interpersonal conflicts are common in our day-to-day activities, which range from those at home, through organisations to nations (Nathan, 1996). If managed effectively, conflict can be constructive, if not; it can be a destructive for people and organisations (Sadowski, 1998).

Effective communication between individuals provides a foundation for preventing and resolving conflicts in a friendly and informal way. Janet (2015, p. 105) and Shahmohammadi (2014, p.632) argued that managing conflict and developing effective conflict resolution mechanisms encourages the development of values, attitudes and knowledge between individuals and organisations. Hence, conflict management skills are a fundamental aspect of leadership effectiveness in many organisations. For the purpose of this study, the definition of Olu and Abosede (2003) was adopted. This says that conflict management is a process of coordinating all resources through the processes of planning, organising, leading and controlling interpersonal conflicts in order to attain the objectives of organisations. The implication is that conflict management should imply a change from destructive to constructive in the mode of interaction.

Though students' interpersonal conflicts are very serious in many universities in Ethiopia in general and at Bahir Dar University in particular, no exhaustive and adequate studies were conducted in the latter university. Few studies such as Gidey (2000) studied traditional mechanisms of conflict resolution in Ethiopia. Likewise, Mulatu (2007) examined the conflict management practises at Admas University College. Abebaw (2014) studied students' conflict in relation to ethnic and religious diversity at Bahir Dar University. Yalew (2007) investigated causes of conflict and conflict resolution at Bahir Dar University. However, none of them dealt with where conflict is commonly practised (hot spot areas) in their studies. Besides, conflict-related issues are dynamic and need up-to-date information for a healthier teaching and learning process. Thus, this research tries to fill these gaps and add knowledge to the existing literatures in areas of conflict management styles. The general objective of the study was to assess interpersonal conflicts and styles of managing conflicts among students at Bahir Dar University. The specific objectives of this study include: First, to find out the causes of interpersonal conflict between students and administrative workers at Bahir Dar University, and second, to examine conflict management styles that are frequently practised by the university communities. 


\section{Research methods}

\section{Research design}

There are different philosophies in research. Among others, positivism and post-positivism are the dominant philosophical thoughts throughout centuries. The present study was neither on the side of positivism nor post-positivism philosophical assumptions. Instead, the study employed a mixture of the two, which is called pragmatism (Creswell, 2009). This is due to the fact that pragmatism is not committed to any one system of philosophy and reality. However, it applies mixed-methods research composed of both quantitative and qualitative approaches. Concurrent mixed-methods research was employed because quantitative and qualitative data were collected simultaneously and the results were embedded during the analysis. Questionnaires and key informant interviews were employed to collect the necessary information for the study.

\section{Selection of sample sites and respondents}

Regular undergraduate students ranging from first to third year on different campuses were included for the study. Multi-stage sampling techniques were employed to select the survey respondents to fill in the questionnaire.

First, there are five campuses at Bahir Dar University. With the objectives of making fair representations, all the campuses were included for this study (Table 1). This is due to the fact that the causes of conflict on different campuses might vary; the same is true in managing interpersonal conflicts. Second, based on the number of departments and the number of students, Social Science Faculty, Natural Science College, Behavioral and Educational College, Agriculture College, Business and Economics College, Institute of Land Administration and Bahir Dar Institute of Technology were selected purposively for the study. Third, using simple random sampling techniques, Department of Biology, Department of Civics, Department of Geography, Department of Curriculum and Educational Planning, Department of Disaster Risk Management, Department of Marketing, Institute of Land Administration and Department of Computer Engineering were selected for the study. Fourth, the sample sizes that could be taken for the study were determined using Kothari’s (2004, p. 179) formula as it is shown below:

$$
n=\frac{\mathrm{z}^{2} \cdot \mathrm{p} \cdot \mathrm{q} \cdot \mathrm{N}}{\mathrm{e}^{2}(\mathrm{~N}-1)+\mathrm{z}^{2} \cdot \mathrm{p} \cdot \mathrm{q}}
$$

Where,

$$
\begin{aligned}
& n=\text { sample size } \\
& \mathrm{z}=\text { the value of standard variant at } 95 \% \text { confidence interval (1.96) } \\
& \mathrm{p}=\text { the sample proportion }(0.03) \\
& \mathrm{q}=\text { is } 1-\mathrm{p} \\
& \mathrm{e}=\text { the estimate should be within } 3 \% \text { of the true value } \\
& \mathrm{N}=\text { the total number of regular students } \\
& n=340
\end{aligned}
$$


Fifth, taking into consideration representativity, the years of study of students in each department were selected using simple random sampling techniques (Table 1). Finally, 340 students were sampled for a questionnaire survey from eight departments using proportional stratified random sampling techniques based on the sampling frames obtained from each department. However, out of the total 340 questionnaires distributed to the respondents, 317 (93\% of total) were returned for analysis.

Table 1. Number of respondents in each college, faculty, institute and department

\begin{tabular}{|l|l|c|c|}
\hline College, faculty or institute & \multicolumn{1}{|c|}{ Name of department } & $\begin{array}{c}\text { Year of } \\
\text { study }\end{array}$ & $\begin{array}{c}\text { Total } \\
\text { samples }\end{array}$ \\
\hline College of Sciences & Department of Biology & II & 37 \\
\hline Faculty of Social Sciences & Department of Civics & III & 33 \\
\hline Faculty of Social Sciences & Department of Geography & I & 57 \\
\hline $\begin{array}{l}\text { College of Education and } \\
\text { Behavioral Sciences }\end{array}$ & $\begin{array}{l}\text { Department of Curriculum } \\
\text { \& Educational Planning }\end{array}$ & I & 17 \\
\hline College of Agriculture & $\begin{array}{l}\text { Department of Disaster Risk } \\
\text { Management }\end{array}$ & II & 36 \\
\hline College of Business and Economics & Department of Marketing, & I & 35 \\
\hline Institute of Land Administration & Land Administration & III & 24 \\
\hline Bahir Dar Institute of Technology & $\begin{array}{l}\text { Department of Computer } \\
\text { Engineering }\end{array}$ & II & 37 \\
\hline Total & & & 317 \\
\hline
\end{tabular}

\section{Data collection techniques}

Primary data were collected using questionnaire and key informant interview. The questionnaire was organised in a mix of closed- and open-ended questions. It was tested as a pilot survey before the actual data collection. This helped to improve the quality of questions. Key informant interviews were conducted from 25 participants selected purposively from the whole target population. Issues raised during the discussions included excessive alcohol consumption, psychological acts, causes of interpersonal conflict and styles of conflict management. With the awareness of key informants, tape recording was employed to provide time to listen and to have eye contact with the participants.

\section{Data analysis}

Both quantitative and qualitative data analysis techniques were employed in this study. The information that was collected through key informant interviews and observations in relation to interpersonal conflicts and management styles of students were documented and analysed textually to substantiate the statistical results from the structured questionnaire. Upon completion of the quantitative data collection, the data were coded, edited and entered into SPSS and presented using descriptive statistics such as frequencies, percentages and tables. Inferential statistics such as One-way MANOVA was employed to answer the following research questions: Do male students and female students differ in terms 
of compromising, avoiding and collaborating in managing conflicts? Are females better adjusted than males in terms of compromising, avoiding and collaborating in managing conflicts? To answer these questions, one categorical independent variable (gender) and three continuous dependent variables (compromising, avoiding and collaborating scores) were employed. Normality, outliers, linearity, homogeneity and multicollinearity were checked and no significant violations were observed. Thomas and Kilmann's (1974) model of conflict management styles (competing, accommodating, avoiding, collaborating and compromising) were also used for data analysis.

\section{Results}

\section{Causes of conflict among students at Bahir Dar University}

As shown in Table 2, theft (95.3\%), borrowing money (94.3\%), and ethnic conflict (97.2\%) were the major causes of conflict at Bahir Dar University. Key informants on different campuses added that religious and some ethnic songs such as Tigrigna were the main sources of conflict and quarrel on all campuses.

Table 2. Causes of interpersonal conflict among students at Bahir Dar University

\begin{tabular}{|l|r|r|c|}
\hline \multirow{2}{*}{ Causes of Interpersonal Conflict } & \multicolumn{2}{|c|}{ Responses } & \multirow{2}{*}{$\begin{array}{c}\text { Percent of } \\
\text { Cases }\end{array}$} \\
\cline { 2 - 3 } & N & Percent & 94.3 \\
\hline Borrowing money/materials & 299 & 10.7 & 74.4 \\
\hline Psychological problems & 236 & 8.4 & 95.9 \\
\hline Political motivations & 304 & 10.9 & 87.4 \\
\hline Religion-related issues & 277 & 9.9 & 83.9 \\
\hline Sexual abuse & 266 & 9.5 & 95.3 \\
\hline Theft & 302 & 10.8 & 74.4 \\
\hline Taking too much alcohol & 236 & 8.4 & 97.2 \\
\hline Ethnicity-based conflict & 308 & 11.0 & 87.7 \\
\hline Interferences/intrusions & 278 & 9.9 & 883.0 \\
\hline Total & & 100.0 & \\
\hline Note: The total is not 100\% because of multiple responses & & \\
\hline
\end{tabular}

Key informants on different campuses added that religious and some ethnic songs such as Tigrigna in the dormitory were the main source of conflict and quarrel on all campuses. The study revealed that different music in different Ethiopian languages such as Tigrigna, Oromigna or Gojamigna/Gonderigna are vital sources of conflict between students, particularly in their dormitories. Key informants further added that claiming superiority of one ethnic group over another is also a main cause of conflict on all university campuses. In this regard, about $87 \%$ of the respondents showed their agreement. Key informants further informed that ethnic-based federal and political systems contributed to students' misconceived ethnic and political orientation, which resulted in ethnic conflict that 
affected the intergroup relations among students in the university. Furthermore, lack of conflict resolution through discussions and lack of tolerance among members of different groups resulted in suspicion and mistrust, suspension of healthy communication, needless tension and development paralysis.

A question was asked of the respondents as to whether there is conflict between students or not. As shown in Table 3, about $70 \%$ of the respondents assured that there were serious conflicts between students. More importantly, the survey results evidenced that interpersonal conflicts were serious in College of Business Economics (FBE) followed by the main campus of the university. These results were in agreement with the document analysis made between 2014 and 2015 .

Table 3. Students' opinion of the presence of conflicts among students at Bahir Dar University

\begin{tabular}{|l|c|c|}
\hline Conflicts between students & Frequency & Percent \\
\hline Yes & 221 & 69.7 \\
\hline No & 96 & 30.3 \\
\hline Total & 317 & 100.0 \\
\hline
\end{tabular}

Students were also asked to respond as to whether they observed quarrels between students and university police and/or leaders. About $54 \%$ of students responded that they had observed these situations. As far as gender is concerned, about $42 \%$ female and $58 \%$ male respondents confirmed the presence of these situations. Key informants were also asked to inform regarding the reasons behind these occurrences. Political affiliation, borrowing money, ethnic tension, sexual abuse, taking property without permission and interferences were the major causes of quarrels among students.

\section{Gender and Interpersonal Conflict}

During the survey, students were asked whether they were engaged in conflicts during their stay at Bahir Dar University. Accordingly, it emerged that about 70\% of male respondents engaged in conflicts ranging from gossip to physical challenges against 30\% of female students (Table 4). Key informants pointed out that female students were commonly engaged in gossip and insulting while male students commonly practised insulting and physical challenge. It was also noted that male students frequently create conflicts due to sexual harassment of female students.

Table 4. Gender and engagement in conflict (percentage respondents)

\begin{tabular}{|l|c|c|c|}
\hline \multirow{2}{*}{ Response } & \multicolumn{2}{|c|}{ Sex of respondents } & \multirow{2}{*}{ Total } \\
\cline { 2 - 3 } & Male & Female & \\
\hline Yes & 69.7 & 30.3 & 100.0 \\
\hline No & 44.4 & 55.6 & 100.0 \\
\hline Total & 61.8 & 38.2 & 100.0 \\
\hline
\end{tabular}


Age and religion of students and interpersonal conflicts

This study investigated whether age of students has some effects on students' engagement in conflicts or not. As shown in Table 5, age and engagement in conflicts have inverse relationships. As age increases engagement in conflicts decreases as evidenced by the fact that about $63 \%$ of the respondents who were engaged in conflicts were aged between 15 and 25 against less than $2.5 \%$ above the age 26 years. As the key informants pointed out, greater age is directly related to greater ability to shoulder responsibilities and become cool in many ways.

Table 5. The relationship between religion, age, cumulative grade point and interpersonal conflicts

\begin{tabular}{|l|c|c|c|c|c|}
\hline Religion & Orthodox & Protestant & Islam & Others & Total \\
\hline Yes & 74.9 & 63.6 & 14.3 & 66.7 & 71.9 \\
\hline No & 25.1 & 36.4 & 85.7 & 33.3 & 28.1 \\
\hline Total & 100 & 100 & 100 & 100 & 100 \\
\hline Respondents' age & $15-20$ & $21-25$ & $26-30$ & $36-40$ & Total \\
\hline Yes & 67.6 & 72.0 & 70.0 & 33.3 & 70.0 \\
\hline No & 32.4 & 28.0 & 30.0 & 66.7 & 30.0 \\
\hline Total & 100 & 100 & 100 & 100 & 100 \\
\hline
\end{tabular}

As shown in Table 5, students who were engaged in interpersonal conflicts were higher among those practising Orthodox religions (74.9\%) followed by Protestants (63.6\%). Key informants from FBE campus also substantiated the survey results. On the other hand, few key informants from main campus indicated that Orthodox religion is the source of conflict among students. The informant further indicated that some religious ceremonies such as Mahiber (religious association in the names of angels) is commonly practised in dormitories among Orthodox follower students, creating conflicts with Muslim and Protestant followers. According to information obtained from the students' representative, such conflicts decreased from time to time and many activities that create tensions between students have been dramatically reduced nowadays. However, under actual conditions it is quite the opposite.

\section{Place of conflict (hot spot areas)}

There are places where students commonly create conflicts. Knowing places where conflicts frequently occur will help university leaders to overcome the problems. In this regard, students were asked to indicate where conflicts commonly took place in the university. As shown in Table 6, dormitories and the gate of the campuses were places where conflicts frequently took place. Key informants strongly pointed out that TV rooms were sources of conflicts between students next to gate of the university. Many of the students in one way or another are supporters of one of the England football clubs. Inside or outside the campuses, supporters were also engaged in conflicts. As discussed in the previous topic, 
different ethnic music with loud voices was the key source of conflict in the dormitory. As the key informants indicated, instead of solving conflicts through discussion, students try to solve them through insulting. Posting some pictures and writing religious proverbs on the walls of the café and/or dormitory were also sources of conflict on all campuses.

Table 6. Places frequently exhibiting interpersonal conflicts among students at Bahir Dar University

\begin{tabular}{|l|c|c|}
\hline Options & Frequency & Percent \\
\hline Dormitory & 67 & 21.1 \\
\hline Cafe & 16 & 5.0 \\
\hline Gate of university & 130 & 41.1 \\
\hline Library & 18 & 5.7 \\
\hline Lounge & 29 & 9.1 \\
\hline Classroom & 24 & 7.6 \\
\hline Others & 33 & 10.4 \\
\hline Total & 317 & 100.0 \\
\hline
\end{tabular}

\section{Interpersonal Conflict Managing Styles employed by University Students and Leaders}

As key informants from different campuses indicated, conflicts between students and university police and among students have reduced from time to time. However, there are still some symptoms of the occurrence of conflicts among students and university leaders. As shown in Table 7, the majority of the respondents (58.1\%) indicated that the involvement of guidance and counseling in managing conflicts was low, and only about $10 \%$ agreed to the presence of high involvements in these situations. Likewise, students responded that university leaders had a low level of involvement in minimising conflicts (55.2\% of the respondents) (Table 7$)$.

Table 7. The role of university leaders, police, and guidance counsellors in managing conflict at Bahir Dar University

\begin{tabular}{|c|c|c|c|c|c|c|c|c|}
\hline \multirow{2}{*}{ Involvement } & \multicolumn{6}{|c|}{ Options } & \multirow{2}{*}{ Total } & \multirow{2}{*}{$\%$} \\
\hline & Low & $\%$ & Medium & $\%$ & High & $\%$ & & \\
\hline University leaders & 175 & 55.2 & 112 & 35.3 & 30 & 9.5 & 317 & 100 \\
\hline University police & 111 & 39.4 & 150 & 40.8 & 56 & 19.8 & 317 & 100 \\
\hline Guidance counsellors & 205 & 58.1 & 86 & 32.2 & 26 & 9.7 & 317 & 100 \\
\hline
\end{tabular}

Using Thomas and Kilmann (1974) conflict management styles, five strategies were employed to collect data from the survey respondents. The strategies are forcing (obliging), accommodating (lose-win styles), avoiding (sidestepping), compromising (give and take), and collaborating (positive-sum styles). From the total respondents, only 67 students managed conflict situations using collaborating style (Table 8). The second style in terms 
of frequency of utilisation was the compromising style ( 34\%). Significant numbers of students (about 40\%) have used the avoiding style of managing conflict. However, the avoiding style of conflict management has its own disadvantages. It could progress from changing the subject of discussion to avoiding the person and finally keeping away from the relationship between the contestants.

Table 8 . Scores of conflict management styles by students

\begin{tabular}{|c|c|c|c|c|}
\hline \multicolumn{5}{|c|}{ Styles of conflict management among students } \\
\hline Competing & Collaborating & Compromising & Avoiding & Accommodating \\
\hline $64(20.2 \%)$ & $67(21.1 \%)$ & $107(33.8 \%)$ & $126(39.7 \%)$ & $59(18.6 \%)$ \\
\hline
\end{tabular}

\section{Results on multivariate analysis of variance}

A one-way between-groups Multivariate Analysis of Variance (MANOVA) was performed to investigate gender differences in interpersonal conflict management styles. The result showed that there was a statistically significant difference between male and female students on the combined dependent variables: $F(3,161)=13.7, p<0.001$; Wilks' Lambda $=0.83$; partial eta squared $=0.173$. When the results for the dependent variables were considered separately, the only differences to reach statistical significance, using a Bonferroni adjusted alpha level of 0.017 , were compromising: $F(1,164)=41.23, \mathrm{p}<0.001$, partial eta squared $=0.173$. An inspection of the mean scores indicated that male students reported slightly higher avoidance $(M=3.8, S D=1.7)$ than female students $(M=2.8, S D=0.3)$.

\section{Discussion}

\section{Discussions on interpersonal conflicts}

At present, students' aggressive and violent behaviour in the university remains a significant threat to safe and secure learning environments. Among the many factors that impede the learning process, interpersonal conflicts among students, and between students and university leaders are by far the major ones. The types of interpersonal conflicts are many and manifested in different forms. Sany (2010), for example, indicated that the underlying causes of conflict in Côte d'Ivoire are multiple and complex, and include economic and political factors; however, politicisation of ethnicity was at the forefront. While the choice of the leadership of a community can be the source of conflict, religious and ethnic differences are the major causes of conflict in almost any heterogeneous community in Ghana and elsewhere (Anthony, 2012). Abebaw (2014, p. 144) in a study made at Bahir Dar University, Ethiopia, indicated that the main cause of conflict in the dormitory was religious songs using mobile devices. Students who are highly ethno-centric reject others' religion, culture or ethnic groups because they considered them as contemptible and inferior (Mekonnen, 2013, p. 130). Abebaw (2014, p. 118) substantiated that superiority of one ethnic group over the other manifested through insulting was the major cause of conflict at Bahir Dar University. 
In a broader context, Muhabie $(2015$, p. 32) stated that causes of conflict in the horn of Africa have emanated from their wildness and backwardness, radicalisation and religious fundamentalism. Similarly, Olu and Abosede (2003) indicated that misunderstanding of motives, personality clashes, poor administration, naughtiness (on the part of both staff and students) and sexual abuse were the major causes of conflict in many universities in Africa. A recent study made by Rahel, Negussie and Getnet (2013) added that sexual abuse (68\%) was the major source of conflict between students in many schools in Addis Ababa. Results from qualitative analysis made by Yalew (2007, p. 35) identified that the major sources of conflict were ethnicity, religious diversity, defying rules, and sexual and love affairs, in order of importance. Ramani and Zhimin (2010) for their part noted that conflicts arise due to differences in individual capabilities, differences in social-cultural backgrounds, ethnicity, and differences in target goals among students in many universities in Africa.

\section{Discussion on conflict management styles}

As stated in the preceding discussions, students and the university community are engaged in different conflict management styles to smooth the teaching and learning process. Janet (2015) stated that conflict management skills are a fundamental and critical aspect of leadership effectiveness in many universities in Africa. In relation to this, the study made by Yalew (2007, p. 3) reported that the major conflict resolution styles among students were compromising, avoiding, mediating and dominating in order of importance. A previous study made by Betty (1998) in selected USA schools found that about 25\% engaged in compromising and $26 \%$ in collaborating as major conflict management styles. Dincyürek et al. (2009, p. 1209) also added that compromising followed by collaborating were the most frequently used strategies for university students. Accommodating was the least frequently used strategy in handling conflicts. Shahmohammadi (2014) found that written warnings, reproaches, physical punishment and, in extreme cases, dismissal, are among common conflict management systems in many universities in dealing with students' violent behaviours.

A considerable number of research findings indicated that there is a difference between male and female students in handling conflicts. Kelly, James and Debra (2007), for example, in their correlation analyses, indicated that among high school and university students, males were involved in higher levels of physically aggressive strategies and lower levels of effective communication compared with females. A study by Kenneth and Thomas (2008, p. 18) showed that female students usually employ more mediating or avoiding strategies than actually engaging in conflicts. Kimberly, Mark, Emmeline, Kerrilynn and Hannah (2014) in their study noted that males argue and communicate more anger than females. This is due to the fact that males tend to display their powers when they feel irritated while females do not practise as such because they do not have such powers. Likewise, Yasin and Khalid (2015, p. 705) added that females tend to avoid conflicts significantly more than males. 
Males commonly prefer styles such as forcing, problem solving, competing and dominating while female students, on the other hand, prefer smoothing, avoiding and compromising management styles (Waithaka, 2015, p. 2).

Scholars in the area of education stressed that conflict management styles differ between ages of students. Davis, Kraus and Capobiancom (2009) evidently stated that aged people are generally less likely to engage in destructive responses and more likely to avoid confrontations

In general, the major causes of interpersonal conflict and styles used to manage conflicts were discussed in-depth. The implication is that interpersonal conflicts are natural and should be managed to smooth the teaching and learning process. As observed in the field and from key informants' opinions, Bahir Dar University is facing challenges in relation to ethnic differences, religious acts and cultural differences. Unless these tribulations are managed, the university will face serious problems in addressing its major goals.

\section{Concluding Remarks}

The study examined the causes aggravating interpersonal conflicts and the role of conflict management styles for enhanced teaching and learning processes. The final goal of any university is to create a productive, collaborative and smooth environment for positive learning outcomes. However, there are cases where students are engaged in some interpersonal conflicts that create impediments in their day-to-day educational performances. From this study, it was learnt that ethnic differences, theft, drinking too much alcohol and insulting were the major causes of conflict in the university. The study also indicated that respondents commonly practise compromising, avoiding and collaborating strategies as measures of minimising conflicts.

Students do not come to Bahir Dar University with all the necessary social skills and experiences to cooperate with each other. Therefore, instructors, students, university leaders, campus police and students' guidance counsellors have to be aware of the real causes of conflicts and they have to create a dialogue on how to manage conflicts in the university. In general, the findings of this study could contribute towards enabling university instructors, administrators, campus police and students to manage interpersonal conflicts wisely and successfully in the achievement of Bahir Dar University's mission and vision.

Finally, this study is not free of limitations. Interpersonal, intrapersonal, intergroup and intra-group are commonly observed types of conflicts at Bahir Dar University. However, this study had focused on interpersonal conflicts. Besides, this study had been done in one university. It is believed that interpersonal conflicts could vary between universities. If other universities in different Regional States of Ethiopia are included, generalisation from the findings will be more sound and reliable. Therefore, future research has to consider those issues for the reason that conflicts might take various forms and manifest at different levels on a continuum. 


\section{References}

Abebaw, Y. (2014). Ethnic and religious diversity in higher education in Ethiopia: The case of Bahir Dar University. Unpublished doctoral dissertation, University of Tampere, School of Education, Finland.

Anthony, A. (2012). Conflict management in Ghanaian schools: A case study of the role of leadership of Winneba senior high school international. Journal of Educational Planning and Administration, 2(2), 65-76.

Betty, P. (1998). The Effects of conflict mediation training on attitudes toward conflict and interpersonal problem-solving strategies of middle school students. Unpublished doctoral dissertation, Faculty of the Virginia Polytechnic Institute and State University, Virginia.

Campbell, R.F., Carbally, J.E. \& Nustrand, R.O. (1983). Introduction to educational administration. Boston: Allyn and Bacon.

Creswell, J.W. (2009). Research design: Qualitative, quantitative, and mixed methods approaches. Los Angeles: SAGE publications.

Davis, M.H., Kraus, L.A. \& Capobianco, S. (2009). Age differences in responses to conflict in the workplace. International Journal of Aging Human Development, 68(4), 339-355. https://doi. org/10.2190/AG.68.4.d

Dincyürek, S., Yeliz, K. \& Beidoglu, M. (2009). Determining the conflict resolution strategies of university students. Procedia Social and Behavioral Sciences, 1, 1205-1214. https://doi.org/10.1016/j. sbspro.2009.01.217

Gebretensay, T. (2002). A Study of factors that generate conflict between government secondary school teachers and educational managers in Addis Ababa Administrative Region. Unpublished master's thesis, Addis Ababa University, Addis Ababa, Ethiopia.

Gidey, D. (2000). Traditional mechanisms of conflict resolution in Addis Ababa. Addis Ababa, Ethiopia.

Hartwick, J. \& Barki, H. (2002). Conceptualizing the construct of interpersonal conflict. Faculty of Management, McGill University, Quebec, Canada.

Janet, W. (2015). Influence of principals' age on conflict management styles in secondary schools in Kisumu County, Kenya. International Journal of Scientific and Technology Research, 4(5), 105-112.

Kelly, N., James M. \& Debra, V. (2007). Teaching conflict resolution skills to middle and high school students through interactive drama and role-play. Journal of School Violence, 6(4), 57-79. https:// doi.org/10.1300/J202v06n04_04

Kenneth, W. \& Thomas, G. (2008). Conflict styles of men and women at six-organization level. International Journal of Conflict Management, 14 (2), 1-38.

Kimberly, F., Mark, B., Emmeline de, P., Kerrilynn, H. \& Hannah, F. (2014). Differences between male and female communications and conflict management styles in virtual teams. Journal of Management and Marketing Research, 17, 1-6.

Kothari, C. (2004). Research methodologies, methods and techniques (Third revised edition). New Delhi: New Age International Publishers.

Mekonnen, H. (2013). The impacts of ethnocentrism and stereotype on inter-cultural relations of Ethiopian higher education students. Journal of Communication and Media Technologies, 3(4), $126-148$.

Muhabie, M. (2015). The root causes of conflicts in the Horn of Africa. American Journal of Applied Psychology, 4(2), 28-34. https://doi.org/10.11648/j.ajap.20150402.12

Mulatu, M. (2007). Assessment of conflict management practice: A case study of Admas University College. Unpublished master's thesis, Addis Ababa University, Addis Ababa, Ethiopia. 
Olu, O. \& Abosede, O. (2003). Conflict management in secondary schools in Osun State, Nigeria. Nordic Journal of African Studies, 12(1), 23-38.

Peter, F. (1996). Interpersonal conflict management in-group psychotherapy: An Integrative Perspective, (29), 257-275.

Rahel, T.H., Negussie, D.K. \& Getnet, M. (2013). Prevalence of sexual abuse of male high school students in Addis Ababa. Journal of Health Human Rights, 6, 13- 24.

Ramani, K. \& Zhimin, L. (2010). A Survey on conflict resolution mechanisms in public secondary schools: A case of Nairobi province, Kenya. Educational Research and Reviews, 5(5), 242-256.

Sadowski, Y. (1998). Ethnic conflict. Journal of Foreign Policy, 1(11), 12-23. https://doi. org/10.2307/1149375

Salleh, M. \& Adulpakdee, A. (2012). Causes of conflict and effective methods of conflict management at Islamic secondary schools in Yala, Thailand. International Interdisciplinary Journal of Education, $1(1), 15-22$.

Sany, J. (2010). Education and conflict in Côte d'Ivoire: Special report 235, United Institutes of Peace.

Shahmohammadi, N. (2014). Conflict management among secondary school students. Social and Behavioral Sciences, (159), 630-635. https://doi.org/10.1016/j.sbspro.2014.12.438

Thomas, K.W. \& Kilmann, R.H. (1974). Thomas-Kilmann Conflict Mode Instrument. Mountain View, C.A.: Xicom.

Waithaka, A.G. (2015). Influence of conflict resolution training on conflict handling styles of college students. Journal of Higher Education, 28, 1-17.

Windle, R. \& Warren, S. (1999). Collaborative problem solving and dispute resolution in special education: Training manual. Retrieved 27 August 2015 from www.directionservice.org/cadre/contents.cfm

Yalew, E. (2007). Causes of conflict and conflict resolution styles among Bahir Dar University students. Ethiopian Journal of Development Research, 29(1), 35-70.

Yasin, M. \& Khalid, S. (2015). Conflict management styles: A study of organizational politics among professionals. Journal of Political Studies, 22(2), 697-710. 
RefleCtive PRACTICE

\title{
Professionalisation of Student Affairs Educators in China: History, Challenges, and Solutions
}

\author{
Yongshan $\mathrm{Li}^{\star} \&$ Yuanyuan Fang ${ }^{\star \star}$
}

\begin{abstract}
Student affairs administration in Chinese universities is characterised by a dual-layer system of governance, with student affairs practitioners, i.e. advisors to students, being supervised by either central university administration or by affiliated colleges. In the last decade, government-oriented developments have achieved great success in China. This paper introduces the background and major strategies adopted by the Chinese government in professionalising university advisors. Major challenges are analysed, and solutions to address these challenges are proposed.
\end{abstract}

\section{Keywords}

student affairs educators, professionalisation, professional development, higher education, China

\section{Historical Development of University Advising in Student Affairs}

Professional student affairs management in China can be traced back to the year of 1956, when the then president of Tsinghua University, Jiang Nanxiang, set up the first political advisor position. At that time, political advisors were senior undergraduates or young teachers, that is, they served in two roles: as students and advisors of other students (as peer counselors), or as teachers and advisors (similar to the tutorial system in British universities), and involved in both the ideological and political education of students, and learning or teaching, and doing research themselves. This practice was believed to be politically incorrect and was discontinued by the Revolutionary Committee of Tsinghua University during the Great Cultural Revolution (1966-1976) (Lin \& Peng, 2003). After 1978, the practice was resumed in universities throughout China. Since then, and gradually, the position of "advisor" (i.e. student affairs practitioner) has become a full-time job. The advisors serve as educators, academic advisors, psychological counselors, administrators, and service providers.

The development of a class system is a unique feature of early American college life. In the earliest days, all students who entered the university at the time were considered members of a single "class" (equivalent to "cohort" as used today in the west) and

* Dr Yongshan Li is the Deputy Director of the Department of Educational Administration and Dean of Humanistic Quality Education Center, Hefei University of Technology, Hefei, Anhui, China.

** Dr Yuanyuan Fang is Associate Professor of the School of Foreign Languages, Hefei University of Technology, Hefei, Anhui, China. 
continued so for instructional and administrative purposes throughout their college career (Brubacher \& Rudy, 1977). Chinese universities follow a similar practice except that students who enter at the same time are further organised and managed in groups of about 30 to 50 students based on their major discipline. Each advisor would take charge of several such groups, usually totaling 150 to 200 students. Both central university administration and affiliated "schools" (equivalent to "colleges" and/or "faculties" of academic disciplines) are in charge of student affairs management. Hence, student affairs practitioners in Chinese universities may either be supervised by the "student affairs office" of the central university administration, or by the deputy dean in charge of student affairs in affiliated "colleges" (in this paper we mainly focus on the latter).

In 1984, the Ministry of Education of China initiated a new academic discipline, namely, "ideological and political education," in 12 universities. This is believed to be the very beginning of "professionalised" training of university advisors. However, these positions were met with challenges of low professional recognition among other university positions, discouragingly low pay, and high turnover rate, among others. Though a position of political superiority, it is widely perceived, even by the college deans, that being an advisor is not a lifelong professional career. As Zhan (2004) observed, quite a number of student affairs practitioners enter this profession only to use it as a stepping stone to their intended position of choice in the academic or administrative divisions. Thus, they have little investment in this career, nor possess any sense of responsibility towards their work. There is not much interest in furthering their career in student services. A survey of 601 advisors (Peng \& Wang, 2008) revealed that about $60 \%$ of them felt reluctant to remain in the job long term, and most of them were disappointed by an occupation that both lacked specific professional goals and the future of which was obscure. All such challenges were related to the low level of professional training and development at that time (Feng, 2007).

Large-scaled enrollment expansion in China began in 1998, and by 2005, the admission rate reached $21 \%$, compared to $9 \%$ in 1997 . This marked the massification of higher education in China. However, issues also emerged with expansion, especially those related to university student services. Among them, the biggest challenge is recruiting new staff members with potential skills or professional experience of student affairs work. For instance, in 2004, Gang Feng, an officer of the Chinese Ministry of Education (MOE), conducted a survey that showed that many universities did not provide full-time positions for advisors, and one extreme example revealed that one advisor was in charge of a total of 1,500 students from 38 different classes in that university. Hence, MOE undertook several systematic measures to promote professional training of university advisors. These strategies were divided into five actionable areas. First, policies to support development of advisors were established. In May of 2006, the Ministry released the "University Advisor Development Regulations" under which the selection, allocation, training, development, management and evaluation of advisors were specified. The Regulations mandated an allocation of at least one full-time advisor for every 200 students. Second, in-service training and education of Ph.D students in the field was promoted. Since 2006, the MOE successively enacted two five-year plans aimed at promoting training of advisors. 
Twenty-one training and research centers were set up in higher education institutions capable of granting Ph.D degrees in student affairs. Third, exchange platforms for professional development were established. In 2008, the University Advisors Board was set up, and MOE sponsored two academic journals in the field: the Journal of University Advisor and the College Advisor in 2009. Next, funding for relevant research projects and training programmes was created to enhance research and increase work efficiency. And finally, an interim list of career qualifications of university advisors was enacted in 2014. This list provided standards for various levels of in-service training, professional competence recognition, and talent cultivation of professionals.

The Ministry of Education continues to promote, among all universities in each province in China, the professional development of advisors. A series of supporting measures were implemented to help establish policies, funding and training opportunities. For example, in Liaoning Province, full-time university advisors enjoy extra subsidies of $200 \mathrm{RMB}$ in addition to their basic salary and position allowance. A quota policy is used to promote full-time advisors and grant tenureship through an application process. Nominating excellent faculty and staff members, including full-time student affairs advisors, of the university is another policy adopted. Excellent full-time advisors will be trained by a special "successor programme" (a programme aimed at training potential leaders in the field), and promotion by exception may apply to them.

Another example is located in the Shaanxi Province where universities were asked to allocate at least one advisor for every 200 students in 2015, and 1,763 vacancies in 41 provincial universities were assigned to full-time advisors. A quota system is also employed in this province, and a special channel for promotion and tenure application is set aside for full-time advisors so as to guarantee a reasonable and longer lasting professional team structure. Each advisor can enjoy a working allowance of 3 RMB per student per month. Moreover, funds are set aside to reward advisors serving in the post for more than 12 years. Each year at least 1,000 RMB would be assigned to each advisor to offset the training cost. All these incentives contributed to the developmental goals of advisors, who are provided with comfortable working conditions (e.g. large offices, better office furniture and air conditioning, etc.), better pay, and a promising career (Feng, 2015).

During the initial stage of developing student affairs as a respectable profession, the effort relied on a "top-down" approach from the government to the universities. This strategy seemed to have worked and achieved great success in China. However, after years of developmental efforts, deep-seated problems began to emerge (Gao, 2012). Challenges mainly come from three areas: (1) a large proportion of young and inexperienced advisors may overload the current capacity in personnel training; (2) a systematic academic or preparatory programme specifically designed for student affairs administration is still elusive; and (3) personnel policy reform fails to conform to the dual career track system (supervision of positions by University administration and Colleges) of advisor governance and promotion (Gao, 2012). 


\section{Challenges in the Professionalisation of University Advisors}

\section{Emphasis on quality}

Professionalisation of university advisors parallels the popularisation of higher education in China, and demonstrates the practical needs for the professional development of student affairs practitioners. It also guarantees the stability of university development and talent cultivation goals. During the following five years from 2016, "quality" will become the "buzz" word in higher education. The new phase of professionalisation of student affairs will put more focus on the cultivation of students' social responsibilities, innovation, and practical abilities in solving problems. As an important component of talent/staff training, student affairs practice should also emphasise the promotion of quality of programmes and services. Such enhancement relies mostly on the professional level of currently seasoned student affairs practitioners. Therefore, clarifying and solving the problems in professionalisation serves as the premise and foundation in this process.

\section{Theories in student affairs}

Due to historical and traditional factors, establishing a major discipline in ideological and political education has been the means used for training university advisors in China. However, as a discipline, for the last 30 years, it has failed to provide plans focusing on "personal, interpersonal and advisory skills" training of advisors (Xu \& Zhao, 2011). With the massification of higher education, the functions of the advisors have been expanded from traditional student education and management to include various other duties, e.g. academic advice, employment guidance, psychological counseling, financial aid counseling, college life guidance, orientation, and so on. Under the current practice, the university advisors have to undertake various tasks from both university administration and the affiliated colleges. Subsequently, diverse professional knowledge and capabilities are required for the job. A gap needs to be bridged between the job training and position qualifications. As a matter of fact, it has become apparent that the advisors' professional knowledge and capabilities failed to meet the new needs in some new areas (Qi, 2016). It is realised that training of professional advisors should be supported by a multi-disciplinary approach, e.g. disciplines in education, psychology, management, sociology, law, and politics. The urgent problem to be addressed is how to build a systematic and detailed theoretical foundation for the professionalisation process. However, no consensus has been achieved to that end. In 2015, the Shanghai Education Commission started the training plan that aimed to train students from various majors, like philosophy, law and politics, sociology, education, psychology and public administration, aside from ideological and political education, to become skilled advisors to students of the next generation, possibly with a Ph.D degree conferred upon graduation.

\section{Continuing professional education of university advisors}

Universities in China currently fail to reach consensus on the professional background that an advisor should possess. Three representative views co-exist as proposed by Chen 
and Zhu (2014) based on their investigations: (1) the professional background is not important at all; (2) the advisors should have a degree in humanities and social sciences; and (3) their major should be consistent with the students they advise. The three views are well supported in research literature, and each has its advantages and disadvantages. Due to this lack of qualifications, graduates from diverse majors and with different degrees entered the field of student affairs. By the year 2015, full-time advisors in Chinese universities had grown from 40,000 in 2005 to 137,000 in accordance with the governmental regulation that mandates at least one advisor for every 200 students and an explosive growth in university enrollment. Among them, 42\% have a master's degree or above, and 53\% are still in their twenties (Feng, 2015). As mentioned above, the Ministry of Education had previously established 21 training centers that provide training courses annually. Since these centers are located in specialised institutions, and training is theory-oriented, such training has failed to cover the practical issues and problems in the field of student affairs. The training courses provided by the universities also lack systematic and consistent procedures and contents. A survey of 16 universities in Guangdong in 2016 revealed that almost $67.7 \%$ of the advisors claimed that they had never been asked about their training needs; $73.4 \%$ of the interviewees believed the training courses failed to adapt to their specific educational backgrounds, majors, job requirements, or advisors' skills. Only $38.7 \%$ believed that the training courses were effective (Xie, 2016). Four factors caused the unsatisfactory phenomenon: (1) training courses failed to solve practical problems; (2) training methods lack creativity and practicality; (3) courses were not well planned or organised, and (4) training content was routine and simplified. Therefore, the major challenge for the continuing professional education of university advisors is how to customise systematic in-service training of advisors from various professional backgrounds in order to guarantee the quality and effectiveness of the courses providing the necessary knowledge and skills.

\section{Professional motivation of the university advisors}

In universities in China, advisors are either faculty members or administrative staff. Therefore, they can flexibly choose their promotion track. Such flexible career track aims to appeal to more staff. It is hoped that the two options could help avoid career impediments, and show that the goal of the government is to keep a stable job market and a harmonious team (Qi, 2016). However, due to the fact that the advisors are from various professional backgrounds, they tend to have low motivation to do research or write academic papers needed for promotion and tenure and required of academic professors. Eventually, they hardly devote any time or effort to professional research (Chen, Le \& Chen, 2014). In practice, they scarcely choose any professional enhancement during their tenure as advisors. Instead, they tend to seek promotion within the central university administration which has lower requirements regarding professional background. This preference inevitably eliminates their inner motivation for professional development and serves as an impediment to the professionalisation of the advisors. Consequently, the professional recognition and career loyalty of the university advisors remain comparatively low (Zhu, 2016). 
Carpenter, Miller and Winston (1980) suggested five propositions for a model of professional development in student affairs. First, professional development is continuous and cumulative in nature, and moves from simpler to more complex behaviour. Secondly, optimal professional development is a direct result of the interaction between the total person striving for positive professional growth and the environment. Next, optimal professional preparation combines mastery of a body of knowledge and a cluster of skills and competencies within the context of personal development. Fourth, professional credibility and excellence of practice are directly dependent upon the quality of professional preparation. Finally, professional preparation is a lifelong learning process (Carpenter, Miller $\&$ Winston, 1980). Therefore, the speed and degree of the professionalisation of university advisors must rely more on their self-consciousness and motivation than on the priority or policy established by the government. Professional development is in essence personal and advisors should be responsible for their own professional development. Clear goals and powerful motivations outweigh policies and guaranteed supports from the government, which only help to construct favorable external conditions. Low recognition by other academic colleagues, high turnover rate, inconsistent developmental goals and lack of personal passion may all lead to a failure of the professional development of advisors.

Not until the advisors themselves have a clearer understanding of their own professional goals, can they begin to assess their knowledge, evaluate their capabilities and reflect upon their personal values. They will be unable to focus on professional study for enhancement, nor will they initiate any professional development that becomes truly an "internal and organic part of the higher education, hence acquiring more developing space and stronger voice in the field" (Yang, 2016, p. 15).

\section{Proposals for Promoting Professionalisation of University Advisors}

During the past decade, university advisor team building in China has achieved a great deal and it has laid a solid foundation for the future development of student affairs as a profession. However, with the dramatic changes in higher education in China, new challenges and conflicts also emerged. Experiences from student affairs development in US universities reveal that these are common for the transitional stage moving from the primary to the advanced level, and that these problems need to be handled if professionalisation is to be pursued. Therefore, in the new phase of development, Chinese student affairs advisors need to strengthen their goals for professionalisation, learn from experience, and employ new strategies to solve the deep-rooted problems, in order to optimise the development process.

\section{Establishing a Steering Committee for University Advisor Professionalisation}

"Professional associations have an obligation to ensure the quality of professional preparation and practice, to provide continuing professional education, and to recognize those practitioners who take steps to improve their knowledge and practice" (Janosik, Carpenter \& Creamer, 2006, p. 228).

At the early stages of university advisor professionalisation, the small numbers of associations in the field of student affairs failed to play their leading role in professional 
development. Meanwhile, the faculty in relevant majors scarcely put their minds to the theories and practice of student affairs due to their lack of practical experience. For instance, of all the 18 supervisors of master's and doctoral programmes in the field of ideological and political education in Wuhan University, 14 have never undertaken such administrative duties concerning co-curricular education and personal development of the students. Therefore, electing experts in student affairs nation-wide and establishing a national steering committee for professional advice and leadership in the professionalisation process might counter the insufficient role played by student affairs associations in China. The core tasks of the national committee should be:

1. to enact or modify professional standards and qualifications;

2. to provide professional advice for professional development;

3. to organise and undertake theoretical and practical research; and

4. to assess and evaluate student affairs practices.

\section{Modifying the dual career track system}

Dual career tracks system of university advisors is unique to Chinese higher education. However, due to the fact that faculty and administrative staff are obviously different in terms of each of their own career culture, professional assessment and promotion requirements, the system has failed to motivate the advisors in their own professional development. In 2014, the Ministry of Education released Higher Education Advisor Qualifications (interim regulations) which put advisors into three qualification levels - primary, intermediate and advanced level - with clarification of the basic knowledge and capabilities each level should possess. The "levels" illustrate the progressive stages the career entails, illuminates the match between promotion and qualifications, and helps to avoid previous disadvantage of implicit policies in career development. Moreover, it helps the advisors to gain a better understanding of their professional status, the necessary qualifications and the specific goals they should set based on their years of service. Modifying the system design of dual career tracks, especially in terms of the promotion and the salary systems, based on the professional qualifications, is aimed at inspiring the advisors' internal motivation to seek advancement in the profession.

\section{Promoting interdisciplinary studies on Chinese college student development}

Currently, diverse activities are employed in developing student affairs professionally. These activities are mainly drawn from experiences in past practices, but they are scarcely directed by student development theories in design. Although the practitioners in the field have come to realise the importance of interdisciplinary theories (e.g. of education, psychology and sociology) in directing the design of student affairs professional development, most experts in the relevant majors care more about their own professional development, and scarcely focus on the student affairs practices. The limited research findings were scarcely used in designing their activities. Although college student development theories in the US could be used, most are not applicable in the Chinese context due to differences in 
social reality, history, culture, and political orientation. Therefore, interdisciplinary studies on college student development based on the unique socio-political structures and cultures of China will be more appropriate. Establishing developmental theories in accordance with the laws pertaining specifically to Chinese university students will help promote the student affairs practice from experience-based to scientifically-based.

\section{Developing professional associations in particular functional area}

The role that professional associations play in staff development is "to advance understanding, recognition, and knowledge in the field; to develop and promulgate standards for professional practice; to serve the public interest; and to provide professionals with a peer group that promotes a sense of identity" (Nuss, 1993, p. 365). With the functional expansion of student affairs in Chinese universities, a dozen functional areas have been formed. We can take advantage of the US experiences in student affairs professional development, and promote the development of professional associations by functional areas to cultivate the function-specific skills. This is a key step for the professionalisation of student affairs in China. More specifically, plans should be made to establish professional associations in selected functional areas on the basis of criteria established by the National College Advisor Association in China. Secondly, missions and tasks should be set and regulations and rules should be laid down for the smooth operation of the professional associations and for strengthening the ethical responsibility and behavioural norms of the staff involved. Moreover, efforts should be made to help professional associations plan and organise academic research and exchanges, professional training activities, and publication of academic journals in the field. Finally, management level should be promoted in various associations by regular evaluations and assessments, and by holding international exchanges.

\section{Conclusion}

Chinese universities enjoy a good tradition of focusing on the ideological and political education of students in their education system, which serves as the social background of professionalisation and development of advisors. Meanwhile, the massification of higher education and increasing diverse needs of college students, as well as higher expectations and demands for talents from the society, call for further development and professionalisation of the advisors. This trend is similar to the professional development of advisors in the US, and in other countries around the world. However, Chinese universities still remain at the primary stage, and the achievements accomplished by Chinese university student affairs have mainly relied on central governmental support. To seek further development, Chinese universities need to take their current conditions into consideration, and refer to successful experiences from other countries, especially the advanced experiences from the US and other western countries. By combining governmental support with advisors' selfmotivation and personal efforts, professionalisation of student affairs advisors in Chinese universities will enjoy a prosperous future. 


\section{Acknowledgements}

Thanks go to Dr Howard Wang, Associate Dean of Duke Kunshan University, for his insightful advice in the writing and modifying of the paper. We also thank the reviewers for their valuable revision suggestions.

\section{References}

Brubacher, J.S. \& Rudy, W. (1977). Higher education in transition: A history of American colleges and universities (4th ed.). New Brunswick, NJ: Transaction.

Carpenter, D.S., Miller, T.K. \& Winston Jr., R.B. (1980). Toward the professionalization of student affairs. NASPA Journal, 18(2).

Chen, Y. \& Zhu, P. (2014). Exploration into the professional backgrounds of university advisors. Leading Journal of Ideological \& Theoretical Education, 11, 118-121.

Chen, J.R., Le, C. \& Chen, Y. (2014). Analysis of the research abilities of university advisors and proposals for improvement. Journal of College Advisor, 4, 17-20.

Feng, G. (2007). Training and professionalization of university advisors. Studies in Ideological Education, $11,13-15$.

Gao, D.Y. (2012). Reflections on the development of university advisors. Social Sciences in Chinese Higher Education Institutions, 9, 53-54.

Janosik, S.M., Carpenter, S. \& Creamer, D.G. (2006). Beyond professional preparation programs: The role of professional associations in ensuring a high quality workforce. College Student Affairs Journal, 25(2), 228-237.

Li, T. (2014). Current status of university advisor professionalization and developing strategies. Journal of College Advisor, 1, 14-17.

Lin, T. \& Peng, Q. (2003). The characteristics and development of the system of political advisor at Tsinghua University. Journal of Tsinghua University (Philosophy and Social Sciences), 6, 85-90.

Liu, Y. (July 16, 2005). Second to none for the university advisors in Liaoning Province. China Education Daily.

Ministry of Education of the People's Republic of China. Double guarantees for advisors' development in Shaanxi Province. Retrieved 18 May 2016 from http://www.moe.gov.cn/s78/A12/ moe_2154/201605/t20160518_245013.html

Nuss, E. M. (1993). The role of professional associations. In: M.J. Barr (Ed.), The handbook of student affairs administration (pp. 364-377). San Francisco: Jossey-Bass.

Peng, Q.H. \& Wang, Y. (2009). Challenges and solutions for university advisors' professionalization. Proceedings of university advisors' forum (pp.342-352). Beijing: China Renmin University Press.

Qi, M. (2016). Professionalization of university advisors: Challenges and new tasks. Ideological $\mathcal{E}$ Theoretical Education, 8, 22-25.

Xie, Q. (2016). University advisor training problems and solutions: A case study of 16 universities in Guangdong. Journal of College Advisor, 1, 42-45.

Xu, Y.J. \& Zhao, X. (2011). Oriented training of ideological and political education majors. Ideological and Political Education Research, 6, 5-8.

Yang, J.Y. (2016). Professionalization of university advisors: Review and prospect. Ideological $\mathcal{E}$ Theoretical Education, 8, 17-21. 
Zhu, L.P. (2004).Reflections on the establishment of college counselor in Jilin Province in the new era. Modern Education Science, 5(185), 109-111.

Zhu, H.J. (2016). University advisor team building design: A multi-dimensional perspective. Studies in Ideological Education, 4, 106-110. 
REFLECTIVE PRACTICE

\title{
Advocating for Standards in Student Affairs Departments in African Institutions: University of Botswana experience
}

\author{
Barbra M. Pansiri \& Refilwe P. Sinkamba ${ }^{\star \star}$
}

\section{Abstract}

The Student Affairs Departments have seen immense growth over the years, from a discourse which had no academic relevance in higher education, to that which is expected to add value to the attraction, retention, and graduation of students. However, the latest developments have seen the role of Student Affairs Departments grow from in-loco parentis' to educators who are expected to strategically position the image of their institutions to ensure that students are equipped with relevant, tried and tested skills in preparation for their studies, work, and civic engagement. The level of personal growth of students as they transition from secondary to tertiary institutions is now also traced to the effectiveness of Student Affairs personnel, policies, and structures. Thus the need for the visibility of such departments and the need to add value to higher education in the 21st century has escalated. More innovative ways of engaging students and academics in this social discourse has a bearing on a professional approach that places emphasis on standards. The argument is made for advancing standards in the sphere of Student Affairs as a method of enhancing needed visibility and adding value to African higher education, the focus of which is leading the continent's transformation agenda towards socio-economic development.

\section{Introduction}

Efforts are being made to enhance the intellectual faculties of students and to engage a holistic approach to producing well-rounded individuals. Trends around the world have demonstrated a growth in, and emphasis on, student affairs standards in addition to those in the academic arena. Graduating students are expected to exhibit employability skills and be prepared in wellness categories, socially (appreciating individual uniqueness), physically (wellbeing), emotionally (self-awareness and awareness of the needs of others), intellectually (development of cognitive skills), occupationally (practical skills), and spiritually (attitude towards life) as a foundation for educating the whole person (Barber, 2011). At the University of Botswana, the institutional mission emphasises graduates who have been involved in relevant and quality programmes, and who are equipped with both academic and personal development skills (University of Botswana, 2008). Emphasis on standards has traversed even the southern African region.

\footnotetext{
* Barbra M. Pansiri is the Director, Student Welfare, of the University of Botswana.

** Refilwe Precious Sinkamba is a Senior Lecturer in the Department of Social Work at the University of Botswana.
} 
In the USA, student affairs staff are not only well equipped with professional qualifications, but are guided by standards in discharging their day-to-day responsibilities (Evans \& Ranero, 2009; Rose, 2014). Botswana has not been left out of this upsurge in professional requirements. It is not unusual to come across references to world rankings in terms of quality services and products nor to see job advertisements for vacancies calling for accreditation or affiliation with professional associations. The Government of Botswana has recently established an accreditation body - the Botswana Qualification Authority (BQA) - to oversee quality standards related to institutions of learning.

Therefore, it is now common practice across professions to emphasise standards in order to establish the best way to attain the highest levels of quality. Being at the core of contributing to a well-rounded student, the Student Affairs Department has not been excluded from this demand for quality services to prove its value through the overall quality of education in particular and national development in general. Expectations for standardisation are thus apparent.

Standards are defined as incorporating a comprehensive and valid set of criteria that judge and/or support programme quality and effectiveness, representing best practices that colleges and university programmes can reasonably achieve (CAS, 2006). Professionalism has always been associated with standards in that professions should exhibit a set of standards that guide their work. The move towards professionalisation of Student Affairs Departments through the establishment of standards can be understood from several perspectives. One perspective comes from The Council for the Advancement of Standards in Higher Education (CAS) in the United States of America affirming that national standards are one of the key means by which a profession matures (CAS, 2006). Arminio (2009) observed that, by establishing standards, professions indicate their determination to control their own destiny. And finally, the commitment to the pursuit of excellence, knowledge, and truth invariably implies that "the university must always be a cauldron of bubbling engagement, a site of robust and rigorous debate, with no room for complacency or mediocrity" (Makgoba \& Seepe, 2004, p. 15). Hence, quality should form part of everything that an institution of higher learning does and promotes. It is argued in this paper that quality cannot be left only to academic programmes but should be extended to interventions outside the classroom for meaningful student success.

\section{Benefits of Professionalising Student Affairs}

Describing the role of student affairs within higher education can be challenging. Although most individuals understand the role and importance of faculty and administration within an institution, student affairs professionals may struggle to articulate the role they play within institutions to those unfamiliar with the concept. It might be explained that faculty members are responsible for educating students and for creating new knowledge through research, while administrators are responsible for the bureaucratic aspect of the organisation and providing leadership and administrative support to the institution. Student affairs professionals may be involved in all of these activities yet, because they may not be attached to an academic department nor directly reporting to senior administrators, their work may be misunderstood or overlooked (Gansemer-Topf, 2013). 
Student affairs and services professionals, along with teaching faculty, bring to the institution a particular expertise regarding students, their development, and the impact of their learning environments. They are closely associated with the academic mission and serve as important links between students and the institution (Ludeman \& Strange, 2009; Ludvik, Gardner \& Hickmott, 2012). The World Higher Education Declaration (1998), a creation of the International Association of Student Affairs Services (IASAS), and annual conferences of the South African Association of Senior Student Affairs Professionals (SAASSAP) and the African Student Affairs Conference, suggest an interest by student affairs professionals in becoming more recognised and valued within African higher education. In addition to these organisational activities, student affairs professionals can also elevate the importance of the profession through their work on different campuses.

Gansemer-Topf (2013) states that Student Affairs Departments can develop a common language of assessment in enhancing the importance of and respect for the student affairs profession. The title 'student affairs professional' implies that student affairs is a profession. Greenwood (1957) listed five characteristics of a profession, which include: grounding in systematic theory; authority recognised by clientele; broader community sanction and approval of that authority; an ethical code regulating relations with clients and colleagues; and a professional culture sustained by professional associations. In addition, Klegon (1978) examined the evolution of professions from a sociological perspective and suggested that there are two dynamics at play in the development of a profession. The internal dynamic is the efforts of practitioners to raise their status, define services which they perceive only they can perform properly, and achieve and maintain autonomy and influence. The external dynamic relates to the larger social and institutional forces that either contribute to or reduce the conceptualisation of the work as a practice or true profession. These characteristics provide insights into the evolution of student affairs from practice to profession.

In reflecting on the current context of higher education abroad, Ludeman, Osfield, Hidalgo, Oste, and Wang (2009) stated that there is increasing evidence that higher education must address the basic personal needs of students by providing a comprehensive set of out-of-classroom student services and programmes commonly referred to as student affairs and services. Given the various definitions of a profession, it is evident that student affairs in Africa, with its development of professional organisations, legitimacy by internal and external stakeholders, and the larger societal recognition of the need to improve college student access and success, is becoming more pronounced (Gansemer-Topf, 2013). This requires student affairs professionals to become more confident in their personal ability to learn and grow, and promote that process among students.

There has been a great deal of effort by student affairs practitioners and researchers to promote the benefits of professionalising Student Affairs Departments through the establishment of standards. Evans and Ranero (2009) highlight the following as some of the tangible benefits of professionalisation:

- creation of a platform for sharing common interests and goals;

- professional development of members;

- professional enhancement of the field; 
- establishment of ethical and professional standards for guidance; and

- creation of a networking forum for dialogue, lobbying and advocacy.

A great deal has been written about the traditional role of Student Affairs Departments in academia. Traditionally, personnel dealing with students' affairs have been regarded as people handling student issues outside the classroom or what others termed being 'in-loco parentis' (someone to perform a parental role in the absence of biological parents). Student Affairs Departments had no academic relevance, and there was little communication with other academic structures. This was further supported by low enrolments and fewer social issues. Student Affairs staff had no defined job profiles or any expectations towards students' learning. Recent years have seen a significant growth in expectations of these practitioners to a point that the majority feel overwhelmed by roles that are now both academic and social in nature.

The broad recruitment/enrolment-to-graduation role of Student Affairs Departments now includes marketing, internationalisation, registration, orientation, academic advising, scheduling, counselling, catering, discipline, leadership development, multi-culturalism, wellness, collaboration, and partnerships with other key stakeholders such as ministries, sponsors, and parents. Such expectations are emanating from academics, industry, national, international levels, and students themselves. The understanding is that students spend more than $70 \%$ of their time outside the classroom and thus the opportunity for learning outside the classroom to augment what happens in class should be promoted, particularly for positive behavioural change. More than $50 \%$ of life skills and general learning occurs in this manner. Similarly, the Student Affairs Department is seen as a living laboratory for student development and is being called upon to provide structures for students' development in the 21st century (Hiscock, 2012; Keeling, 2006; Major \& Mangope, 2014).

\section{Benefits of Professionalised Student Affairs Departments in the USA}

In the USA, the roots of the student affairs profession date back to the colonial era and the earliest years of American higher education. The profession developed rules and regulations that governed students' behaviour and conduct, and college rules and expectations even when students were not on the college premises (Arminio, 2009; Evans \& Ranero, 2009). Over the years the profession grew as it attracted more research attention (Arminio, 2009; Evans \& Ranero, 2009; Keeling, 2006; Magolda \& Magolda, 2011). The initial exploration of the growing out-of-class curricula by the American Council on Education (ACE) finally resulted in various ways leading to the establishment (Keeling, 2006), of the Council for the Advancement of Standards in Higher Education (CAS) in 1979 with the following aims:

- Formalising assessment of programmes;

- Justifying the impact of Student Affairs work;

- Justifying structural adjustments;

- Justifying organisational support for growing diverse needs including those related to gender, minority groups, sexual orientation, disability, mental health, faith, and values; and

- Intensifying research. 
The USA thus has the largest number of Student Affairs professional associations highly regulated by agreed-upon standards.

\section{Student Affairs in Southern Africa}

There is growing interest in professionalising student affairs in Africa. For instance, in the last decade, academic programmes with a focus on student affairs have sprung up in a number of African universities. At Eduardo Mondlane University (EMU) in Maputo, Makerere University (MAK) in Kampala, and the University of the Western Cape (UWC) in Cape Town, programmes have been developed and are being delivered (Long, 2012). Further, development of programmes in higher education studies and student affairs, and the demand that has been shown by both students and prospective employers reflect training needs that clearly go beyond the on-the-job training model that is otherwise so prevalent. This indicates the requirement of specialised and high-level skills for those entering the profession. This is supported by research conducted in new and existing centres, in research programmes focused on African higher education, and in growing literature on higher education and student affairs in Africa (Long, 2012).

It is also essential that higher education should be fully developed and understood in order to create an enabling environment for student affairs to thrive. However, it appears that there is still a need to develop an African identity and vision for higher education (Makgoba \& Seepe, 2004). This contributes to the slow growth of the tradition of student affairs in Africa. South Africa is an example of developed higher education policies. Concurrently, professional associations in student affairs are developing. Long (2012) states that among them are: the International Association of Student Affairs and Services (IASAS), founded in 2010; the Association for College and University Housing Officers International, Southern Africa chapter (ACUHO-I-SAC); the Southern African Association for Counselling and Development in Higher Education (SAACHDHE); National Associations such as the South African Association of Senior Student Affairs Professionals (SAASSAP), and the National Association of Student Development Practitioners (NASDEV), in South Africa. Many of these associations hold annual conferences, which include insightful presentations, professional reflections on good practices, and research relevant to the profession (Long, 2012).

\section{The History of Student Affairs at the University of Botswana (UB)}

In understanding the history of student affairs in Botswana there has to be an appreciation of the overall Student Affairs Departments in the country. However, there is limited published research and documentation on this matter. Anecdotal data suggest that Student Affairs Departments in the majority of tertiary schools was mostly subsumed under other administrative departments and where this was not the case there was a relevance to the academia. For example, academic staff members used to be responsible for sports, wellness, and career guidance programmes. Currently, this situation still pertains in most tertiary education centres. Such a scenario relegates student affairs' key functions to the periphery and compromises a holistic approach to student development. The Human Resource 
Development Council (HRDC; 2014) concept paper observes the dire marginal presence of student affairs structures in the country that address the social aspect of students and absence of national guiding frameworks.

Transformation of the Student Affairs Department at the University of Botswana became more pronounced in the 1990s due to high student enrolments and diverse student population. There was an identified need to restructure the administrative functions. A fully established Division of Student Affairs was finally created in 1999 under the Deputy Vice Chancellor, Student Affairs with five Departments and three Units. Their core mandate was generally to support the student life outside the classroom and, more specifically, to follow up on the university objective of "improving students' experience". The expectation was for each department or unit to develop programmes and services meant to empower students' learning and to address their needs. Ensuring quality in established programmes and services was to be done through service-level standards, accreditation, and partnerships (University of Botswana, 2016).

\section{Successes}

Student Affairs at the university led to various services and programmes in support of students' learning such as: peer support, counselling, wellness programmes, equity programmes, interest in and focus on first-year students, cultural and sports events, living and learning community programmes, health care, leadership development programmes, and more active engagement with students outside the classroom. The understanding was that the experiences that students were exposed to would ultimately determine their life success.

\section{Challenges}

The above successes were not without challenges. As much as structural adjustments were successfully accomplished and there was recognition of the value added by student affairs infrastructure, there was no anecdotal evidence that the envisaged success and intended soft skills were attained. The University continued to be a predominantly academic institution evidenced by budget priorities and decisions skewed to support this aspect of the institution. Anything else that occurred outside the classroom was perceived as a waste of time and resources.

In addition, the level of staff competencies in student affairs issues remained very low with no predetermined qualifications required for the job. Job vacancies in some of the departments indicated a degree qualification in any field. Few staff members had an appreciation of the need for a qualification in student affairs. Support for partnerships and associations were minimal with no clear procedures for such engagement. Participation of student affairs staff in international events were met with uncertainty. As the flagship university in the country, this approach meant that most institutions in the country had even more limited student affairs structures. Absence of a national guiding framework for student affairs did not improve the situation, a factor observed by the HRDC as worrisome (HRDC, 2014). 
The University did not have any visible standards to be attained in student affairs and the value it was adding was constantly challenged. Absence of professional associations in the country to measure and monitor the work of student affairs practitioners meant that the profession was relegated to the periphery. Surprisingly, students' behavioural and engagement issues outside the classroom continued to be a centre of debate across the institutions of learning. High failure rates, disengagement, HIV and AIDS prevalence, alcohol and substance abuse, and moral decadence continued to frustrate efforts towards student retention, success, and graduation, including their readiness for the employment market.

Therefore, a conclusion can be made that while the university had objectives, vision and mission, and structures for a student affairs academic component, the impact and value of work on the ground remained invisible and of scant significance. This presents a challenge for future growth in the area.

\section{Literature Validation}

Research has shown the significant impact that Student Affairs Departments can have on student, retention and success through quality services and programmes (Astin, 1993; Davenport \& Pasque, 2014; Long, 2014; Tinto, 1993). A clear demonstration of this is a study of 2,685 freshmen in 23 colleges and 16 states in the USA, that established that students at Community Colleges (less selective in admissions) had similar scores to their counterparts at most four-year colleges which are highly selective in this regard (Hankin \& Gardner, 1996). The difference was attributed to the experiences that students were exposed to through thoughtful, quality interventions (often provided by student affairs and services). Wenger's (1998) model of communities of practice depicts value that can be added through well defined, articulated, and personally guided experiences. Professional associations are about enabling quality. Therefore, Student Affairs Departments must adopt professional approaches if they are to create a lasting impression.

The literature further confirms that greater numbers of students are attending universities and colleges with complex personal and health issues that profoundly challenge their capacity to thrive (Yakaboski \& Birnbaum, 2013). A professional approach will shape the way the students interact with each other and with the university, as well as transforming how student affairs professionals communicate with each other (Yakaboski \& Birnbaum, 2013). There are various challenges to those professionals across institutions and a common ground pursued through shared standards will present an opportunity to customise and address the many emerging issues. Additionally, the student affairs literature suggests several successful initiatives emanating from collaboration between student and academic affairs professionals (Ely, 2009; Fried, 2000; Pascarella \& Terenzini, 2005). These include first-year enrichment programmes, residential-based education and the living learning communities (Astin, 1996). The value derived from well-focused, researched, quality connections guided by appropriate standards and expectations would result in a coherent, seamless, and integrated learning experience. 


\section{Considerations for Establishing Standards at UB}

The changing demographics of students in African tertiary institutions; environmental impact; emerging issues in higher education; the threat and survival of Student Affairs Departments; changes in the ICT industry; the impact of globalisation; the competition from world campuses; Africa's transformation agenda for socio-economic issues, and constrained resources, all elicit the need to refocus attention on quality and value-adding initiatives through student affairs and services. Student Affairs Departments need new solutions for the current dynamic and volatile environment. How to add value may be located in professional bodies with established, and tried and tested standards. The presence of national frameworks will not only provide guidance but also the development of norms and standards in student affairs. This is in cognisance of the fact that in developing countries, where student affairs is fully established, the determining factors have been policies at national levels and a supportive environment for such a focus which is a challenge in Botswana.

The following are areas where professionalising student affairs will add value:

- Aligning and focusing programmes to institutional missions and thus creating support from significant stakeholders;

- Developing cutting-edge competencies with clear learning outcomes for both social and academic skills;

- Establishing and maintaining collaborative partnerships;

- Career definition for champions of the change including defining relevant qualifications for Student Affairs;

- Establishing student-focused environments;

- Developing an African Student Affairs identity through establishing common grounds;

- Ethical practice and accountability;

- Understanding of and intervention for higher education landscape and trends;

- Commitment of resources and innovations for sustainable impact;

- Staying current in the field and eliminating comfort zones;

- Self-regulation by student affairs and taking control of its own destiny; and

- Maximising opportunities such as research, professional writing, and presentations.

\section{Way Forward}

Departments of Student Affairs will need to understand what they do and why they do it, by taking stock of desired goals and focusing on creating impact. In so doing they will need to establish a well-articulated and integrated student affairs philosophy linked to their mission. Due to absence of similar contexts they may consider joining existing professional associations and learning from others' positive experience. Establishment of uniform structures for coherence at local, national, and regional levels will be essential. Role divisions might be necessary to further reinforce the team spirit and ensure that those with capabilities in certain areas are supported. Professional associations thrive on a 
spirit of voluntarism and members will need to commit to going beyond the normal call of duty. This would necessitate a change from the norm by intensifying research to inform new ideas and innovations and engagement in continuous evidence-based evaluations and improvements. As much as this sounds like a tedious process, benefits will ultimately outweigh the costs as professionalisation is both a responsibility and an opportunity.

According to a report by the United Nations Educational, Scientific, and Cultural Organization (UNESCO; 2002) on the role of student affairs and services in higher education, the profession should develop and adhere to high standards of practice and behaviour including educational training and preparation, assessment of student outcomes, codes of ethics, and management practices. All are necessary in order to deliver the best services and programmes and to be accountable to students and other stakeholders. In addition, staff members in student affairs and services are required to be, or at least become (along with their faculty partners), the campus experts on knowledge and understanding of students and their development. Through careful analysis of existing data, the staff members need to develop a comprehensive and accurate socio-cultural picture of their student population. This is done through identifying inadequate or missing information so that they can initiate appropriate action and inform campus administrators, faculty, student leaders, and government officials on the nature of the student body. Although work in this area readily gives staff an awareness of students' needs and wants, a phenomenological understanding that scientific instruments and methods be used to supplement this view and provide a wider perspective of the student body is crucial.

\section{Conclusion}

There is no doubt on the importance of standards in the maturity of a profession that seeks to add value to existing structures like student affairs. We profess that standards have multiple benefits, especially to growing economies. An exploration of experiences in the USA, where such standards have been adopted, has demonstrated a possibility and a solution for Africa in the 21 st century to drive desired change in terms of student retention and success. It augurs well for the African transformation agenda which has placed emphasis on various units that should come into play to graduate a market-ready student. When education goes beyond the status of elites to being a basic necessity for all, then the diverse environment calls for more innovations of value.

The University of Botswana does recognise the need to create value through studentfocused interventions and beyond classroom curricula. A number of processes were put in place to respond to the call but more are needed as most programmes lack the depth and breadth of effective intervention with key visible competencies. Literature reviews in student affairs support interventions which are evidence-based, and context-specific interventions are the ideal. Such common ground can be established through standards. Interrogation of student affairs knowledge, gaps, and desired impact will provide a platform for relevant conversations and attitudes needed for change. 


\section{References}

Arminio, J. (2009). Applying professional standards. In: G.S. McClellan, J. Stringer \& Associates (Eds.). The Handbook of student affairs administration (3rd ed.). San Francisco: Jossey-Bass.

Astin, A. (1993). What matters in College? Four critical years revisited. San Franscisco: Jossey-Bass.

Astin, A.W. (1985). Achieving educational excellence. San Francisco: Jossey-Bass.

Astin, A.W. (1996). Involvement in learning revisited: Lessons we have learned. Journal of College Student Development, 37(2), 123-134.

Astin, A.W. (1999). Involvement in learning revisited: Lessons we have learned. Journal of College Student Development, 40(5), 587-598.

Barber, J.P. (2011). If curbing alcohol abuse on college campuses is an 'impossible dream,' why bother with interventions aimed at curbing abuse? Navigating the drinking culture to become a productive citizen. In: P.M. Magolda \& M.B.B. Magolda, (2011). Contested issues in Student Affairs: Diverse perspectives \& respectful dialogue. Virginia: Stylus Publishing.

Barr, M.J. \& Desler, M.K. (2000). The handbook of student affairs administration. San Francisco: Jossey-Bass.

CAS (Council for the Advancement of Standards in Higher Education). (2006). CAS Professional Standards for Higher Education (6th ed.). Washington, D.C.: CAS Professional Standards for Higher Education.

Davenport, A.M. \& Pasque, P.A. (2014). Adding breadth and depth to college and university residential communities: A phenomenological study of faculty-in-residence. The Journal of College and University Student Housing, 40(2), 46-65.

Ely, K.E. (2009). An assessment of student affairs preparation. Rochester, N.Y.: University of Rochester.

Evans N.J. \& Ranero, J.J. (2009). Professional associations in student affairs. In: G.S. McClellan, J. Stringer \& Associates (Eds.). The handbook of student affairs administration (3rd ed.). San Francisco: Jossey-Bass.

Fried, J. (2000). Steps to creative campus collaboration. Washington, D.C.: NASPA.

Gansemer-Topf, A.M. (2013). Enhancing the professionalisation of student affairs through assessment. Journal of Student Affairs in Africa, 1(1-2), 23-32.

Gillepsie, J., Braskamp, L. \& Dwyer, M. (2009). Holistic student learning and development abroad: The IES 3-D program model. New York: Routledge.

Greenwood, E. (1957). Attributes of a profession. Social Work, 2(3), 45-55.

Hiscock, J. (2012). Building leaders: Purposeful student staff training makes the RA's of today the true campus leaders of tomorrow. Talking Stick Magazine, 29(5).

HRDC (Human Resource Development Council). (2014). Concept paper on student support services: Advocacy towards student persistence, retention and successes. Gaborone: Unpublished.

IASAS (International Association of Student Affairs and Services). (n.d.). History. Retrieved from http://www.iasasonline.org/history

Keeling, R.P. (2006). Learning reconsidered 2: Implementing a campus wide focus on the student experience. Washington, D.C.: American College Personnel Association (ACPA).

Klegon, D. (1978). The sociology of professions an emerging perspective. Work and Occupations, 5(3), 259-283. https://doi.org/10.1177/073088847800500301

Long, L.D. (2014). Does it matter where college students live? Differences in satisfaction and outcomes as a function of students' living arrangement and gender. The Journal of College and University Student Housing, 40(2), 66-83. 
Long, D. (2012). The foundations of student affairs: A guide to the profession. Environments for student growth and development: Librarians and student affairs in collaboration. Chicago: Association of College \& Research Libraries.

Ludeman, R.B., Osfield, K.J., Hidalgo, E.I., Oste, D. \& Wang, H.S. (2009). Student affairs and services in higher education: Global foundations, issues and best practices. Paris: UNESCO.

Ludeman, R.B. \& Strange, C.C. (2009). Basic principles, values and beliefs that support an effective student affairs and services programme in higher education. In: R.B. Ludeman, K.J. Osfield, E.I. Hidalgo, D. Oste \& H.S. Wang (Eds.). Student affairs and services in higher education: Global foundations, issues and best practices (pp. 5-10). Paris: UNESCO.

Ludvik, M.J.B., Gardner, M.M. \& Hickmott, J. (2012). Demonstrating student success: A practical guide to outcomes-based assessment of learning and development in student affairs. Virginia: Stylus Publishing.

Magolda, P.M. \& Magolda, M.B.B. (2011). Contested issues in student affairs: Diverse perspectives \& respectful dialogue. Virginia: Stylus Publishing.

Major, T.E. \& Mangope, B. (2014). Multicultural competence in student affairs: The case of the University of Botswana. Journal of Student Affairs in Africa, 2(1), 23-34. https://doi.org/10.14426/ jsaa.v2i1.58

Makgoba, M. \& Seepe, S.P. (2004). Knowledge and identity: An African vision of higher education transformation. In: S.P. Seepe, (Ed.). Towards an African identity of higher education. Pretoria: Vista University \& Skotaville Media.

Mohamedbhai, G. (2008). The effects of massification on higher education in Africa. Accra: Association of African Universities.

Pascarella, E.T. \& Terenzini, P.T. (1991). How college affects students: Findings from twenty years of research. San Francisco: Jossey-Bass.

Pascarella, E.T. \& Terenzini, P.T. (2005). How college affects students: A third decade of research (Vol.2). San Francisco: Jossey-Bass.

Rose, R. (2014). Council for the Advancement of Standards in Higher Education [Presentation with audio]. Assessment \& Accountability in Student Affairs \& Higher Education (CNS 610). Paper 40. Retrieved from http://digitalcommons.wku.edu/cns_assmt/40/

Tinto, V. (1993). Leaving college: Rethinking the causes and cures of student attrition (2nd ed.). Chicago: The University of Chicago Press.

UNESCO (United Nations Educational, Scientific and Cultural Organisation). (2002). The role of student affairs and services in higher education: A practical manual for developing, implementing and assessing student affairs programmes and services. Paris: UNESCO.

University of Botswana. (2007). Student affairs concept paper. Gaborone: Deputy Vice Chancellor, Student Affairs. Unpublished.

University of Botswana. (2008). A strategy for excellence: The University of Botswana strategic plan for 2016 and beyond, to be a leading center for academic excellence. Gaborone: Vice Chancellor, Student Affairs. Unpublished.

University of Botswana. (2016). Submission of the Student Affairs Division on the restructuring of the division. Gaborone: Unpublished.

Upcraft, M.L. \& Gardner, J.N. (1987). The Freshman Year Experience. In: J.N. Hankin (Ed.). The community college: Opportunity and access for America's first year students monograph series. S.C.: South Carolina National Resource Centre.

Wenger, E. (1998). Communities of practice: Learning as a social system. Systems Thinker, 9(5), 2-3. https://doi.org/10.1017/cbo9780511803932 
World Declaration on Higher Education. (1998). World declaration on higher education for the 21st century: Vision and action. Retrieved from http://www.unesco.org/education/educprog/ wche/declaration_eng.htm

Yakaboski, T. \& Birnbaum, M. (2013). The challenges of student affairs at Kenyan public universities. Journal of Student Affairs in Africa, 1(1-2), 33-48. 


\title{
REFLECTIVE PRACTICE
}

\section{Promoting Social Change amongst Students in Higher Education: A Reflection on the Listen, Live and Learn Senior Student Housing Initiative at Stellenbosch University}

\author{
Munita Dunn-Coetzee ${ }^{\star}$ \& Magda Fourie-Malherbe ${ }^{\star \star}$
}

\begin{abstract}
Twenty-two years after apartheid South African higher education is still struggling with challenges around access, success and transformation. Stellenbosch University (SU), as a historically white university, is striving to become significantly better and different in terms of relevance and active roleplaying. SU wants to prepare students to become South African citizens who bring about and enable positive change in society. The Listen, Live and Learn (LLL) initiative at SU is a senior student housing programme with the aim of providing experiential opportunities for students to make contact with 'the other'. By being in closer, more regular contact with 'the other', students' stereotypes, biases and discriminatory attitudes should start changing for the better. This article focuses on the evaluation of one of the proposed outcomes of the LLL programme - increased levels of interaction among students in a LLL house lead to reduced stereotyping and diminished bias. A quantitative investigation by means of an electronic survey was conducted. The second phase of the research was of a qualitative nature and consisted of focus group interviews. The conclusion can be made that LLL participants are a self-selecting group and that students who tend to apply for the LLL programme probably already have low levels of prejudice, bias and stereotyping. For the programme to effect social change, it needs to be considerably expanded in order to include more students who may not necessarily share the 'openmindedness' of this cohort.
\end{abstract}

\section{Keywords}

Listen, Live and Learn initiative; social change; stereotyping; social change model; higher education

\section{Introduction}

In 2017, 23 years after apartheid, South African society is still characterised by racial inequalities and social exclusion (Leibowitz, Rohlede, Bozalek, Carolissen \& Swartz, 2007; Soudien, 2014). Particularly over the past two years the fault lines in the 'rainbow nation' have been starkly exposed in the higher education sector with student protests in the \#FeesMustFall movement becoming ever more violent, destructive and divisive. More

\footnotetext{
* Dr Munita Dunn-Coetzee is the Director of the Centre for Student Counselling and Development, Division of Student Affairs, at Stellenbosch University, South Africa. Email: mdunn@sun.ac.za

** Prof. Magda Fourie-Malherbe is Professor of Higher Education Studies in the Centre for Higher and Adult Education, Faculty of Education, Stellenbosch University.
} 
than ten years ago Walker (2005a) pointed out that students' lives are still marked "by race, by racialised subjectivities, and by a past of racial separateness" (p. 53). This is now being graphically demonstrated.

Yet, many societal institutions, including higher education institutions, are "striving to make a different present and a new future" (Walker, 2005b, p. 133). Whereas South African higher education in the past primarily targeted and served a minority ethnic group, universities are now striving to ensure equitable representation of all South Africans in their student and staff components. But making a new future is more than widening access to previously underserved groups and appointing black academics; it is also about contributing to "the socialisation of enlightened, responsible and constructively critical citizens", and "a commitment to the common good" as envisaged in the 1997 White Paper for Higher Education (DoE, 1997, p. 9). What makes this particularly challenging is that South Africans are by no means homogenous in terms of economic, educational or social attributes (Mdepa \& Tshiwula, 2012, p. 20). We shall return to this point later.

This reflective account reports on the evaluation of an institutional initiative to bring a diversity of students together in living spaces in order to break down traditional barriers of race, gender, language and nationality and to achieve some of the goals of the White Paper as noted above. We firstly paint the institutional context in which this initiative was introduced, after which we describe the programme and how it has developed over the eight years of its existence. The second part of the article reports on a programme evaluation that was performed to garner more insight into the effect of the programme. The complexities of such an evaluation are highlighted as well as ways of overcoming them. Lastly, we share some conclusions and recommendations that could be of value to an international audience.

\section{Institutional context of the programme}

The positioning of Stellenbosch University (SU) in a rapidly changing higher education context necessitates institutional transformation, the promotion of diversity, and social integration among all students on campus. SU, as a historically white university, was founded in 1918, has ten faculties on five campuses, and currently has 30,305 students of whom less than $40 \%$ are students of colour. Approximately $30 \%$ of SU students make use of residential housing while the majority are commuting students. Table 1 depicts SU undergraduate enrolments from 2011 to 2016.

Table 1: Stellenbosch University undergraduate enrolments according to race, ${ }^{1}$ 2011-2015

\begin{tabular}{|l|r|r|r|r|r|}
\hline Race & 2011 & 2012 & 2013 & 2014 & 2015 \\
\hline African & 1297 & 1389 & 1661 & 1922 & 2200 \\
\hline Coloured & 2790 & 2725 & 2980 & 3397 & 3732 \\
\hline Indian & 274 & 284 & 327 & 419 & 473 \\
\hline White & 12690 & 12534 & 12325 & 12400 & 12646 \\
\hline Total & 17051 & 16932 & 17293 & 18138 & 19042 \\
\hline
\end{tabular}


Table 1 illustrates that the number of undergraduate enrolments of white students has remained more or less constant over the past five years, and that the growth in student numbers occurred primarily among African, coloured and Indian students, albeit from a very low base. These figures give evidence of moderate success of a variety of recruitment and support initiatives to diversify the student population and to enhance student success, as part of SU's commitment to addressing its exclusionary past, and contributing to building a new just and inclusive society. There has, however, also been a realisation that it is not sufficient to simply widen access for African, coloured and Indian students to Stellenbosch University. Change with regard to the institutional culture and social climate of the institution also needs to be effected. One intervention aimed at achieving this is the Listening, Living and Learning programme, promoting social change among students.

As it is transforming into an institution that is not only significantly different, but also significantly better, SU aims to produce dynamic young individuals who will contribute to positioning the African continent as an important role-player in the global knowledge economy. Change agents are needed to "keep the hope alive" if this effort is to succeed (Kloppers, 2013). If the LLL programme is to realise its aim of having a significant impact within the Stellenbosch student population, this effort must move from being an innovation or an interesting initiative to being a reform. Being a reform requires structural change, rethinking roles and relationships, and generally re-engineering student life so that these learning communities are appropriately supported (Kloppers, Dunn \& Smorenburg, 2013).

\section{The Listening, Living and Learning Programme}

The Listening, Living and Learning (LLL) programme at SU is focused on senior students, and whilst providing student accommodation, also offers experiential learning opportunities. The LLL houses are designed to provide students with a unique on-campus living environment complemented by an educational, service-oriented programme. It aims to promote listening, living and learning among students, but also between students and external thought leaders so that every house becomes an innovative "think tank" (Kloppers, 2013; Kloppers, Dunn \& Smorenburg, 2013). Its core element is bringing together a diversity of students and enabling them to embrace diversity, amongst others, by helping students to identify and adjust their perceptions of 'the other' (those who are different from them).

The LLL programme was piloted in 2008 when it started with one student house. Currently there are 28 LLL houses with a total capacity of 194 students (Kloppers, 2016). A LLL house ideally makes provision for eight students living together, consisting of a diverse group of students who differ in terms of field of study, gender, race, background and nationality. The inhabitants of every house have a specific theme for the year and engage in conversations on the theme for the year they live together. Every house hosts a conversation around the theme inviting academics, civic leaders, experts and other people to join the conversation in the house (Kloppers, Dunn \& Smorenburg, 2013).

The LLL programme is based on the premise that students in the houses model 'the different present' and should build 'the new future' of South African society by 
demonstrating that living together is possible, healthy and inspirational, and increased contact in physical and temporal spaces allows people to become friends across the boundaries that often accompany diversity. The students share intimate spaces such as kitchen and bathroom facilities, and need to negotiate the house rhythm in the use thereof, requiring them to adapt and find common ground. Lounge conversations, which form the focal point of the initiative, are indispensable to challenge set ways of thinking and to promote a critical stance and open-mindedness. They also act as an inspirational space where academics and students can come together and inspire each other. The project is meant to teach people to not only live together, but also to plan and work together (Kloppers, Dunn \& Smorenburg, 2013).

Senior staff members of SU are appointed as mentors ('theme gurus') for the year, acting as catalysts for the creation of dialogue and guiding the students in terms of conversations. Participants have the unique opportunity to form friendships, to engage with experts on the theme of their house and to connect with the mentor of their LLL house (Kloppers, 2016; Kloppers, Dunn \& Smorenburg, 2013), and are, in the process, confronted with vastly different perspectives.

The LLL programme aims not only to effect personal change in the participants, but also to empower students to facilitate change for themselves, and on behalf of others. In developing them as actors for social change, the programme also provides a form of leadership empowerment. It is expected that students will develop a sense of working toward or serving a greater good beyond themselves. Leadership is contextualised as a value-based, socially responsible process, and as Roberts (2007) indicates, can be defined as 'conviction in action'. The traditional notion of leadership being positional, exclusive and not accessible to all people is discarded. The focus in LLL is rather on raising awareness of their leadership potential vis-à-vis their fellow students, others and society as a whole. As agents of change the LLL students should continue establishing and supporting healthy communities when they leave SU after graduation, and so continue contributing to positive social change. This builds on Freire's (1972) notion that education is a means to change the human condition.

\section{Developing Students as Agents of Change}

In addition to the work of Freire (1972), Bandura (2001) and others, this study built on the Social Change Model of Leadership (SCM). The SCM stresses leadership as a process, and is inclusive of all people regardless of their roles (Komives, Wagner \& Associates, 2009). An important principle of the SCM is its focus on the strong connection between getting involved in social change and learning leadership. A leader in this context is one who is able to effect positive change, and all people thus have the potential to be leaders (Wagner, 2009). For the purpose of this study, the SCM as theoretical model was not primarily used to conceptualise leadership, but to provide a specific perspective on the social change occurring within living-learning communities. The SCM approaches leadership as a process which is purposeful, collaborative and values-based, resulting in positive social change. The model is congruent with professional values in student affairs and affirming of a social justice commitment to professional practice (Komives, Wagner \& Associates, 2009). 
Reeler (2007) explains that all social beings during development experience crisis, and transformative change is about freeing the social being from existing relationships and identities to stimulate further healthy development. As the LLL programme aims to develop students as agents of change, transformative change is essential in furthering healthy development and overcoming challenging or crisis moments.

The SCM includes seven critical values which play out at three levels: individual, group and community (Haber, 2011, p. 67). These levels and the values of SCM are represented in Table 2 below.

Table 2: Values of the Social Change Model of Leadership (Haber, 2011, p. 67)

\begin{tabular}{|c|c|}
\hline \multicolumn{2}{|c|}{ The Seven C's: The Critical Values of the Social Change Model } \\
\hline $\begin{array}{l}\text { Consciousness of } \\
\text { Self } \\
\text { (individual) }\end{array}$ & $\begin{array}{l}\text { Being self-aware of the beliefs, values, attitudes, and emotions } \\
\text { that motivate you to take action. Being mindful, or aware of } \\
\text { your current emotional state, behaviour and perceptual lenses. }\end{array}$ \\
\hline $\begin{array}{l}\text { Congruence } \\
\text { (individual) }\end{array}$ & $\begin{array}{l}\text { Acting in ways that are consistent with your values and beliefs. } \\
\text { Thinking, feeling, and behaving with consistency, genuineness, } \\
\text { authenticity and honesty towards others. }\end{array}$ \\
\hline $\begin{array}{l}\text { Commitment } \\
\text { (individual) }\end{array}$ & $\begin{array}{l}\text { Having significant investment in an idea or person, both in } \\
\text { terms of intensity and duration. Having the energy to serve the } \\
\text { group and its goal. Commitment originates from within, but } \\
\text { others can create an environment that supports an individual's } \\
\text { passions. }\end{array}$ \\
\hline $\begin{array}{l}\text { Collaboration } \\
\text { (group) }\end{array}$ & $\begin{array}{l}\text { Working with others in a common effort, sharing responsibility } \\
\text { and authority. Multiplying group effectiveness by capitalising on } \\
\text { various perspectives and talents, and on the power of diversity } \\
\text { to generate creative solutions and actions. }\end{array}$ \\
\hline $\begin{array}{l}\text { Common Purpose } \\
\text { (group) }\end{array}$ & $\begin{array}{l}\text { Having shared aims and values. Involving others in building a } \\
\text { group's vision and purpose. }\end{array}$ \\
\hline $\begin{array}{l}\text { Controversy with } \\
\text { Civility } \\
\text { (group) }\end{array}$ & $\begin{array}{l}\text { Recognising two fundamental realities of any creative effort: } \\
\text { (1) that differences in viewpoint are inevitable, and (2) that such } \\
\text { differences must be aired openly with civility. }\end{array}$ \\
\hline $\begin{array}{l}\text { Citizenship } \\
\text { (community) }\end{array}$ & $\begin{array}{l}\text { Believing in a process whereby an individual and/or group } \\
\text { become responsibly connected to the community and to } \\
\text { society through some activity. Recognising that members } \\
\text { of communities are not independent, but interdependent. } \\
\text { Recognising that individuals and groups have responsibility } \\
\text { for the welfare of others. }\end{array}$ \\
\hline \multicolumn{2}{|c|}{$\begin{array}{l}\text { Since it is a key assumption of the SCM that the ultimate goal of leadership is positive social } \\
\text { change, 'change' is considered to be the centre of the model. }\end{array}$} \\
\hline $\begin{array}{l}\text { Change } \\
\text { (individual, group, } \\
\text { community) }\end{array}$ & $\begin{array}{l}\text { Believing in the importance of making a better world and a } \\
\text { better society for oneself and others. Believing that individuals, } \\
\text { groups, and communities have the ability to work together to } \\
\text { make that change. }\end{array}$ \\
\hline
\end{tabular}


The individual values involve qualities of individuals that contribute to positive group functioning, the group values reflect group skills and processes that contribute to effecting positive change, and the community values focus on the greater community's needs. These three levels interact and together contribute to the overall goal of the model: positive social change. Group interaction is inherent in this model and is particularly stressed in the group values of the model (Haber, 2011, p. 67). The dynamic nature of the model is illustrated in Figure 1.

\section{Group Values}

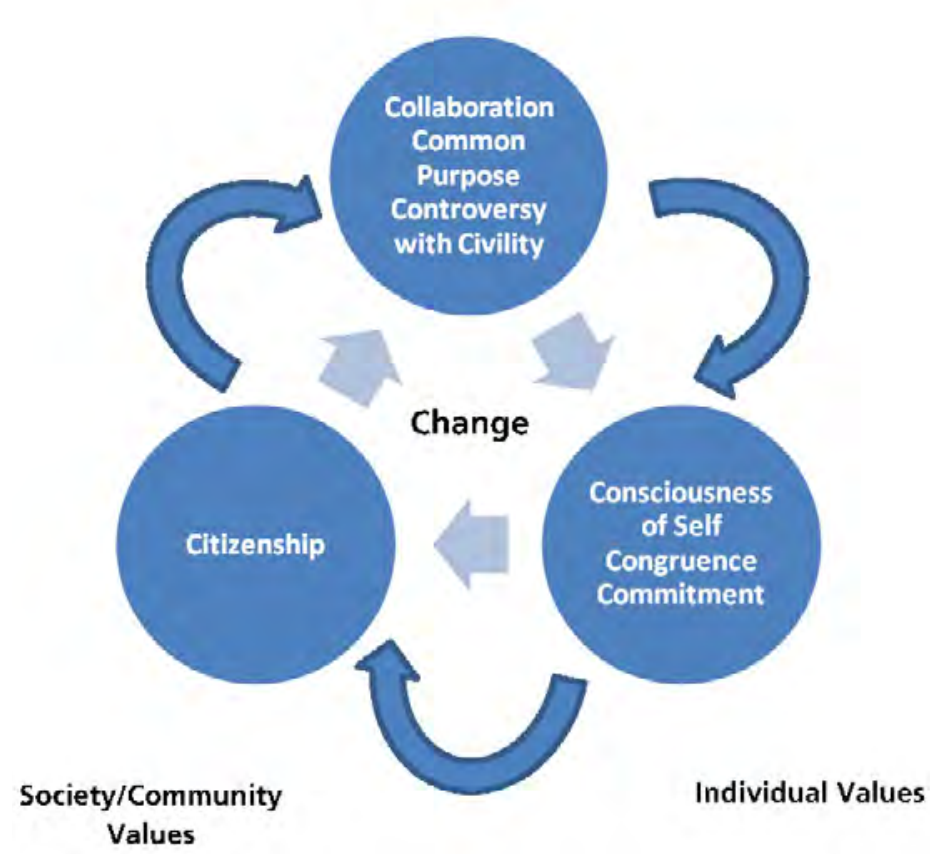

Figure 1: Dynamic reciprocity in the Social Change Model

As illustrated in Figure 1, each dimension of the model is in dynamic reciprocity with the other dimensions. If a group is unable to come to common purpose (group dimension), it could point to an absence of commitment by individuals to the group (individual dimension) and the reasons why individuals are exhibiting resistance (individual dimension) should be examined. The SCM can become a diagnostic process model to explore how an organisation functions or an individual assessment model to examine personal capacity building (Chang, Milem \& Antonio, in Schuh et al., 2011, p. 361).

Research indicated that students taking part in social change activities reported the following benefits: the establishment of personal connections with the relevant issue and with the others involved in the issue, the development of a sense of interconnectedness, the realisation that by helping others the individual also helps him/herself, and the establishment 
of a sense of satisfaction (Wagner, 2009). Despite huge challenges facing many communities across the globe, younger generations seem to be expressing more optimism about social change and becoming more involved in effecting such change. They also are more action orientated and less politically inclined than previous generations (Watson, Hollister, Stroud \& Babcock, 2011, p. 28). This points to the potential for the development of a variety of attributes in a co-curricular setting, specifically with reference to social change. Amongst these attributes that will contribute to social change are absence of stereotype and bias, and non-discrimination. The LLL programme deems that by being in closer, more regular contact with 'the other', students' stereotypes, biases and discriminatory attitudes should start changing for the better.

\section{Research Methodology}

The research project was done in two phases. The first phase consisted of an evaluation of one of the proposed outcomes of the LLL programme: 'increased levels of interaction among students in a LLL house lead to reduced stereotyping and diminished bias', by means of a survey, and the second phase consisted of the collection of qualitative data through focus group interviews to learn more about students' motivation for, experiences in and effects of the LLL programme. Ethical clearance and institutional permission were granted for both studies, and all the participants signed informed consent forms. Whereas respondents completed the online survey anonymously, the participants in the focus groups were randomly selected and are also anonymised in the reporting of the results.

The hypothesis was that the LLL experience would lead to significant change in students' stereotyping and discriminatory attitudes with regard to five constructs: gender, language, race, economic status and nationality. These represent the dimensions of diversity in South African society referred to above. In order to test this hypothesis a pre-test post-test research design was used, and quantitative data were collected by means of an electronic survey. The entire population of students enrolled in the LLL programme at that time (99 students) was the target population, and a total number of 79 students (the sample) responded to both the pre-test and post-test. The research instrument was a researchergenerated Student Attitude Questionnaire consisting of a linear numerical scale (depicting social distance) and a semantic differential scale (depicting stereotypes). The instrument was applied in January and in May with a view to measuring differences (if at all) in students' attitudes that may have developed during their time in the LLL programme.

The first part of the questionnaire gathered demographic data of the respondents, including field of study, gender, age, home language, race, nationality and socio-economic status. Table 3 provides a summary of the demographic data. 
Table 3: Demographic profile of survey respondents

\begin{tabular}{|c|c|c|c|c|}
\hline \multirow{2}{*}{$\begin{array}{l}\text { Demographic } \\
\text { factor }\end{array}$} & \multicolumn{4}{|c|}{ Percentages $^{2}$} \\
\hline & $\begin{array}{l}\text { Female } \\
69 \%\end{array}$ & $\begin{array}{l}\text { Male } \\
31 \%\end{array}$ & & \\
\hline Age & $\begin{array}{l}19-20 \text { yrs } \\
11,3 \%\end{array}$ & $\begin{array}{l}21-22 \text { yrs } \\
59,7 \%\end{array}$ & $\begin{array}{l}23-24 \text { yrs } \\
24,7 \%\end{array}$ & $\begin{array}{l}25+\text { yrs } \\
4,1 \%\end{array}$ \\
\hline Race & $\begin{array}{l}\text { African } \\
21 \% \\
\end{array}$ & $\begin{array}{l}\text { Coloured } \\
9 \% \\
\end{array}$ & $\begin{array}{l}\text { Indian/Asian } \\
2 \%\end{array}$ & $\begin{array}{l}\text { White } \\
68 \%\end{array}$ \\
\hline $\begin{array}{l}\text { Home } \\
\text { language }\end{array}$ & $\begin{array}{l}\text { Afrikaans } \\
41,2 \%\end{array}$ & $\begin{array}{l}\text { English } \\
20,6 \%\end{array}$ & $\begin{array}{l}\text { Eng \& Afr } \\
15,5 \%\end{array}$ & $\begin{array}{l}\text { African \& other } \\
\text { languages } \\
22,7 \%\end{array}$ \\
\hline $\begin{array}{l}\text { Years of } \\
\text { registration }\end{array}$ & $\begin{array}{l}\text { Two or less yrs } \\
5,2 \%\end{array}$ & $\begin{array}{l}\text { Three yrs } \\
17,5 \% \\
\end{array}$ & $\begin{array}{l}\text { Four yrs } \\
35,1 \%\end{array}$ & $\begin{array}{l}\text { Five yrs }+ \\
42,2 \%\end{array}$ \\
\hline $\begin{array}{l}\text { Parental } \\
\text { income }^{3}\end{array}$ & $\begin{array}{l}\text { Very poor } \\
2,06 \% \\
\end{array}$ & \begin{tabular}{|l|} 
Poor \\
$15,4 \%$ \\
\end{tabular} & $\begin{array}{l}\text { Middle-income } \\
68 \%\end{array}$ & $\begin{array}{l}\text { Wealthy } \\
10,3 \%\end{array}$ \\
\hline Nationality & $\begin{array}{l}\text { South African } \\
94,9 \%\end{array}$ & $\begin{array}{l}\text { International } \\
5,1 \%\end{array}$ & & \\
\hline
\end{tabular}

From the above table it is noticeable that there was a preponderance of white, Afrikaansspeaking female respondents, that a small minority of respondents regarded themselves as poor, and that by far the majority of respondents were South African.

Table 4 lists the five diversity constructs covered by the questionnaire as well as the forms of behaviour demonstrating bias and stereotyping that respondents had to indicate their agreement or disagreement with on a 10-point scale in the second part of the questionnaire.

Table 4: Diversity constructs and form of behaviour demonstrating bias and stereotyping

\begin{tabular}{|l|l|}
\hline Constructs & Forms of behaviour demonstrating bias and stereotyping \\
\hline Gender & $\begin{array}{l}\text { Distrust } \\
\text { Making jokes about } \\
\text { Using derogatory language } \\
\text { Fearing } \\
\text { Legarding as inferior } \\
\text { Race }\end{array}$ \\
\hline Socio-economic status \\
Swearing at
\end{tabular}

The linear numerical scale in the second part of the questionnaire contained 30 items in which every construct was covered by at least five statements depicting the different forms of behaviour in Table 4. Some of the items were put in the positive (e.g. 'I prefer to associate 
with people who belong to my language group') whereas, for control purposes, others were put in the negative (e.g. 'I do not trust people who do not speak my language').

The third part of the questionnaire required respondents to rate members of five groups (once again representing the five constructs) on seven traits, ranging from very negative to very positive on a 10-point scale. Examples of traits include trustworthiness, reliability and honesty.

The research results of the first phase of the research, i.e. the pre-test post-test survey are depicted in Table 5 .

Table 5: Phase 1 - Survey results: pre-test and post-test mean scores

\begin{tabular}{|lc|c|c|}
\hline Construct \& Question & & Pre-test mean score & Post-test mean score \\
\hline \multirow{2}{*}{ Gender } & $(\mathrm{Qu} \mathrm{2})$ & 56.91 & 49.60 \\
\cline { 2 - 4 } & $(\mathrm{Qu} \mathrm{3})$ & 44.68 & 41.47 \\
\hline \multirow{2}{*}{ Language } & $(\mathrm{Qu} \mathrm{2})$ & 39.24 & 37.24 \\
\cline { 2 - 4 } & $(\mathrm{Qu} \mathrm{3})$ & 43.03 & 40.89 \\
\hline \multirow{2}{*}{ Race } & $(\mathrm{Qu} \mathrm{2})$ & 56.41 & 56.04 \\
\cline { 2 - 4 } & $(\mathrm{Qu} \mathrm{3})$ & 42.97 & 40.73 \\
\hline \multirow{2}{*}{ Socio-economic status } & $(\mathrm{Qu} \mathrm{2})$ & 46.14 & 46.28 \\
\cline { 2 - 4 } & $(\mathrm{Qu} \mathrm{3})$ & 40.75 & 39.37 \\
\hline \multirow{2}{*}{ Nationality } & $(\mathrm{Qu} \mathrm{2})$ & 43.58 & 41.91 \\
\cline { 2 - 4 } & $(\mathrm{Qu} \mathrm{3})$ & 43.49 & 40.59 \\
\hline
\end{tabular}

Table 5 shows that the mean scores of responses from the pre-test to the post-test declined, indicating less tolerance and acceptance. This means that our hypothesis that the LLL experience would lead to significant change in students' stereotyping and discriminatory attitudes with regard to the five constructs of gender, language, race, economic status and nationality was not proven. On the contrary, the results of the post-test in May were somewhat more negative, indicating less tolerance for 'the other' after five months of living together. The biggest change occurred with regard to discriminatory behaviour in terms of gender. However, in most cases the differences in mean scores were very small and not statistically significant.

The results of the quantitative investigation left many questions unanswered. We tried to find possible reasons for the changes, but they remained of a conjectural nature. We therefore decided to undertake a second phase of qualitative inquiry where we could 'drill down' into students' attitudes and their experiences of the LLL programme. For this purpose four focus group discussions were conducted with current participants in the LLL programme who had also participated in the online survey. Each focus group consisted of three to four students. The interview schedule aimed at getting a better understanding of the reasons why students choose to participate in the LLL programme, how they would describe the experience and how they believed they were changed by the experience. 


\section{Reasons for entering the LLL programme}

Most participants deliberately chose the LLL programme because they wanted to live in a more diverse environment than that afforded by residences or other forms of housing.

One participant said:

“... what I really also enjoy about it is just the fact that you stay with people that you wouldn't normally choose to stay with. They're not people that are in your normal sort of environment or circle of friends. So it's just being exposed to different people from different backgrounds. It was really nice."

Another participant commented that "it is about bringing people who are not necessarily going to meet, together", whereas another one referred to the lack of diversity of ideas in other residential environments: "I did not encounter many people in res who are willing to confront bigger ideas, to find a place where I could live where you could debate ideas". This need to be part of an environment where critical debate took place was also reflected in the following extract: "So to find a place on campus where I could live that was kind of built around debating ideas ..."

From the participants' responses it became clear that participants in the LLL programme are actually a self-selecting group as they wanted to have a more diverse experience and therefore applied for the programme. We shall return to this in the conclusion.

\section{On being prepared for the LLL experience}

The responses to the question whether participants felt that they were prepared for the LLL experience revealed their eagerness to join the programme and the expectations with which they did so, but also gave evidence of some uncertainty of whether they would cope with the experience. Even though most participants underwent some form of training when entering the programme, they felt that nothing could really prepare them for the experience. Some entered with confidence: “... I entered with a certain, like a fair level of confidence."

Others were filled with trepidation: "I was really scared and intimidated by some of the people in the house." One participant made quite a profound observation in likening the experience to life: "It is difficult to prepare anyone for an experience like this. It's like preparing for life."

\section{Participants' perspectives on their LLL experience}

For most participants the LLL experience was a dynamic process, with ups and downs. One participant mentioned feeling overwhelmed: "I was extremely overwhelmed in the beginning ...". Most participants reported finding their feet over time: “... things got better over time and in that sense, I think we were more real in our responses or interactions with each other ...". 
Although it took some time, eventually being more comfortable in the LLL environment led to a greater openness to engage with "the others: "At some point in time you kind of break through and then you realise you have common interests and common goals and at that point it doesn't need to be intentional any more." Another participant remarked that "... it became more and more organic".

But it remained a process of personal growth as reflected in the following comments: "It was just about challenging myself ...", and "You become a lot more uncomfortable with some things about yourself ... You are forced to confront it. This leads to inner conflict. I'm not going to be this person anymore. If I don't I'd be stupid.' The latter reflections of participants point to the personal changes that resulted from their LLL experience.

\section{Personal changes because of the LLL experience}

Participants agreed unequivocally that the LLL experience was life-changing:

“... I can now also say, I grew exponentially and without which I probably wouldn't ...”

"LLL has played a role in how I see people and to deal with conflict and organising your life ..."

Reflecting on who they were and what effect the experience had on their lives seemed to have led to greater self-insight. One participant reflected: "LLL did not change me but gave me the freedom to be who I am."

Another participant related LLL to his life experience in the following words:

“... everyone is thrown into this world and into this journey called life ... and ... we're always struggling to make sense of it and when you're stuck in a house together with other people and you're intentionally pursuing understanding of one another, you're kind of forced to make sense of it a lot quicker and you're also trying out more ways to make sense of it and I think that's very helpful."

\section{Discussion and Conclusion}

The interview data shed light on the survey results as it transpired that the LLL participants are a self-selecting group - students who want to open themselves up to a diverse group of people and new experiences. This means that students who apply for the programme probably already have low levels of prejudice, bias and stereotyping. Therefore their scores would not have changed much from the pre-test to the post-test.

A further implication of this is that, for the programme to effect social change, it needs to be considerably expanded in order to include more students who may not necessarily share the 'open-mindedness' of the cohort involved in the study. As the group becomes less self-selecting, the potential for conflict will probably increase, which will require greater involvement by trained facilitators than is currently the case.

Our study has shown that the LLL experience had a profound effect on the students who participated in the programme, and led to better self-understanding as well as 
understanding and acceptance of 'the other'. The programme has also equipped students with critical life skills which they would put to good effect in their role as change agents in a healing society. In this regard this study has broader application for other higher education institutions in diverse societies aiming at preparing global citizens for tomorrow. It also confirms the value added to holistic student development by the out-of-class experience, but such experiences should be based on sound theoretical perspectives, properly planned, sufficient resources should be made available for their effective implementation, and should be monitored to ascertain that intended outcomes are reached.

\section{References}

Bandura, A. (2001). Social cognitive theory: An agentic perspective. Annual Review of Psychology, 52, 1-26. https://doi.org/10.1146/annurev.psych.52.1.1

Chang, M.J., Milem, J.F. \& Antonio, A.L. (2011). Campus climate and diversity. In: J.H. Schuh, S.R. Jones, S.R. Harper \& Associates (Eds.), Student Services: A handbook for the profession. San Francisco: Jossey-Bass.

DoE (Department of Education). (1997). White Paper 3. A programme for higher education transformation. Pretoria: Department of Education.

Freire, Paulo. (1972). Pedagogy of the Oppressed. Montevideo: Editorial Tierra Nueva.

Haber, P. (2011). Peer education in student leadership programmes: Responding to co-curricular challenges. New Directions for Student Services, 133, 65-76. https://doi.org/10.1002/ss.385

Kloppers, P.W. Director: Centre for Student Communities, Stellenbosch University. 2013. Personal communication. 21 May, Stellenbosch.

Kloppers, P.W. Director: Centre for Student Communities, Stellenbosch University. 2016. Personal communication. 29 July, Stellenbosch.

Kloppers, P.W., Dunn, M. \& Smorenburg, M. (2013). Listening, living and learning at Stellenbosch University: Moving towards building healthy student communities. Unpublished: Stellenbosch University.

Komives, S.R., Wagner, W. \& Associates. (2009). Leadership for a better world: Understanding the social change model of leadership development. San Francisco: Jossey-Bass.

Leibowitz, B., Rohleder, R., Bozalek, V., Carolissen, R. \& Swartz, L. (2007). 'It doesn't matter who or what we are, we are still just people': Strategies used by university students to negotiate difference. South African Journal of Psychology, 37(4), 702-719. https://doi.org/10.1177/008124630703700403

Mdepa, W. \& Tshiwula, L. (2012). Student diversity in South African higher education. Widening Participation and Lifelong Learning, 13, 20-33. https://doi.org/10.5456/WPLL.13.S.19

Reeler, D. (2007). A three-fold theory of social change. The Centre for Developmental Practice.

Roberts, D.R. (2007). Deeper learning in leadership: helping college students find potential within. San Francisco: Jossey Bass.

Soudien, C. (2014). Inclusion, innovation and excellence: Higher education in South Africa and its role in social development. South African Journal of Higher Education, 28(3), 907-922.

Wagner, W. (2009). What is social change? In: S. Komives, W. Wagner \& Associates (Eds.). Leadership for a better world: Understanding the Social Change Model of Leadership Development. San Francisco: Jossey-Bass.

Walker, M. (2005a). Race is nowhere and race is everywhere: narratives from black and white South African university students in post-apartheid South Africa. British Journal of Sociology of Education, 26(1), 41-54. https://doi.org/10.1080/0142569042000292707 
Walker, M. (2005b). Rainbow nation or new racism? Theorizing race and identity formation in South African higher education. Race, Ethnicity and Education, 8(2), 129-146. https://doi. org/10.1080/13613320500110501

Watson, D., Hollister, R., Stroud, E. \& Babcock, E. (2011). The engaged university: International perspectives on civic engagement. New York: Routledge.

\section{Endnotes}

1. Student numbers are given according to race, as required by the Department of Higher Education and Training. 'Coloured' depicts students of mixed race. African, coloured and Indian/Asian students constitute 'black' students, compared to 'white' students of European descent.

2. Percentages do not in all cases add up to $100 \%$ due to missing responses.

3. According to respondents' own perceptions. 


\title{
ON CAMPUS
}

\section{Global Summit on Student Affairs and Services}

\author{
Lisa Bardill Moscaritolo ${ }^{\star}$ Karen Davis ${ }^{\star \star}$
}

In the most recent issue of the Journal of Student Affairs in Africa (JSAA), readers were introduced to the 3rd Global Summit on Student Affairs and Services that was hosted by Stellenbosch University (SU) in Cape Town, South Africa, this past October 2016. This summary will provide a more detailed outline of the organisation of the summit, its processes, and the final written product for the 2016 summit, which was initiated by the International Association for Student Affairs and Services (IASAS) and Student Affairs Administrators in Higher Education (NASPA).

The first Global Summit in 2012 was held in Washington, D.C., which is the home office of NASPA and in 2014 the summit was held in Rome, Italy and was hosted by the European University College Association (EuCA). Perozzi, Giovanucci and Shea (2016), note that the summit "is not a 'conference' in the traditional sense; rather, the methodology allows for emergent issues and a discussion of concepts that are most relevant to participants" (p.24). Following the same ideals, forty participants, from 19 different countries, who support students on college and university campuses around the world, were invited to South Africa for a rich dialogue around critical issues facing student affairs and services. Some of the issues that surfaced in 2012 and 2014 were used as a basis for further reflection in the 3rd summit. These themes included professionalisation and internationalisation of the field, employability and soft skills, engaging in student activism, and access and inclusion.

While planning each summit and choosing a framework or theme for the summit, a deliverable was discussed early on. In 2012, the output was an Executive Summary of the proceedings including the themes and recommendations suggested, as well as a video. In 2014, a summary was written on the event and outcomes. The planning committee identified deliverables for the summit and the 2016 IASAS/NASPA/SU planning committee feels that the process and outcome was fully realised with the 3rd summit.

\footnotetext{
* Dr Lisa Bardill Moscaritolo serves as Associate Vice President and Dean for Students at Pace University, New York, USA. She is also a founding member and general secretary of IASAS.

** Karen Davis is Associate Director, Student Academic Services (Retention, Achievement and Equity) at Victoria University of Wellington, New Zealand.
} 
The Wallenberg Research Centre at STIAS in Stellenbosch was the perfect venue for the two-day dialogue on the UNESCO Operational Strategy on Youth (Medium Strategy 2014-2021), concentrating on access to tertiary education in Africa and gender. This document was sent to participants ahead of time.

While at the summit, participants first worked in groups based on their region in the world, to consider the impact of the UNESCO Medium Term Strategy on Youth on their specific work. Professor Adam Habib, Chair of Universities South Africa (USAf) helped to set the stage by contextualising higher education in South Africa and provided comparisons to other parts of the world during a most inspiring opening address. Mr Yousaf Gabru, Chair of the South African Commission for UNESCO, provided further perspectives on the Medium Term Strategy document and the connections to student affairs and services work.

Participants used the overarching UNESCO document as high-level goals for our work in student affairs and brought these goals into their local environments, while commenting on the global goals from an indigenous perspective. Participants also worked in cross-border teams to continue analysing the UNESCO publication and specifically make affirmations and suggested contributions that can be shared with UNESCO in relation to the work of student affairs and services. This collaborative work allowed for a shared understanding of the UNESCO objectives and provided a platform for embracing the most salient concepts.

The Summit allowed for large group discussion with all participants on four topics that had surfaced in past summits. As noted above, the 2012 topics were professionalisation and internationalisation of the field, employability and soft skills, engaging in student activism, and access and inclusion. The UNESCO Medium Term Strategy was cross-referenced with these topics to further understand student affairs and services work globally, help practitioners develop shared goals and outcomes, and work toward attaining these outcomes.

The end result of the summit was a global response on the impact that student affairs and services have on students and how our work contributes to the objectives in the UNESCO strategy. The Medium Term Strategy articulates the shared goals of the member states and a vision for the attainment of peace and equitable and sustainable development with two global priorities focused on Africa and gender equality. Education has a key role in achieving human rights for all.

The UNESCO strategy describes nine strategic objectives and five of these are particularly aligned to the global aims of student affairs and services in higher education. These are:

1. Developing education systems to foster high-quality and inclusive lifelong learning for all;

2. Empowering learners to be creative and responsible global citizens;

3. Advancing Education for All (EFA) and shaping the future international education agenda;

4. Supporting inclusive social development, fostering intercultural dialogue for the rapprochement of cultures and promoting ethical principles; and

5. Fostering creativity and the diversity of cultural expression. 
In response to these objectives, several themes emerged in the global discussions at the summit as delegates shared their local knowledge and expertise. There was a strong commitment to high-quality lifelong learning grounded in holistic and inclusive approaches. Delegates reflected on the challenge of achieving human rights through education for all and our responsibility to contribute to addressing peace, sustainability and gender equality. The value of multiple voices was noted, along with the need to empower students to act as partners and change agents in their educational experience. A reframing of co-curricular design was seen as a way to value indigenous knowledge and unique ways of sharing knowledge. While recognising different worldviews, through collaboration there can be greater alignment of educational systems and institutions as we shape the future international education agenda.

Achim Meyer auf der Heyde, President of IASAS and General Secretary for the Deutsches Studentenwerk, is working with UNESCO to promote the recommendations of the Global Summit 2016. Our UNESCO response as well as the finalised documents on previous summits can be read at http://iasas.global/global-summit-student-affairs-andservices/.

The gains of the Global Summit in 2016 can be understood in our response to UNESCO but can also be described through the following thoughts.

The Summit "constitutes a precious opportunity to share experiences, highlight problems and identify possible common solutions. As some participants at the Global Summit of Stellenbosch explain in an interview, "it's an opportunity to compare one's experience with the world" (Ceccarini, 2016, p.4). Barbra Pansari from Botswana University adds that for her "the value of the Summit is our networking and sharing experiences and lessons with colleagues from all continents of the world".

"Discussing student affairs initiatives with colleagues from around the world helps to enhance overall student learning and success," noted Achim Meyer auf der Heyde, President of IASAS (personal communication, 28 October 2016).

\section{References}

Ceccarini, I. (Decembre, 2016). Student affairs and services - Open to the world. Universitas: Studi e Documentazione di Vita Universitaria, (142), RUI Foundazione.

Perozzi, B., Giovannucci, G.L. \& Shea, R. (2016) The global dialogue. In: K.J. Osfield, B. Perozzi, L. Bardill Moscaritolo \& R. Shea (Eds.). Supporting students globally: Trends and perspectives for student affairs and services (pp. 21-41). Washington, D.C.: NASPA. 
BOOK REVIEW

\title{
Roberts, Dennis C. \& Komives, Susan R. (Eds.) (2016). Enhancing Student Learning and Development in Cross- Border Higher Education. San Francisco: Jossey-Bass.
}

\author{
Reviewed by Munita Dunn-Coetzee`
}

Enhancing Student Learning and Development in Cross-Border Higher Education, edited by Dennis C. Roberts and Susan R. Komives, is a book that resulted from a short-term study-abroad experience between the Universities of Maryland and San Diego with the Qatar Foundation's Education City in Doha in 2010. This partnership challenged the way in which higher education internalisation was viewed - in such a way that the visit was replicated in 2012 and this book was authored. The book aims to address the opportunities and challenges in developing programmes and strategies for student learning and development that are culturally appropriate - specifically from a student affairs, student development and student services perspective. However, although the majority of the book focuses on western higher education, the book aims to highlight the merit of learning from other international constituencies to enhance the student experience. In essence, how can we benefit our own practices by learning from others within the global realm?

The book's chapters are organised into three sections. Part One, consisting of two chapters, elaborates on the consideration of cross-border applications. Chapter One provides an overview of the expansion and internationalisation of higher education, as well as providing strategies and frameworks for optimising the student experience and student success. The chapter highlights that institutions make four choices when applying best practices across borders and contexts - relating to transferring of best practices, programme adaption, the hedging of an initiative and the possible avoidance of the partnership. The importance of the integration of students' experience in both the classroom and beyond is emphasised and key principles for internationalising student affairs and student services conclude the chapter. Chapter Two builds on Chapter One by exploring the underlying motivations that institutions use in their specific international context by applying a lens of five diffusion models - learning, imitation, competition, normative and coercion. This chapter aims to guide understanding of the rationale institutions and practitioners use to decide on practices for internationalisation. The chapter emphasises that although shared practices can be motivated, the diversity in terms of offerings - on institutional and cultural levels - must be carefully considered to ensure the best choices are made.

* Dr Munita Dunn-Coetzee is the Director of the Centre for Student Counselling and Development, Division of Student Affairs, at Stellenbosch University, South Africa. Email: mdunn@sun.ac.za 
Part Two, consisting of four chapters, portrays a more practical approach to internationalisation - providing examples from South Africa, China, the United Kingdom and Mexico. Chapter Three shares a perspective on first-year adjustment within the South African region. A model, known as the First-Year-Village, has been piloted and the aim of the model is to provide support to first-years in a communal environment - this might be understood as the South African example of establishing living communities. The context of student support as well as the fact that the goal of all student support is student success, form the two basic principles of the chapter. Chapter Four explains how one private university in China promoted resilience for students coming from single-child families. A series of workshops were embedded in the orientation calendar focusing on independent self-management. In order to integrate curricular and co-curricular learning, the university also adopted a curricular approach to 'Whole Person Education', experiential learning by nature. More studies on the outcome of the success of these interventions are recommended.

Chapter Five brings a perspective from the United Kingdom to the fore - exploring what is necessary to foster retention and success for students who were at great risk, specifically in this context, care leavers - youth receiving care outside or beyond the family. Since 2007, the University of Sheffield set out its intentions to support looked-after children and care leavers within the higher education realm. This programme has since expanded vastly and further initiatives to create a holistic support system for these students' journey have been developed. Chapter Six, the last chapter in this section, elaborates on the challenging situations Mexico faces and how opportunities for change are provided for students by leadership and citizenship education to strengthen democracy. A leadership development model focusing on four pillars is explained by the Universidad de Monterrey (UDEM). This holistic model is yielding successful results. This section helps the reader to reflect on how internationalisation can be practically positioned within institutions.

The last section of the book - Part Three - consists of five chapters and discusses foundations and strategies that are broadly applicable across all educational, cultural and national contexts. Chapter Seven provides a social justice perspective on research and student development theories - emphasising that development and learning are complex processes across a holistic spectrum. The important message of the integration between learning and development within context is elaborated upon in the chapter and raises awareness about a variety of factors that advance student learning and development in ways that promote social justice. Students interacting in their environments, with the influence of culture in student learning and development, is discussed in Chapter Eight. Bronfenbrenner's Social-Ecological Model is used as contextual framework within the chapter and a practical example of an educational system in Singapore illustrates this ecological systems view - providing the opportunity to pose questions regarding curricular and co-curricular design.

Chapter Nine aims to highlight international best practices and resources used in adopting assessment, evaluation and educational research. The history of the assessment movement, specifically in the United States and other countries, indicates that higher 
education institutions still tend to be more reactive - rather than pro-active - regarding assessment and evaluation practices. This chapter challenges practitioners to take initiative and to advance these practices in a pro-active manner. Chapter Ten explains the findings of a study on the engagement of educators in student affairs on an international level - looking at the state of student affairs and services in terms of educational pathways and professional development. It is emphasised that the building of capacity needs to be prioritised - identifying what internationalisation means for the specific institution, what it consists of as well as appropriate training for staff, specifically looking at attaining cultural competence. The last chapter of this section, Chapter Eleven, aims to summarise the journey in terms of internationalisation embarked on in this book by exploring the value of partnerships in international higher education. It is advocated that authentic partnerships ensuring mutual benefit will enhance the impact and effectiveness of these endeavors. The readers are encouraged to start the conversation at their own institutions.

Enhancing Student Learning and Development in Cross-Border Higher Education elaborates on a very important discourse regarding internationalisation within higher education, particularly for academic and Student Affairs staff, as well as staff working with internationalisation at institutions. Overall, this is a very interesting book that not only significantly contributes to the dialogue on internationalisation in higher education, but also aims to turn questions into action. 
JOURNAL REVIEW

\title{
Asia-Pacific Journal for Student Affairs (AJSA)
}

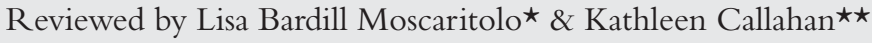

The International Association of Student Affairs and Services (IASAS) serves as a global network of student affairs and services workers that encourages sharing, cooperation, research, exchanges, and attendance at each other's conferences. The Vice President and General Secretary of IASAS attended the 2016 Asia Pacific Student Services Association (APSSA) Conference in Chiang Mai, Thailand. Long-time colleague and past regional coordinator in Asia for IASAS, Evelyn Ariola-Songco, presented both members with a copy of the inaugural Journal of the Philippine Association of Administrators of Student Affairs (PAASA). This is the first journal in the South East Asian region and is an important first step in advancing the field.

The editorial board for the Asia-Pacific Journal for Student Affairs (AJSA) is comprised of student affairs practitioners in the Philippines and although not peer-reviewed at this time, they are working to develop this journal and set high standards. Volume 1, April 2015, Institutionalizing Research in Student Affairs Administration, is a true accomplishment for the region and the field as properly noted by Ma. Paquita Diongon-Bonnet:

Student affairs practitioners all over the world are selfless individuals who contribute their time and effort, as well as expertise and talent, in honing the future. Truly, we join our fellow educators who handle academics in the quest for the total development of every student whose parents entrust their formation to our institutions.

It seems natural to provide an overview of this seminal document in this issue of the Journal of Student Affairs in Africa because of its connection with IASAS and the theme of this issue is about hearing international voices of those who work outside of Africa. From the other side of the world those who work in student affairs are similarly concerned about student success.

* Dr Lisa Bardill Moscaritolo serves as Associate Vice President and Dean for Students at Pace University, New York, USA. She is also a founding member and general secretary of IASAS.

** Dr Kathleen Callahan is Lecturer for Leadership Studies at Christopher Newport University. Email: kathleen.callahan@cnu.edu 
The creation of the Association of South East Asian Nations (ASEAN) has changed the landscape in higher education. Cooperation of the 10 member states is to provide for better prosperity and peace for all. In the first article the author, Ma. Paquita DiongonBonnet, offers a reflection on the ASEAN integration and how the skills students need to be successful after graduating from college have expanded to meet the demands of the new work force. Additionally, recommendations are provided for colleges and universities on how to effectively help students develop these employability skills.

This issue also includes understanding the voices of children of Overseas Filipino Workers (OFW) who must leave their families to make a living outside of the Philippines.

Researcher Abenir uses the Philippines as a case study and provides insight into these children's lives, their rights, and what they believe the responsibilities of their parents should be to the family through mixed methods using surveys and text analysis. It is expected that more work opportunities abroad will be a result of the ASEAN pact. The results of this study show that a majority of children (91\%) believe their migrant parent is fulfilling family obligations but that there are still some concerns regarding parents leaving for an extended time. Understanding the psychological concerns of this underrepresented group of children, who will eventually come to our campuses, will help student affairs and services respond more appropriately and provide support where needed.

Research on life skills and how students gain these skills through involvement in student organisations is highlighted in the third article written by Dr Songco. These life skills will help students to become more employable post-graduation. Through the use of emotional intelligence as a framework, the researcher developed a qualitative study to observe university student organisations and life skills development in connection with these organisations, and provided recommendations based on findings.

Melegrito proposes in the fourth article to provide an institutional framework to develop socially responsible students through three critical areas: spiritual enhancement, leadership formation, and social engagement. The author integrates these three areas to create a framework that, in the author's opinion, should be considered and aligned to the goals of any new programme within various units/departments. With this framework being utilised, institutions can develop students who are civically and socially responsible.

The last article in this journal, by Dr Diongon-Bonnet, is a grounded study about how the university community describes and identifies factors of quality of life including administration, faculty, and students. "Quality of life then is defined by university stakeholders as a state of human condition with a general sense of well-being, where needs are met beyond what are basic, and having internal and external resources to live a meaningful and purposeful existence" (p. 111). In addition to defining quality of life, the author found indicators of and enhancers of quality of life and provides the university sector with recommendations to each stakeholder to ensure these factors are being met.

Now that the first issue has been published, Evelyn Ariola-Songco, who is part of the Editorial Board, highlighted some future plans for the Journal. The first task is to initiate a peer review process for the Journal and she noted that before the first issue was published the board had asked members of APSSA to make up a board of reviewers. There are also 
plans "to have a writeshop in collaboration with APSSA-ISA. This aims to enhance the research and writing skills of student affairs practitioners" (Evelyn Ariola-Songco, personal communication, 25 May 2017). Overall, the first volume of the Asia-Pacific Journal for Student Affairs encourages administrators to engage and begin to institutionalise research with the region. This journal is a wonderful new contribution to the literature in the field of student affairs and provides perspective from our colleagues in the Asia-Pacific region. 
Osfield, K.J., Perozzi, B., Bardill Moscaritolo, L. \& Shea, R. (2016). Supporting Students Globally in Higher Education. Washington, D.C.: NASPA.

Reviewed by Jennifer A. Hamilton *

The growth in opportunities for learning between international practitioners of student affairs and services has been exciting over the last number of years. As international students have increased in number on our campuses, and as local issues become global issues, the need for dialogue and sharing amongst student affairs professionals from different geographical regions is crucial. Professional associations based in the United States (ACPA, NASPA) and elsewhere have included international symposia, pre-conference workshops, and knowledge communities that focus on global issues and internationalisation at their conferences for some time. The creation and chartering of the International Association of Student Affairs and Services (IASAS) formalised the opportunity for those from different regions to engage with one another on shared interests. And in 2012, 2014 and 2016, NASPA and IASAS joined together in inviting international professionals together for the "Global Summit on Student Affairs and Services". This volume is a testament to those efforts and the growing professionalisation of student affairs in many parts of the world.

The volume's stated primary focus is "how student affairs professionals can provide students with the best student service opportunities possible", (p.ix) and to examine student affairs and services in the worldwide context. It is divided into three sections: 'An Interconnected and Interdependent World'; 'Helping Ourselves to Help Our Students Succeed', and 'Responsible Global Interaction'. Taking on the topic of "supporting students globally" is a big issue and the title might suggest that this volume is meant for practitioners who have international student services or student exchange programmes in their portfolios. This volume may be of interest to those professional staff, but it is not meant to be a "how to" for supporting students, despite its title. In my assessment, this volume is directed at one of the following three audiences:

- Student Affairs professionals working in international student services who are looking to expand their professional knowledge beyond their day-to-day roles;

- Those who are highly involved in student affairs professional associations; and

- General student affairs practitioners or faculty from various countries interested in learning from others and gaining some perspective on international issues.

* Jennifer A. Hamilton is the Executive Director of the Canadian Association of College \& University Student Services (CACUSS). Email: cacuss-ed@cacuss.ca 
The volume has a number of strong chapters and in particular - beginning with the end - the Appendices are an excellent reference bringing together over 60 pages of international organisations both alphabetically and by country. These are an invaluable resource for anyone wishing to do research, outreach, engage in conversations about possible exchanges or learn about a particular country and its system of post secondary education. It is already a well-thumbed section of my own copy. The volume also does a good job in Chapter 2, 'The Global Dialogue', documenting evolution and execution of the Global Summit. While it may not be of interest to all practitioners, it is an important way to archive what transpired in a volume such as this. Chapter 7, on intercultural competence, is a useful summary of an importance competence for both ourselves as professionals and for our students. Chapters 8 and 10 are also helpful in examining exchange programmes for both staff and graduate students. Chapter 11 looks at the emerging trend of "branch campuses" and how student affairs may be structured in hybrid ways in those unique institutions. Chapter 12 does an excellent job of considering student mobility and its impact on the campus and the student. It is well researched and well written. While it is not possible to summarise each and every chapter, there are several which cover unique topics not covered in other books and journals.

Overall, it does well in attempting to shift the conversation about student affairs into the international arena. However, its lofty goals end up with a volume that is a bit disjointed and with a lack of focus. It isn't clear that the central thesis ties all the chapters or the sections together. The book has multiple purposes and multiple audiences and it may not deliver or meet expectations in any one particular area. One may be left looking for answers to questions such as "how do we support students globally?" in other places.

Another criticism is the lack of diversity of the chapter authors. Of the 30 , the majority are from North America (with half from the U.S.). Although several authors have some exposure to international experiences, there is a missing analysis of the impact of mostly dominant-culture voices and the potential for the colonising of the dialogue about the profession from a North American perspective. Because professional practice, graduate preparation and research in the United States is so very strong, we have all benefited from the shared knowledge of our American colleagues. We could work harder to invite more voices from countries outside of the U.S. and Canada to lend perspective on some of the deeper issues.

On the positive side, the book could help the student affairs practitioner consider the many ways in which we might be more globally minded, gives an introduction to many subjects in the global higher education space, and points to several resources for learning more. The book also leaves us with some great resources and an opportunity to explore further research. Areas that could be explored include the intercultural competency of student affairs professionals, a deeper examination and empirical review of trends, rather than listing individual countries as Chapter 14 summarises.

There is so much potential for exploring issues that may impact all of our students regardless of country or campus. Collaborative and comparative research is needed in areas such as employability, access, learning outcomes, rising costs/funding, participation 
and success of racialised and marginalised students, sexual violence (and other forms of violence), civility, and promising practices and structures which engage faculty. Having truly international research and reflection about these issues would be stimulating.

I applaud the editors, authors, NASPA and IASAS for bringing together the excellent authors for this much anticipated book about the broad range of issues of an international nature in student affairs work. The volume offers the invitation for us to consider our work in different contexts and to reach beyond our borders to be better at our work and support the success of our students. This is an important job not only for those working in international student services, but for all of us. 


\section{Author biographies}

Dr Lisa Bardill Moscaritolo serves as Associate Vice President \& Dean for Students at Pace University, New York, USA. She also serves as the Chief Student Affairs Officer for her campus and provides overall leadership and direction to the Student Affairs division. Lisa has a Masters in Higher Education and College Student Personnel from Florida State University, an Education Specialists degree in Mental Health Counseling and a Doctorate in Leadership from Barry University. She is an advocate for increasing the knowledge, research and practices of student affairs and services around the world and is a founding member and general secretary for the International Student Affairs and Student Services (IASAS) organisation, which was chartered in Brussels, Belgium in July 2013. She has been involved in NASPA's (Student Affairs Professionals in Higher Education) International Education Knowledge community since 1994 and served as chair of the knowledge community in 2003-2004. Lisa was awarded a sabbatical from Pace University during the spring 2015 semester to serve as Dean of Student Life for a Semester at Sea Voyage. She is one of four editors of a new NASPA/IASAS publication, titled Supporting Students Globally in Higher Education:Trends and Perspectives for Student Affairs and Services.

Prof. Arega Bazezew is a livelihood and food security specialist at Bahir Dar University, Ethiopia. He has long experience in teaching and administration at high school and university levels exceeding three decades. In addition, he has served as head of department of Geography and Environmental Studies for four years. Currently he is a $\mathrm{PhD}$ coordinator in the Department of Geography and Environmental Studies. He is also a chairperson for the Serve Ethiopia Development Association (SEDA). He has extensive experience in software applications such as the Statistical Package for Social Scientists (SPSS) and the Geographic Information System (GIS). Berlie Arega has published many peer-reviewed articles in relation to education, development and food security. He has also written teaching materials on Fundamentals of Economic Geography and Basic Concepts of Statistics in Geography and Environmental Studies. He presented scientific works for international conferences such as USAID and SIDA in relation to climate change, food security and agriculture.

Dr Kathleen Callahan serves as a Lecturer for Leadership Studies at Christopher Newport University, Newport News, USA. She received her PhD in Higher Education Administration from Florida State University in 2015 and her Masters in College Student Affairs from the University of South Florida in 2007. She has worked in the field of higher education for over 10 years and her research interests include the history of higher education and student affairs, the internationalisation of higher education, and leadership education. Additionally, she is an adjunct professor for William and Mary's Higher Education programme, as well as adjunct for the Leadership Certificate programme at Florida State University. She has leadership roles in NASPA, Student Affairs Administrators in Higher Education and the International Leadership Association (ILA). 
Dr Kevin Colaner currently serves California State Polytechnic University, Pomona, USA, as Associate Vice President for Student Services where he oversees Student Health and Counseling Services, the Career Center, the Disability Resource Center, Orientation Services, the Veterans Resource Center, and Student Support and Equity Programs. In addition, he is an adjunct associate professor for the Rossier School of Education at the University of Southern California. His service to the profession includes leadership both regionally and nationally in the National Association of Student Personnel Administrators. As a result of his outgoing and collaborative management style, he has been profiled in The G Quotient: Why gay executives are excelling as leaders ... and what all managers need to know, released by Jossey-Bass publishing. He is a contributing author in the recently published Identity and Leadership: Informing Our Lives, Informing Our Practice. His commitment to diversity and inclusion was recognised by the Cal Poly Pomona community as he was selected as a 2014 Diversity Champion. He earned his Doctorate in Education from the University of Southern California and a Master of Science in College Student Personnel Services from Miami University after graduating cum laude from the University of North Carolina, Wilmington, with a Bachelor's degree in Speech Communications.

Karen Davis is Associate Director, Student Academic Services (Retention, Achievement and Equity) at Victoria University of Wellington, New Zealand. In this role, she leads a team of staff who deliver academic and equity-focused student services, including student learning, mentoring and holistic support for Maori and Pasifika students, disability services, and careers and employment services. Karen is Vice President (New Zealand) of the Australia and New Zealand Students' Association (ANZSSA). She completed an MA (Hons) at the University of Auckland and, following this, was a member of a research team, supported by a grant from the Marsden Fund for a three-year project that investigated the use of, and attitudes to, the four main Pasifika languages in Manukau in New Zealand, with the intention of contributing to language maintenance. Karen is particularly interested in students' transition into tertiary study and participation and achievement of students from diverse backgrounds.

Danie de Klerk is a Lecturer and Success Coordinator at the University of the Witwatersrand, Johannesburg, South Africa, whose research interests span teaching and learning in higher education, undergraduate student success and support, at-risk programmes, and data analytics. He holds a Master's degree in English literature and is currently completing a two-year professional Postgraduate Diploma in Higher Education Studies. Danie has been working in the higher education sector for more than 10 years, has assumed instructional and administrative roles at multiple South African universities, and has extensive experience in the area of holistic student success and support in the current tertiary climate. His expertise includes academic advising and student guidance, language instruction and assessment, curriculum planning and course design, course coordination, and academic administration. 
Dr Munita Dunn-Coetzee is currently the Director at the Centre for Student Counselling and Development (CSCD), Stellenbosch University, South Africa. She is a registered Counselling Psychologist and obtained her Master's degree in Counselling Psychology cum laude at Stellenbosch University during December 2001. She has completed her doctoral degree, DDiac in Play Therapy, in 2004 at the University of South Africa. She was employed at Huguenot College until 2010 where she was involved in Psychology and Play Therapy, lecturing pre-graduate students in Psychology and supervising postgraduate students in Play Therapy. As she is fond of research and studying, she obtained an MPhil in Higher Education cum laude during 2013 - the focus being social change within Higher Education. She has published nationally and internationally, and has presented at several national and international conferences. She served as the Deputy Director of the Centre of Student Communities at Stellenbosch University until October 2014, which involved managing activities regarding co-curricular development, student leadership, transformation and integration of different cultures on one campus. In her current role as the Director of the CSCD she focuses on providing a student-centred approach in terms of therapeutic interventions, crisis management, guidance with academic and career development, assisting students with special needs, as well as dealing with issues regarding discrimination, victimisation and harassment.

Dr Yuanyuan Fang is Associate Professor of the School of Foreign Languages, Hefei University of Technology, China. She earned a Master's degree in Applied Linguistics from the University of Science and Technology of China, and a Doctor's degree in Science Communication also from the University of Science and Technology of China. Her research interests include multicultural communication and translation.

Prof. Magda Fourie-Malherbe is Professor of Higher Education Studies in the Centre for Higher and Adult Education, Faculty of Education, Stellenbosch University, South Africa. She is an alumna of the University of the Free State, and has worked at various public higher education institutions in South Africa as a researcher, lecturer, supervisor and higher education manager for almost 30 years. Her research includes work on higher education governance, leadership and management, teaching and learning, and academic development. Currently 15 postgraduate students are doing research under her supervision, mainly on factors that enhance or inhibit student success. She has presented more than 50 papers at international and national conferences and has authored and co-authored 40 contributions to scholarly journals, books and research reports. Recently she co-edited a volume: Postgraduate Supervision: future foci for the knowledge society, published by African SUNMedia. She is a member of a number of professional associations, including the Consortium for Higher Education Researchers and the European Association for Institutional Research. She regularly reviews articles for both national and international scholarly journals. 
Jennifer A. Hamilton is the Executive Director of the Canadian Association of College and University Student Services (CACUSS). She has served in this senior leadership role of Canada's national student affairs association since January 2011. Prior to joining CACUSS, she worked as a student affairs professional for 15 years in the areas of student leadership development and student life, career services, academic advising, orientation/ transition programmes and international student services. Her roles included developing and managing a new department at OCAD University, and serving in staff roles at the University of Toronto and Portland State University. Jennifer has an Honours B.A. from the University of Guelph and a M.S. in Student Affairs in Higher Education from Colorado State University. She is a current $\mathrm{PhD}$ student at OISE, University of Toronto, and her research focuses on how student affairs staff develop professional competence.

Andrew Jones is Assistant Dean: Undergraduate in the Faculty of Commerce, Law and Management of the University of the Witwatersrand, Johannesburg, South Africa, as well as a Co-Grant Holder for the Road to Success programme. His research interests span teaching and learning in higher education, undergraduate student success and assessment and curriculum design within professional qualifications. He holds a Master's degree in Commerce and is currently completing a two-year professional Postgraduate Diploma in Higher Education Studies. Andrew has been working in the higher education sector for more than 20 years, and has extensive experience in the area of holistic student success and support in the current tertiary climate. His expertise includes academic advising and student guidance, lecturing and coordinating courses in accountancy and taxation, curriculum planning and course design, course coordination, as well as academic administration.

Dr Yongshan Li is the Deputy Director of Department of Educational Administration and dean of Humanistic Quality Education Center, Hefei University of Technology, Hefei, Anhui, China. He is responsible for strategic planning and advancement of general education of the college students. He earned a Doctor of Management degree in Management Science and Engineering from Hefei University of Technology. His research interests include student affairs administration in higher education from an international perspective, and comparative study of general education in universities worldwide. He is dedicated to promoting professionalisation of student affairs practitioners in China. In 2015, his study was supported by the "Ideological and Political Education Young Talents Support Program” sponsored by Ministry of Education of the People's Republic of China.

Dr Thierry M. Luescher (Luescher-Mamashela) is Research Director: Higher Education and Development in Africa, in the Education and Skills Development Research Programme of the Human Sciences Research Council (HSRC), Cape Town, South Africa. Before that he was Assistant Director of Institutional Research at the University of the Free State, and Senior Lecturer in Higher Education Studies, extraordinary Senior Lecturer in Political Studies at the University of the Western Cape, and a Senior Researcher in the Centre for Higher Education Transformation (CHET), Cape Town. He obtained his $\mathrm{PhD}$ in Political 
Studies from the University of Cape Town. He researches, teaches and consults on matters of international and comparative higher education, with particular interest in the nexus of higher education with politics in Africa, higher education policy and governance, student politics, the student experience, student affairs, and higher education development in Africa. He has published in local and international scholarly journals, including Studies in Higher Education, European Journal of Higher Education, Journal of Higher Education in Africa, South African Journal of Higher Education, Tertiary Education and Management, Politikon: South African Journal of Political Studies and Perspectives in Education, along with several chapters in internationally edited books. He is an editor of the Journal of Student Affairs in Africa, and member of the editorial boards of the Journal of College Student Development, Makerere Journal of Higher Education and African Higher Education Dynamics. Thierry recently edited the book Student Politics in Africa: Representation and Activism (with M. Klemenčič and J.O. Jowi, 2016, which is available open access). His publication list and links to open access downloads can be viewed at www.thierryluescher.net.

Tshepiso Maleswena is a researcher and coordinator in the Faculty of Commerce, Law, and Management of the University of the Witwatersrand, Johannesburg, South Africa. Her work is based on the various aspects of the faculty's teaching and learning and her responsibilities include facilitating student success and support, student mentorship and research of various learning and teaching methods. Prior to Wits University Tshepiso worked extensively in the corporate sector in the field of marketing and communications where she held various marketing role in Insurance, Risk as well as in the Information Technology space. Tshepiso holds an undergraduate degree in communications, a Master's degree in Political Science and is currently in her first year of a two-year Postgraduate Diploma in Higher Education. Her research interests extend to student social experiences at tertiary institutions, decolonisation of the university curriculum and nuanced approaches to course design and assessment practices. Outside of her work at Wits, Tshepiso is also a gender and social justice activist and frequently works with organisations such as Sonke Gender Justice and Soul City to raise awareness around gender-based violence.

Dr Maria L. Martinez currently serves California State Polytechnic University, Pomona, USA, as University Registrar. Starting from August 2017, she will be Associate Vice President at San Francisco State University. In 2017, she earned the endorsement of the American Association of Collegiate Registrars and Admission Officers as an Enrollment Professional and is included in the organisation's National Registry. In collaboration with various campus partners, she is responsible for providing student-centred enrollment services to former and current students, faculty, and staff. She oversees critical university functions, including registration, evaluation of records, graduation and academic records maintenance and is a primary contributor to University initiatives to boost student success and graduation. In recognition of her excellent leadership skills, CPP's Vice President of Student Affairs awarded Dr Martinez the Leadership Award in 2011. Dr Martinez earned a Bachelor of Arts in Psychology from Fordham University with a cum laude designation, 
a Master's in Public Administration from California State University, Fullerton, and a Doctor of Philosophy in Education degree from Chapman University. Her research interests revolve around the intersection of culture, education and leadership. Her passion is in increasing institutional understanding of the unique needs of students from abroad and aligning student services with these needs.

Chinedu Mba is currently an English as a Second Language/English for Academic Purposes Professor at Algonquin College, Ontario, Canada, where she also serves as a student advisor and sits on the college Academic Advising Steering Committee. Chinedu is an academic coach and works with learners of all ages. She received her BA in Mass Communication from the University of Nigeria, Nsukka (UNN) in 1987, a Postgraduate Diploma in Education from the University of Calabar, Calabar, Nigeria in 2000, a Certificate in Teaching English as a Second Language from Humber College, Toronto in 2002, an MA in Applied Linguistics from York University, Ontario, Canada in 2005, an MA in Educational Studies, specialising in Leadership in post-secondary institutions from the University of Alberta in Edmonton, Alberta, Canada in 2014. Chinedu Mba's experience as faculty in several Canadian Community Colleges and the University of Guelph as well as her roles as a Program Coordinator and Associate Dean, respectively, at NorQuest College in Edmonton, Alberta, Canada have driven her passionate interest and involvement in matters related to Student Affairs and advocacy, particularly in the area of the academic success of international students, Internationally Educated Professionals (IEP), refugees and various classes of immigrants. She has served as Chairperson, Board of Executive Directors, St. Albert District Further Education, St. Albert in Alberta, Canada. Currently, she is a member of the International Association of Student Affairs and Services (IASAS), the Learning Strategists Association of Canada (LSAC), International Centre for Academic Integrity (ICAI), and Teachers of English as a Second Language Association of Ontario (TESL Ontario).

Prof. Teboho Moja is Clinical Professor of Higher Education at New York University, USA. Her teaching experience includes high school and university levels. Teboho has held key positions at several South African universities, including being appointed Chair of the Council of the University of South Africa. She has held positions as Professor Extraordinaire at the University of Pretoria, the University of Johannesburg and the University of the Western Cape, and has been Visiting Professor at the University of Oslo (Norway) and University of Tampere (Finland). She was instrumental in setting up the Centre for Higher Education Transformation (CHET) in South Africa and is currently serving as Chair of its board. In addition, she has served on the boards of international bodies such as the UNESCO International Institute for Educational Planning and the World Education Market. She has also served as Executive Director and Commissioner to the National Commission on Higher Education (1995-1996) appointed by President Mandela. Before joining New York University, Teboho served as a special advisor to two ministers of education in post-1994 South Africa. She has authored several articles on higher education reform issues in areas such as the governance of higher education, policy 
processes, and impact of globalisation on higher education, and co-authored a book on educational change in South Africa. She is a founding member and Editor-in-chief of the Journal of Student Affairs in Africa.

Prof. Mulugeta Neka is Assistant Professor of Geography and Environmental Studies at Bahir Dar University in Ethiopia. He taught in high schools before he joined Bahir Dar University. Now, he is teaching postgraduate students of geo-information, and Geography and Environmental Studies. Currently, he is also involved in training Bahir Dar University teachers for the higher diploma in teaching. Mulugeta has held various positions at Bahir Dar University. He was head of the Department of Geography and Environmental Studies for several years, has served as Registrar of Bahir Dar Teachers' College (the current Bahir Dar University), and was also the Dean of the Faculty of Social Science at the university. He co-authored articles on livestock husbandry and economic sustainability, and detection of Olea europaea subsp. cuspidata and Juniperus procera in the dry Afromontane forest. He also co-authored a book entitled Soil Conservation Practices and has written teaching material on "Basic Concepts and Methods of Teaching Geography".

Barbra M. Pansiri is the Director, Student Welfare, University of Botswana, a job that entails directing the overall management of student life: halls of residence, general welfare of students, student development and alignment of these services to University goals. Her job specifically focuses on: new students' orientation, student accommodation, student welfare, student leadership development, student life programmes, and student discipline. She has worked in Tertiary Institutions for 22 years, of which 19 were in student administration. Her qualification highlights are: a Bachelor's degree (Public Administration) from the University of Botswana, a Master's Degree (Business Management) from Australia with a focus on Organisational Development, a Certificate in Higher Education Management in Southern Africa from Wits University, South Africa, and she trained with the James Grinn National Housing Training Institute (NHTI) in Georgia, USA. She also completed a six-month attachment in Student Affairs at the University of Missouri, Columbia, USA, in 2014. She is very passionate about student development and her achievements have mainly been in this area, particularly in revamping student services under her jurisdiction, facilitating as well as introducing student life and development programmes, one of the key programmes being the Living \& Learning Community (LLC). She has made a couple of presentations in student development in Botswana, South Africa, Zimbabwe and the USA. She has facilitated the first regional (Southern Africa) LLC annual seminar, which has now been incorporated into ACUHO-I-SAC, an initiative she considers not only great, but a welcome development as that's where the LLC belongs.

Dr Birgit Schreiber is Senior Director of Student Affairs at Stellenbsoch University, South Africa. Prior to that she was the Director of the Centre for Student Support Services at the University of the Western Cape (UWC) in Cape Town, South Africa. She holds a $\mathrm{PhD}$ from UWC. Birgit has published in national and international academic journals on student support and development, has presented research papers and keynotes in national 
and international conferences and given lectures at the UC Berkley, the University of Leuven (Netherlands), and the University of Oslo (Norway). She was a visiting scholar at the UC Berkeley, where she was involved in their student affairs department. She has also been involved in various quality assurance panels reviewing student affairs at South African universities and has taken part in the national review of the South African Student Engagement tool (SASSE). She has been a member of the national executive of various national professional organisations including the South African Association of Senior Student Affairs Professionals (SAASSAP), and currently serves on the Executive of the Southern African Federation of Student Affairs and Services (SAFSAS). She is also the Africa Regional Coordinator of the International Association of Student Affairs and Services (IASAS) and is a founding member of the Editorial Executive of the Journal of Student Affairs in Africa.

Refilwe Precious Sinkamba, BSW, MSW, is a Senior Lecturer in the Department of Social Work at the University of Botswana. She is coordinator for the first-year learning experience course. In addition she is a warden and assists students with living and learning activities under the Department of Student Welfare. She has earned her a Bachelor's degree in Social Work from the University of Botswana and a Master's degree in Social Work Mental Health and Substance Abuse emphasis from the University of Utah, USA. She has published in several peer-reviewed journals and presented in several international and national conferences. Her research interests are alcohol and substance abuse, mental health, male abuse, children and youth, student affairs, social security, disability as well as HIV and AIDS.

Linda Spark is a Senior Tutor and programme grant holder at the University of the Witwatersrand, Johannesburg, South Africa. She has been lecturing in Information Systems for more than 20 years, and prior to that worked in the IT industry. She has extensive experience with student advice and support, lecturing and course co-ordination, curriculum and course development, various academic, administrative and citizenship roles, including the portfolio of assistant dean in teaching and learning for the faculty. Her research interests include the use of technology in education, technology and ethics, and student support and success. 


\section{Thank you to our reviewers}

The JSAA Editorial Executive wishes to thank the peer reviewers of Volume 4 of the Journal of Student Affairs in Africa for their time and expertise in evaluating and helping to select and improve the submissions received:

Convy Baloyi

Lisa Bardill Moscaritolo

Jaco Brink

John Butler-Adam

Ronelle Carolissen

Stan Carpenter

Jenni Case

Brenda Leibowitz

Blessing Makunike

Lehlohonolo Innocent Mangena

Henry Mason

Patricia Morris Carey

Thengamehlo Harold Ngwenya

Annsilla Nyar

Brett Perozzi

Rupert Taylor

WP Wahl

Bekele Workie Ayele 


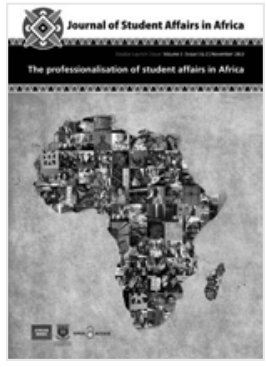

\section{Call for submission of papers for the Journal of Student Affairs in Africa (JSAA), Vol. 6 (2018):}

\section{"Space, language and identity politics in 21st century higher education"}

Guest editors: Philippa Tumubweinee and Munene Mwaniki

As a way of introducing the theme to be tackled in the first 2018 guest-edited issue of the Journal of Student Affairs in Africa, it is worthwhile to pose a question, albeit a rhetorical one: Why would a journal dedicated to theoretical, practice-relevant, and reflective contributions from across the scholarly and professional field of Student Affairs entertain a special edition on space, language and identity politics in higher education?

The short answer would be: everything. The long answer to this question, however, is to be found in an exposition by Benedict Anderson in Imagined Communities (2006). In Anderson's view, style has the potential of producing further assumptions about space and time. 'Style' in this case would refer to $J S A A$ which, in the Student Affairs terrain and discourses in Africa, has provided the intellectual and technical means for representing the kind of imagined community that is the Student Affairs fraternity on the continent - fraternity which comes with its largesse and baggage in the form of the scope of $J S A A$.

It is instructive that the 'representation' under reference occurs primarily through the medium of a code i.e. language. In the imagined community created by JSAA - which existentially approximates the Student Affairs terrain in Africa and even beyond - the multitude of actors are nonetheless bounded by space and time. They are connected by the same encircled, fixed landscape within which they all simultaneously exist. In following this logic through, the commonalities of code and simultaneities of space and time exemplified by $J S A A$ are at the heart of the ways in which actors in the Student Affairs fraternity on the continent, and possibly beyond, consider themselves part of a community, and therefore strive to build an identity informed by the fraternity's imaginary.

By design therefore, this guest-edited issue will address itself to the politics of space, language and identity in higher education, in Africa and globally. The contributions in the guest-edited issue will singularly and collectively grapple with the nuances attendant to the intersections amongst space, language and identity in higher education.

Key topics to be pursued in this issue include:

- Higher education spaces and the politics of space in higher education

- Space and identity, symbols and signs in the post-colonial university

- Politics of identity: student protests, language, institutional culture 
- Institutional policies and their impact on (the politics of) practice (e.g. language policies)

- Social cohesion, diversity and citizenship

- Intersections of language, curriculum, educational access and transformation

- Curriculum, decolonisation, and epistemic injustices | freedoms

- Student experience, student identity, and student politics of diverse student groups (e.g. LGBTIQ+ students).

$J S A A$ is an independent, peer-reviewed, multi-disciplinary, open access academic journal that publishes scholarly research and reflective discussions about the theory and practice of Student Affairs in Africa. $J S A A$ is published twice a year by the $J S A A$ Editorial Executive in collaboration with Stellenbosch University and African Sun Media.

The journal is indexed in international indices and available full-text open access from ERIC, DOAJ, AJOL as well as on its own website hosted with Stellenbosch University. Since 2017, JSAA has been accredited by the South African Department of Higher Education and Training (DHET) as a subsidy-earning journal on the SA list of scholarly journals. Authors publish free of charge; there are no processing or page fees.

\section{Submission Process and Important Dates}

Manuscripts due: 30 September 2017 (or by arrangement with the guest editors) Envisaged publication date: March 2018

Please submit abstracts to the guest editors for guidance or contact them for further information:

- Ms Philippa Tumubweinee, M.Prof Arch, Pretoria email:philippa@inafricadesign.co.za

- Dr Munene Mwaniki, PhD, Free State email:MwanikiMM@ufs.ac.za

Please submit final manuscripts by email to Ms Philippa Tumubweinee. Email:philippa@inafricadesign.co.za with cc to email:jsaa_editor@outlook.com

JSAA: Submission Preparation Checklist - please see online at www.jsaa.ac.za 

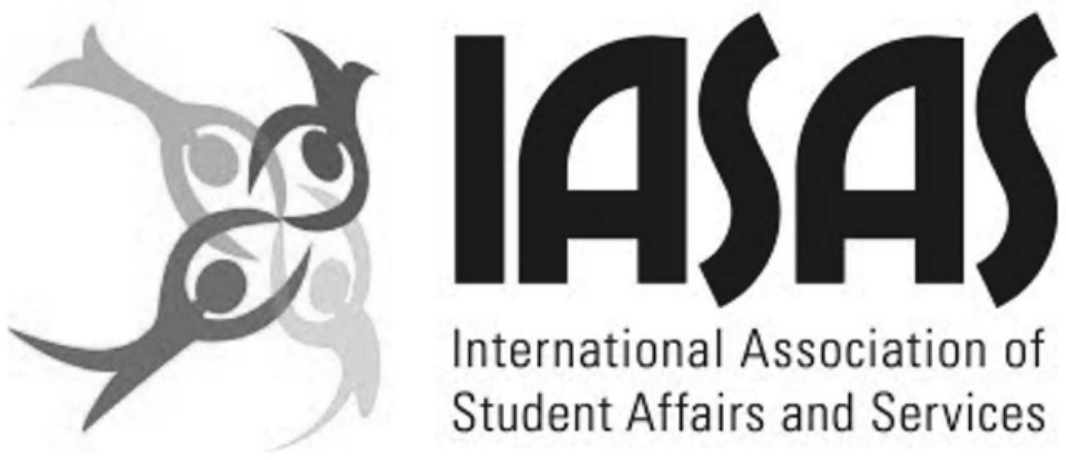

The International Association of Student Affairs and Services was officially founded on March 1, 2010. The purposes of IASAS are to:

- Strengthen and diversity cooperation among individuals and organizations in the student affairs and services field worldwide.

- Promote the student affairs and services profession at the international level through advocacy with governmental and higher education organizations, networking and sharing information among practitioners and student groups, and encouraging high quality preparation and professional development programs.

- Provide a platform for the improvement of multi and intercultural communication and understanding.

- Promote the welfare of students in higher education worldwide through collaboration with international governmental and non-governmental organisations and addressing such issues as access, retention, quality, student rights, and the cost of higher education.

IASAS utilizes technology for conducting most of its activities. This includes such applications as the IASAS website, email, internet and video conferencing, and social networks, etc. Occasional face-to-face meetings are held in various locations around the world and in conjunction with existing meetings of international, national, and regional groups whenever possible.

IASAS Africa Regional Coordinator:

Dr Birgit Schreiber (South Africa), Email: africaregion@iasasonline.org

IASAS website: http://www.iasasonline.org 


\section{Publications by AFRICAN SUN MeDIA}

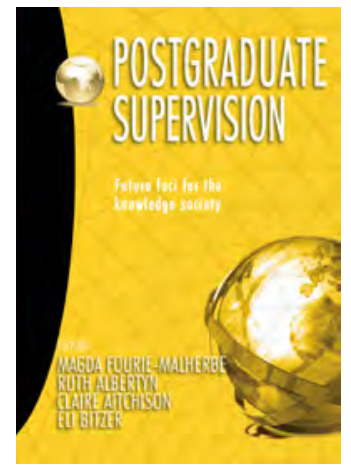

\section{Postgraduate Supervision: Future foci for the knowledge society} by M. Fourie-Malherbe, R. Albertyn, C. Aitchison \&

E. Bitzer (Eds.) (2016)

The 24 chapters in this book move from deliberations on challenges for postgraduate supervision at macro level (such as the pressure to increase postgraduate output and the implications of increasingly managerialist institutions) to meso level matters (the form and function of postgraduate education in specific countries) to the micro level (rich case studies of individual institutions, programmes and supervisors). The publication provides very useful insights into multiple aspects of supervision and serves as a rich source in identifying future research possibilities and agendas in gearing up postgraduate education and supervision for the knowledge society.

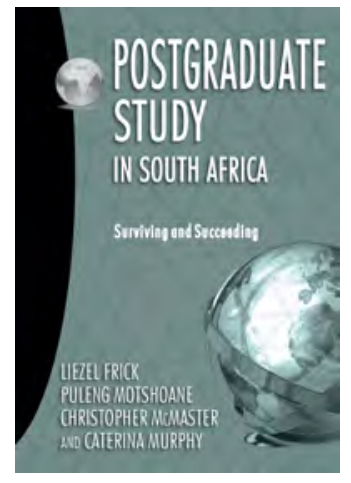

Postgraduate Study in South Africa: Surviving and Succeeding by L. Frick, P. Motshoane, C. McMaster \& C. Murphy (Eds.) (2016)

The book explores concerns about the lack of higher education transformation around issues of equity, curriculum reform, language and race, and how students navigate higher education complexities. Students' self-reflective abilities, creativity and pragmatic approaches to surviving and succeeding are indicators that postgraduate student success is as much internally as externally determined. Each of the 20 chapters speaks from a uniquely South African perspective. The editors have tried to remain true to the voice of each contributor, while simultaneously providing a coherent body of scholarly work.

AFRICAN SUN MeDIA is an integrated content manager and specialist supplier of publishing and printing services for the higher education market and the private sector. We publish under the imprints SUN PRESS, SUN MeDIA, Rapid Access Publishers (RAP) and Conference-RAP. Most of our publications are available in electronic and print format at:

www.sun-e-shop.co.za

africansunmedia.snapplify.com (e-books)

www.africansunmedia.co.za 


\section{Submissions}

Please register as an author and read the Author Guidelines at http://www.jsaa.ac.za. Submissions must be made by email to the Journal Manager at jsaa_editor@outlook.com. Submissions in response to special calls for papers must also be made directly to the guest editors concerned (see Call for Papers).

The JSAA typically has themed issues. However, submissions that fall within the general scope and focus of the Journal can be made at any time and may be published irrespective of the overall theme of the Journal. Particularly encouraged are open-theme manuscripts that address the following:

- Case studies of innovative practices in student affairs in the context of African higher education (e.g. student lifecycle, orientation, residence management, student governance, student counselling).

- High-level reflective practitioner accounts.

- Explorations of the nexus of student affairs theory, policy and practice in the African context and beyond.

- Conceptual discussions of student development, and key enablers and inhibitors of student development in Africa.

- Explorations of authoritative literature, theory and professional trends related to student affairs in Africa.

Please note that there are different requirements for different types of manuscripts:

- Research articles: Contributors are encouraged to submit research-based manuscripts. Research articles must include an extensive consideration of recent literature and relevant theory. Researchbased articles must be original and research-based and must make a significant conceptual (or empirical or normative) contribution relevant to the scope and focus of the JSAA. The length must be approximately 5000 words, including all references, notes, tables and figures. Manuscripts should be accompanied by an abstract of approximately 150-300 words.

- Reflective practitioner accounts: High-quality reports on professional campus practice are screened and reviewed according to the same criteria as for research articles, albeit with a different emphasis. Unlike a research article, they do not need to include an extensive consideration of recent literature and theory, but they must nonetheless comply with standard academic convention and scholarly practice. Reflective practitioner articles must be original, must make a significant empirical contribution, and must significantly enhance our understanding of student affairs practice within their respective scope and focus. Typical length should be 2500-5000 words. Manuscripts should be accompanied by an abstract of approximately 150-300 words.

- Book reviews should be between 800 and 1000 words in length. Competent reviews of key student affairs books are published at the discretion of the Editorial Executive.

- Comments and critique, of no more than 2500 words, are also welcome.

- Proposal for the Journal's Dialogue/Interview section and Calls and Notices should be emailed directly to the Journal Manager. The publication of calls and notices (for conferences, vacancies, etc.) may incur a nominal fee.

Authors are required to check their submission's compliance with all of the following items, and submissions that do not adhere to these guidelines may be returned to authors.

1. The ethical requirements of social research have been considered and fully complied with.

2. The submission has not been previously published, nor is it before another journal for consideration (or an explanation has been provided in Comments to the Editor).

3. The submission file is in MS Word, OpenOffice, or RTF document file format.

4. The text is double-spaced; uses a 12-point font; employs italics rather than underlining (except with URL addresses); and all illustrations, figures and tables are placed within the text at the appropriate points, rather than at the end.

5. The text adheres to the stylistic and bibliographic requirements outlined on the Journal's website.

6. The Journal uses the APA author-date referencing system.

7. If submitting to a peer-reviewed section of the Journal, i.e. as a research article or reflective practioner account, the instructions in Ensuring a Blind Peer Review must have been followed.

8. If submitting a proposal for the Dialogue section, a Call/Notice, or a Comment/Critique, this should be emailed directly to the Journal Manager. 
9. The final text of the article has been professionally edited and proofread prior to submission.

10. The front page of the manuscript indicates the Section under which it is proposed that the article be published, i.e. Research Article (peer-reviewed); Reflective Practice (peer-reviewed); or Book Reviews/Dialogues/other contributions.

11. Permission to reproduce any copyrighted material has been obtained and can be produced should this be requested by the Editorial Excecutive.

\section{Section review policy and process}

The JSAA publishes research articles (peer-reviewed); high-quality reflective practitioner accounts (peer-reviewed); dialogues/interviews (non-reviewed); and book reviews (non-reviewed). The Journal is committed to assisting emerging scholars and professionals in developing promising manuscripts to the point of publication.

\begin{tabular}{|c|c|c|}
\hline \multicolumn{3}{|l|}{ Editorial commentary } \\
\hline$\square$ Open submissions & $\checkmark$ Indexed & $\square$ Peer reviewed \\
\hline \multicolumn{3}{|c|}{ Research articles and professional practitioner accounts } \\
\hline$\square$ Open submissions & $\nabla$ Indexed & $\square$ Peer reviewed \\
\hline \multicolumn{3}{|c|}{ Campus dialogue/interview section } \\
\hline$\square$ Open submissions & $\square$ Indexed & $\square$ Peer reviewed \\
\hline \multicolumn{3}{|l|}{ Book reviews } \\
\hline$\square$ Open submissions & $\square$ Indexed & $\square$ Peer reviewed \\
\hline
\end{tabular}

The editorial and peer-review policy adheres to the ASSAf National Code of Best Practice in Editorial Discretion and Peer Review for South African Scholarly Journals (ASSAf Council, 2008). All submitted manuscripts undergo an initial careful examination by the Editorial Executive to ensure that authors' submissions fall within the mission, scope and focus of the JSAA and conform to scholarly best practice. Qualifying scholarly research-based articles and high-quality, relevant reflective practitioner accounts are blind-reviewed by at least two peer reviewers, who would typically be members of the International Editorial Advisory Board of the JSAA. Peer reviewers have proven scholarly and/ or professional expertise in the subject matter of a manuscript. Reviewer reports are assessed by a member of the Editorial Executive and form the basis of any decision by the Editorial Executive on how to proceed with a manuscript. The suitability of a manuscript is evaluated in terms of originality, significance, scholarship and adherence to the requirements of ethical social research, scope and interest, and accessibility.

\section{Publishing and dissemination policies}

Cost of publishing

There are no processing fees or page fees. No costs accrue to authors of articles accepted for publication.

Licensing notice

Authors who publish with this Journal agree to the following terms:

Authors retain copyright and grant the Journal right of first publication with the work simultaneously licensed under a Creative Commons Attribution License that allows others to share the work with an acknowledgement of the work's authorship and initial publication in this Journal.

Authors are able to enter into separate, additional contractual arrangements for the non-exclusive distribution of the Journal's published version of the work (e.g. post it to an institutional repository or publish it in a book), with an acknowledgement of its initial publication in this Journal.

Authors are permitted and encouraged to post their work online (e.g. in online research repositories or on their website), as it can lead to productive exchanges, as well as earlier and greater citation of published work.

Open access policy

This Journal provides open access to its e-journal content. Free copies can be downloaded from the Journal website at http://www.jsaa.ac.za, and from co-hosting sites e.g. http://ajol.info. Authors are encouraged to place copies of their final articles in their institution's research repository. 


\section{Print copies/subscription}

Online subscriptions to the e-journal are free of charge. Please register at www.jsaa.ac.za.

Printed copies of current and past issues of the Journal can be ordered from the following online bookstores: African Books Collective http://www.africanbookscollective.com/; Amazon Books http://www.amazon.com. 


\section{Journal of Student Affairs in Africa}

The Journal of Student Affairs in Africa (JSAA) is an independent, peer-reviewed, multi-disciplinary, open-access academic journal that publishes scholarly research and reflective discussions about the theory and practice of student affairs in Africa.
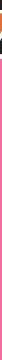

Experience of international education of East Asian students in English-speaking countries:

A four-dimensional approach

Maria L. Martinez \& Kevin T. Colaner

Interpersonal conflicts and styles of managing conflicts among students at Bahir Dar

University, Ethiopia

Arega Bazezew \& Mulugeta Neka

\section{Reflective practice}

Professionalisation of Student Affairs educators in China: History, challenges, and solutions Yongshan Li \& Yuanyuan Fang

Advocating for standards in Student Affairs departments in African institutions:

University of Botswana experience

Barbra M. Pansiri \& Refilwe P. Sinkamba

Promoting social change amongst students in higher education: A reflection on the Listen, Live and Learn senior student housing initiative at Stellenbosch University

Munita Dunn-Coetzee \& Magda Fourie-Malherbe

\section{On campus}

Global Summit on Student Affairs and Services

Lisa Bardill Moscaritolo \& Karen Davis

\section{Book/Journal reviews}

Dennis C. Roberts \& Susan R. Komives (Eds.) (2016). Enhancing Student Learning and Development in Cross-Border Higher Education. San Francisco: Jossey-Bass.

Reviewed by Munita Dunn-Coetzee

\section{Asia-Pacific Journal for Student Affairs (AJSA)}

Reviewed by Lisa Bardill Moscaritolo \& Kathleen Callahan

Osfield, K.J., Perozzi, B., Bardill Moscaritolo, L. \& Shea, R. (2016). Supporting Students Globally in Higher Education. Washington, D.C.: NASPA.

Reviewed by Jennifer A. Hamilton 